Asymmetric Domino Heck Arylation and Alkylation of Nonconjugated Dienes: Double C-F...Sodium Attractive Noncovalent Interaction

Daoyong Zhu, ${ }^{\ddagger}$ Wenqiang Xu, ${ }^{\dagger}$ Maoping Pu, ${ }^{\|}$Yun-Dong Wu, ${ }^{\S}$ Yonggui Robin $\mathrm{Chi}^{\ddagger}$ and Jianrong Steve Zhou ${ }^{\dagger *}$

${ }^{\dagger}$ State Key Laboratory of Chemical Oncogenomics, Key Laboratory of Chemical Genomics, School of Chemical Biology and Biotechnology, Peking University Shenzhen Graduate School, Room F312, 2199 Lishui Road, Nanshan District, Shenzhen 518055, China. ${ }^{\S}$ Lab of

Computational Chemistry and Drug Design, State Key Laboratory of Chemical Oncogenomics, Peking University Shenzhen Graduate School, Shenzhen Bay Laboratory, Shenzhen 518055, China. "Shenzhen Bay Laboratory, Gaoke Innovation Center, Guangqiao Rd, Guangmin District, Shenzhen, 518107, China. Division of Chemistry and Biological Chemistry, School of Physical and Mathematical Sciences, Nanyang

Technological University, 21 Nanyang Link, Singapore 637371

\title{
NMR charts
}




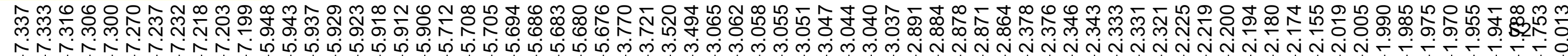

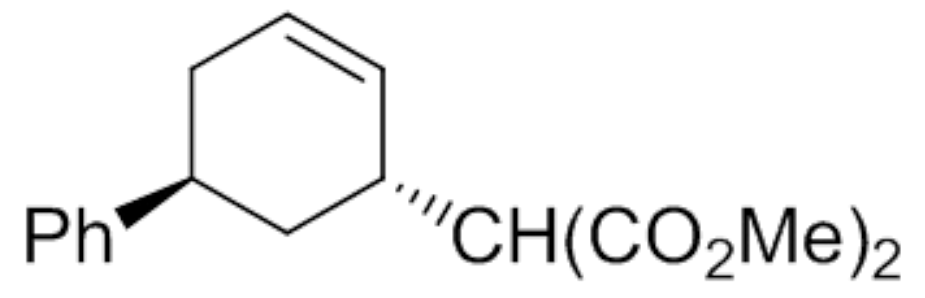

[3a]

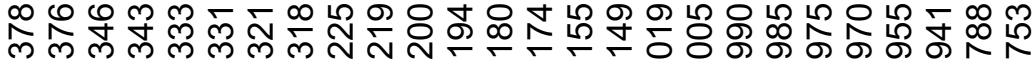

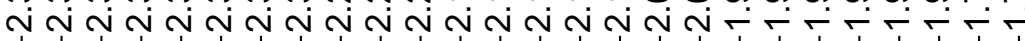

(l)

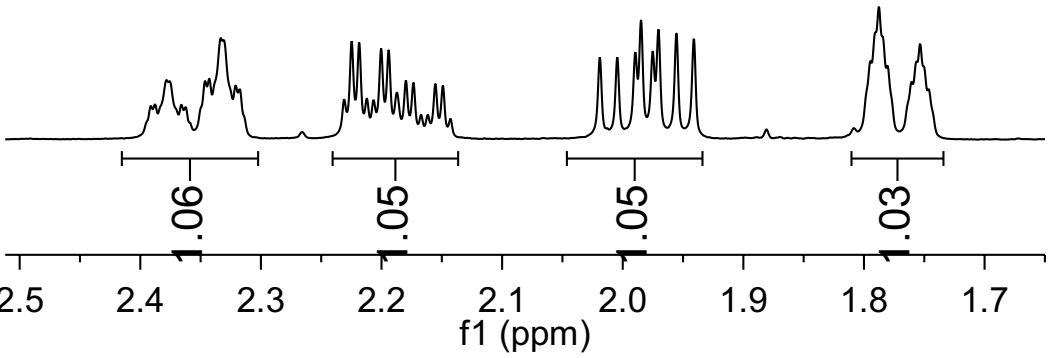

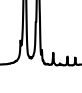

年

ชั ชิ เి

ก กั

눈

प्र

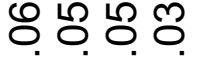

○.

4.0

$\begin{array}{lllll}1.5 & 1.0 & 0.5 & 0.0 & -0\end{array}$




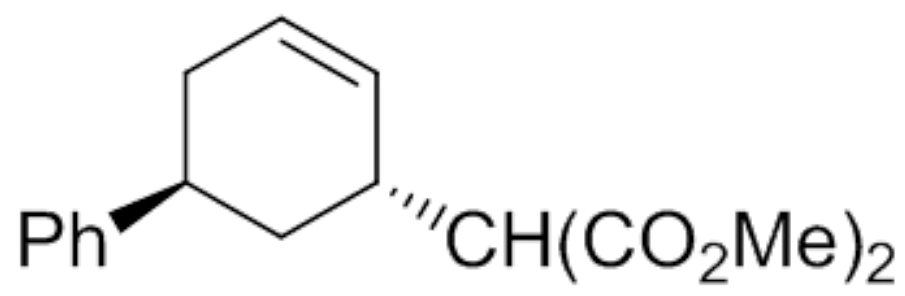

[3a]

|rint 


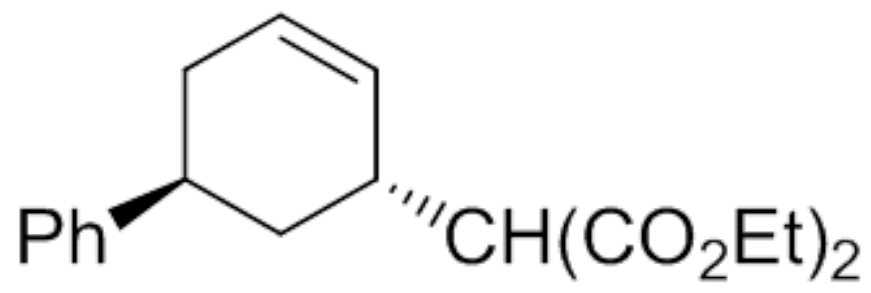

[3b]

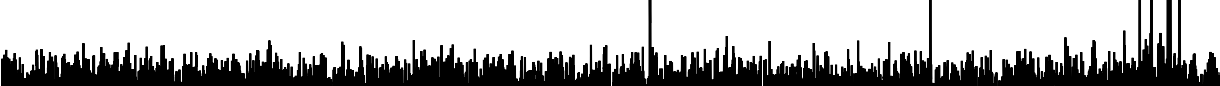
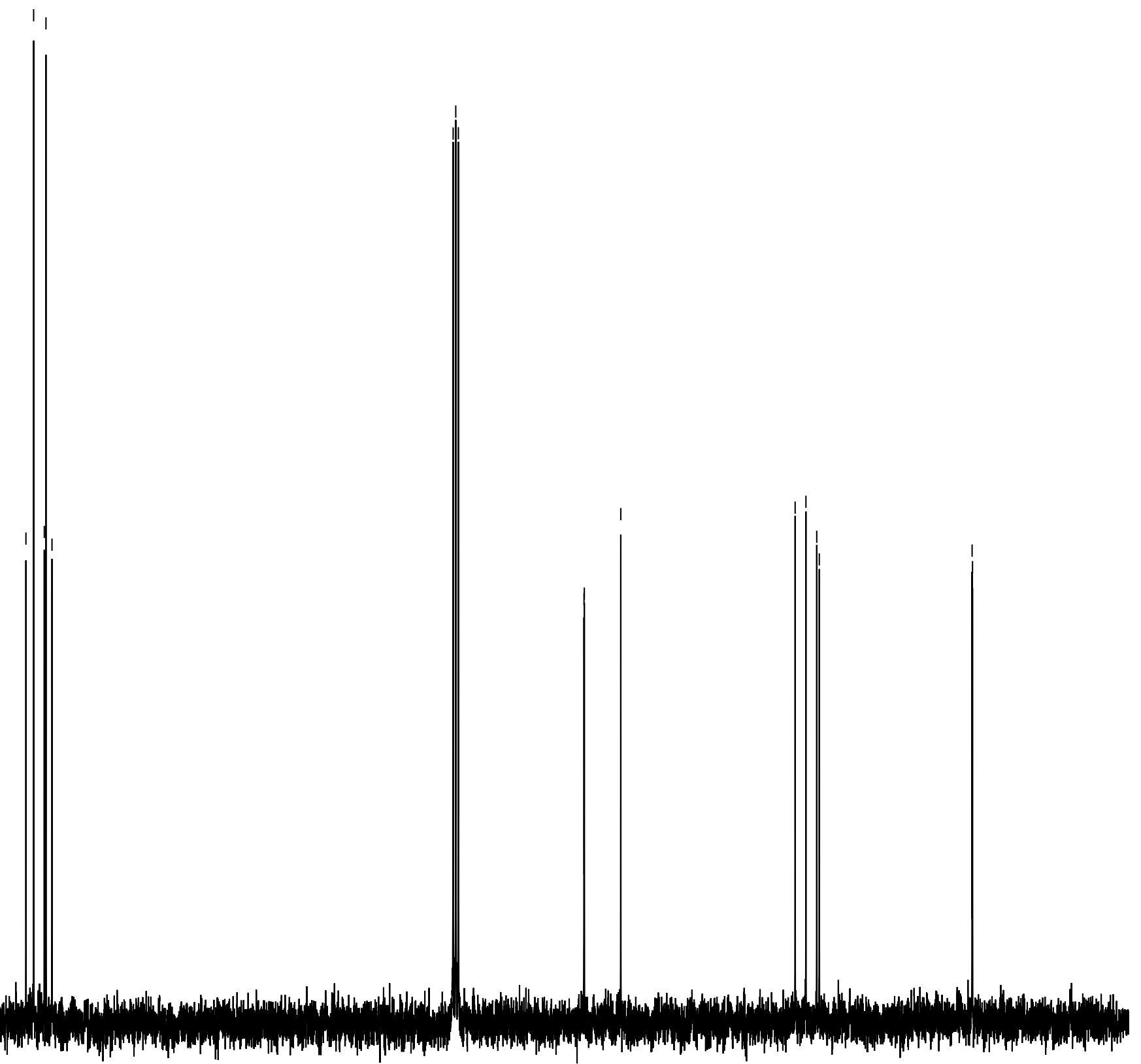


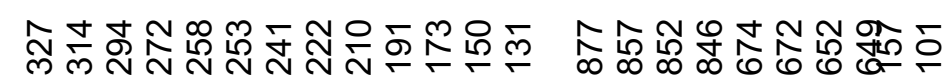

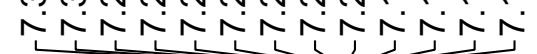

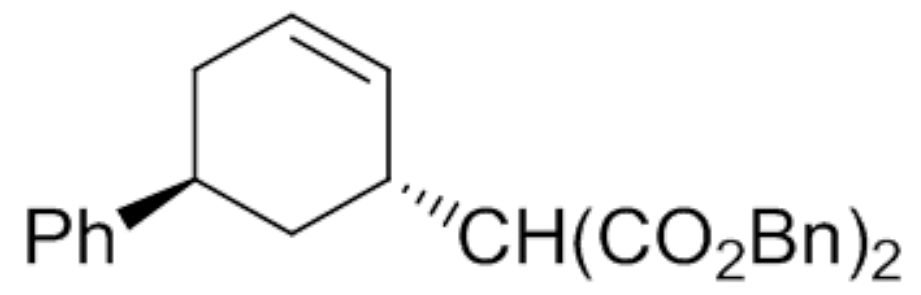

[3c]
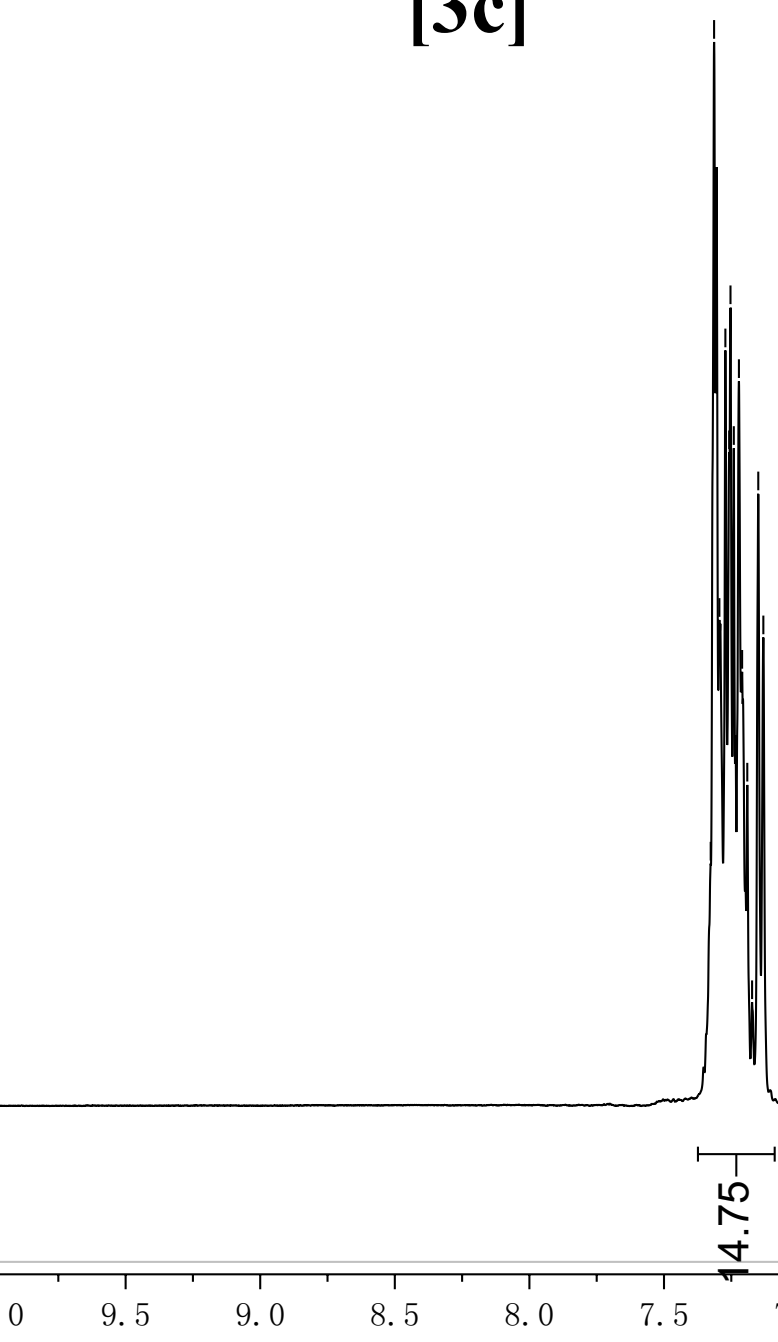

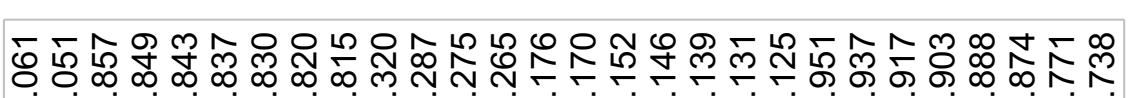

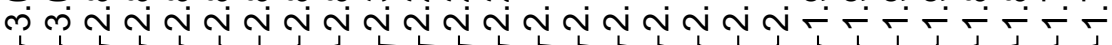

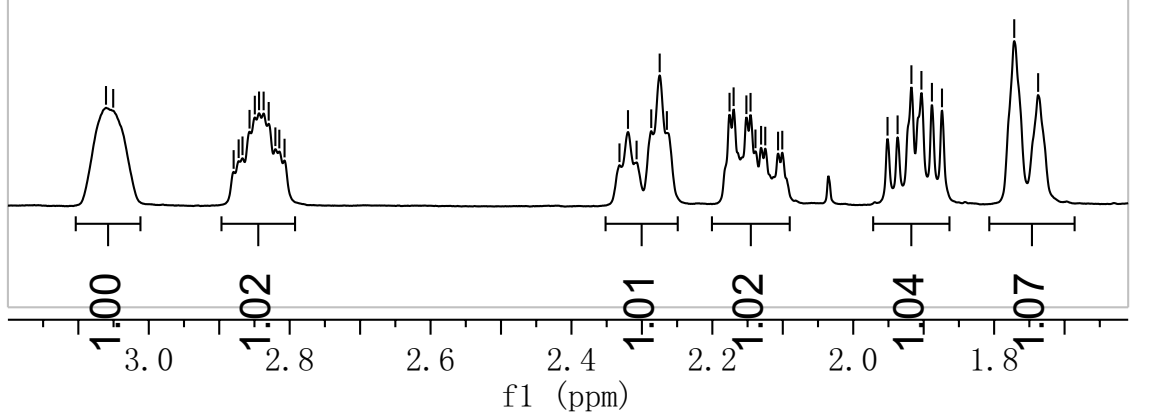

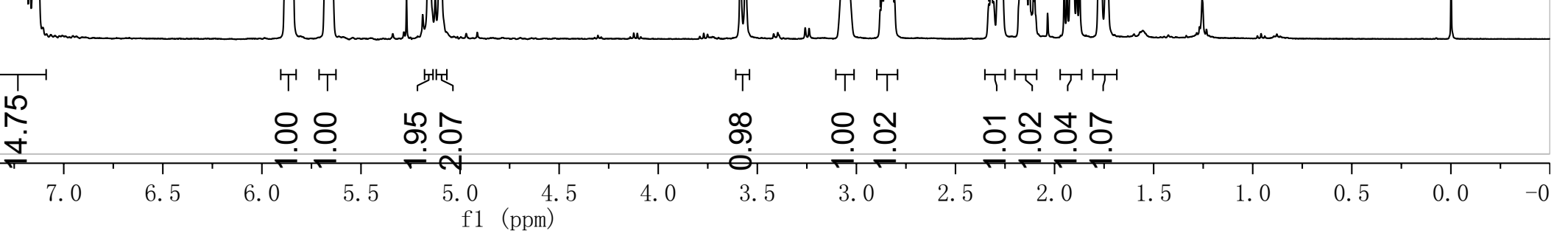




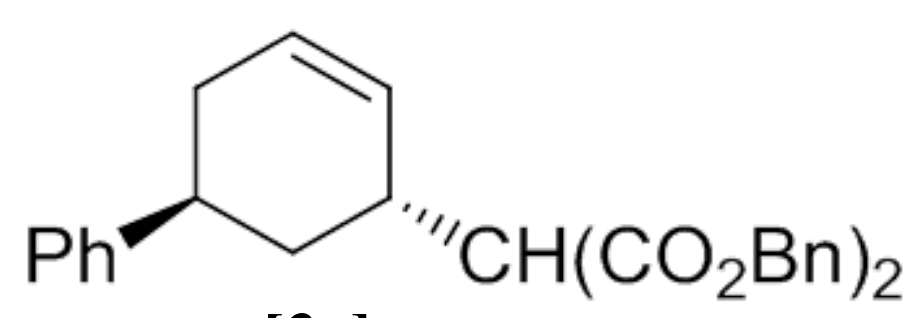

[3c]

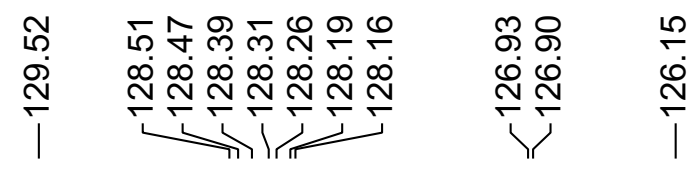

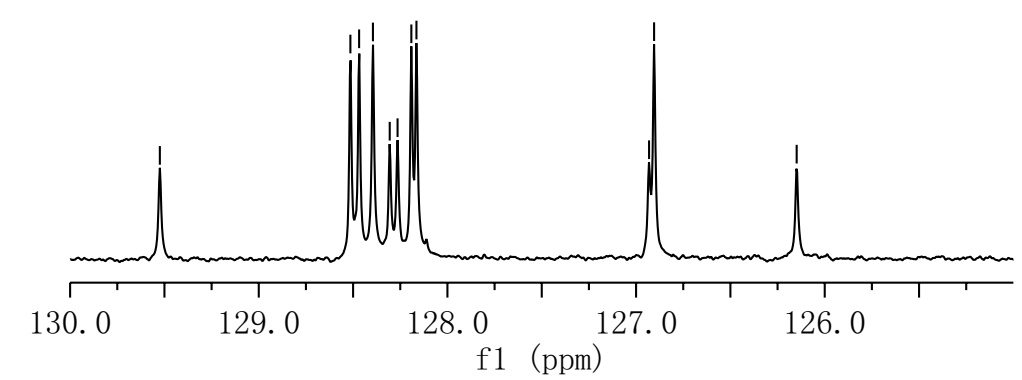

f1 (ppm) 


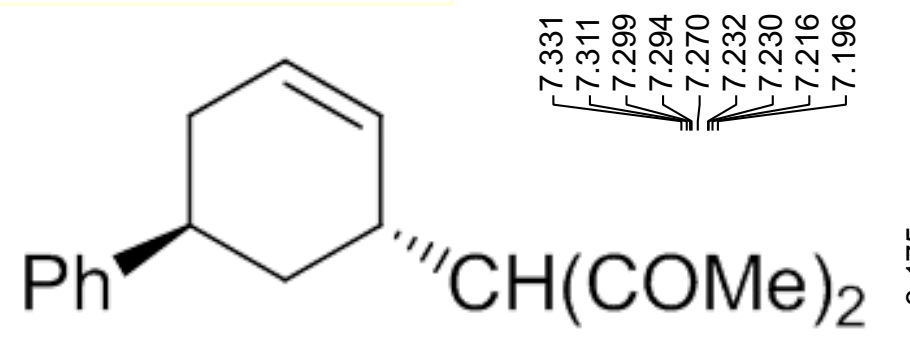

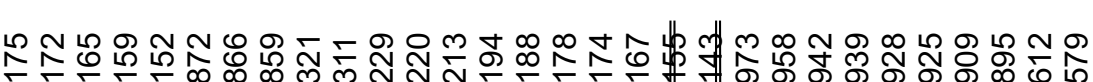

mं

[3d]

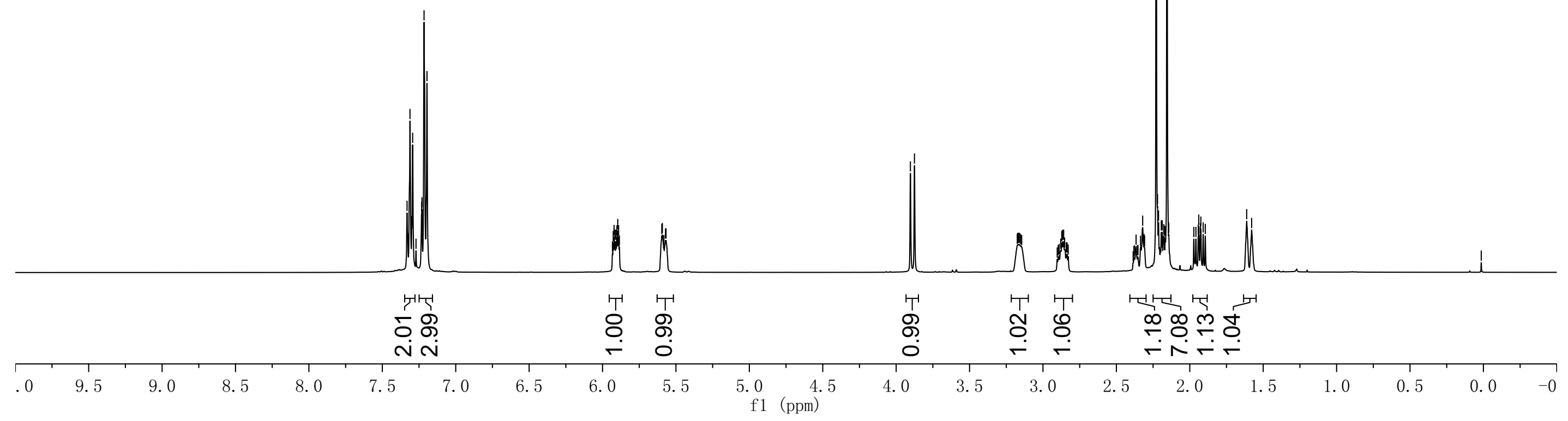


ণ ণ

กั่

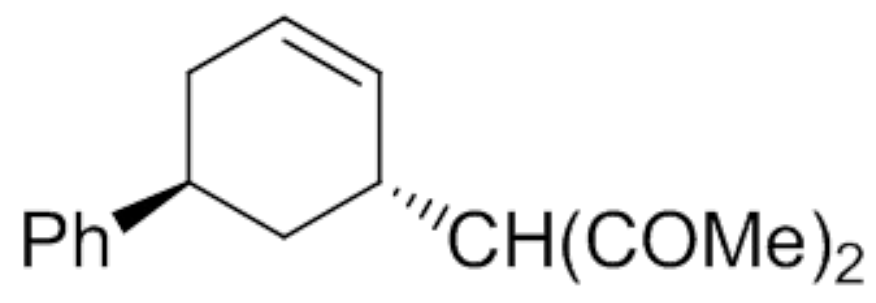

[3d]

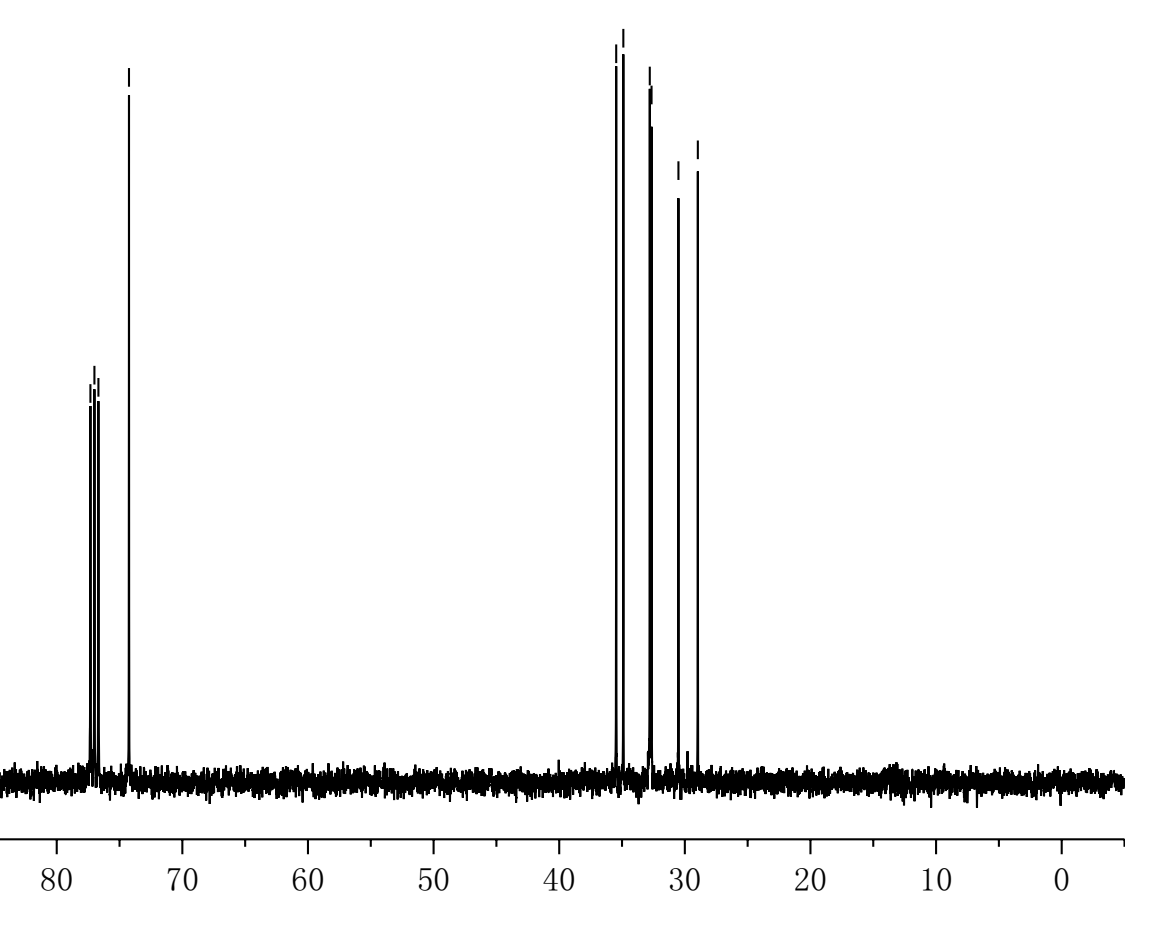




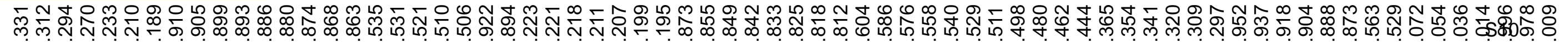
N N N N

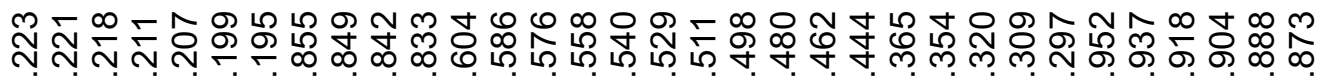
m m

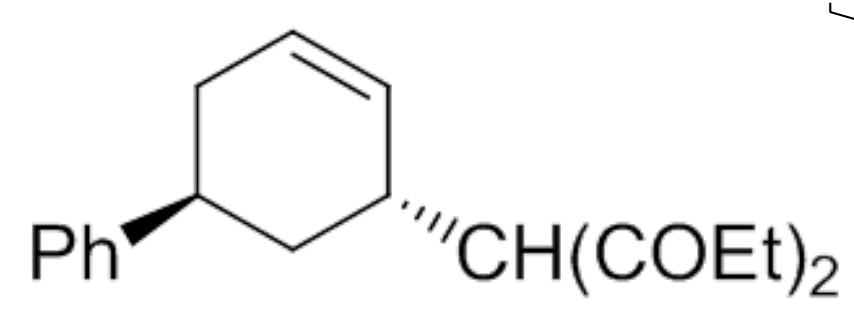

[3e]
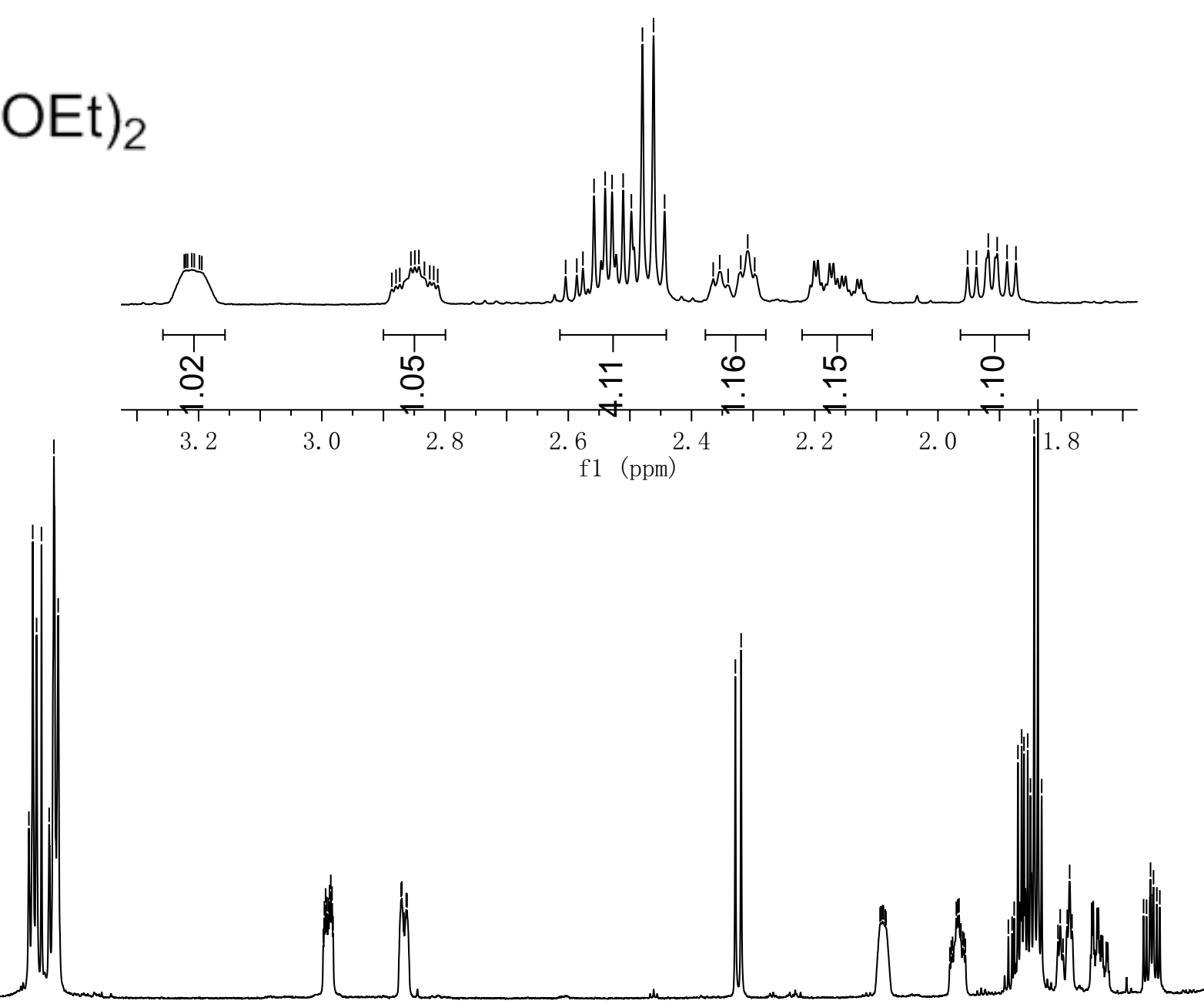

마
Nं n்

T.

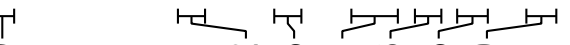

○

F宁宁

F.

$2.0 \quad 1.5$

1.0


$\circ \circ$

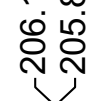

œ $\quad$ व ำ

占 $\quad$ N

Ph"

\section{.}

주유్ㅀ

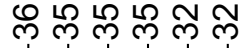

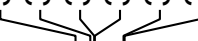

[3e]

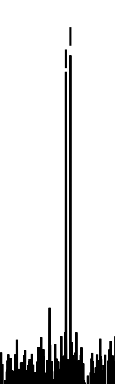




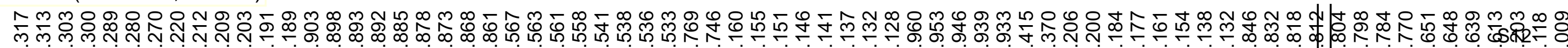

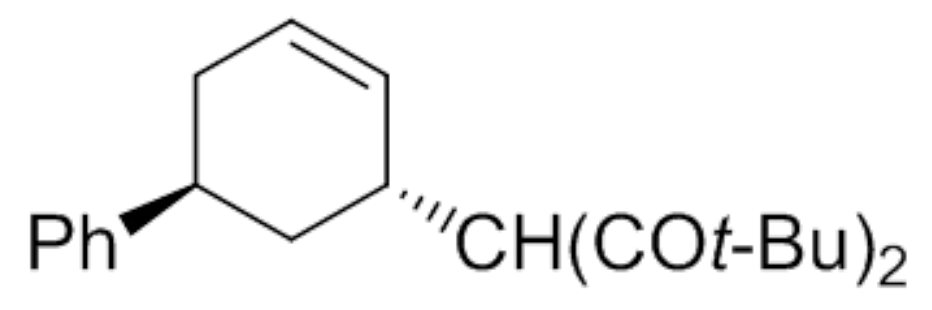

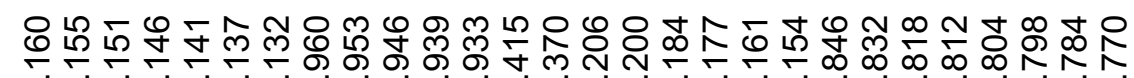

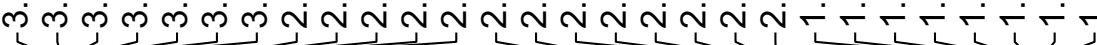

[3f]
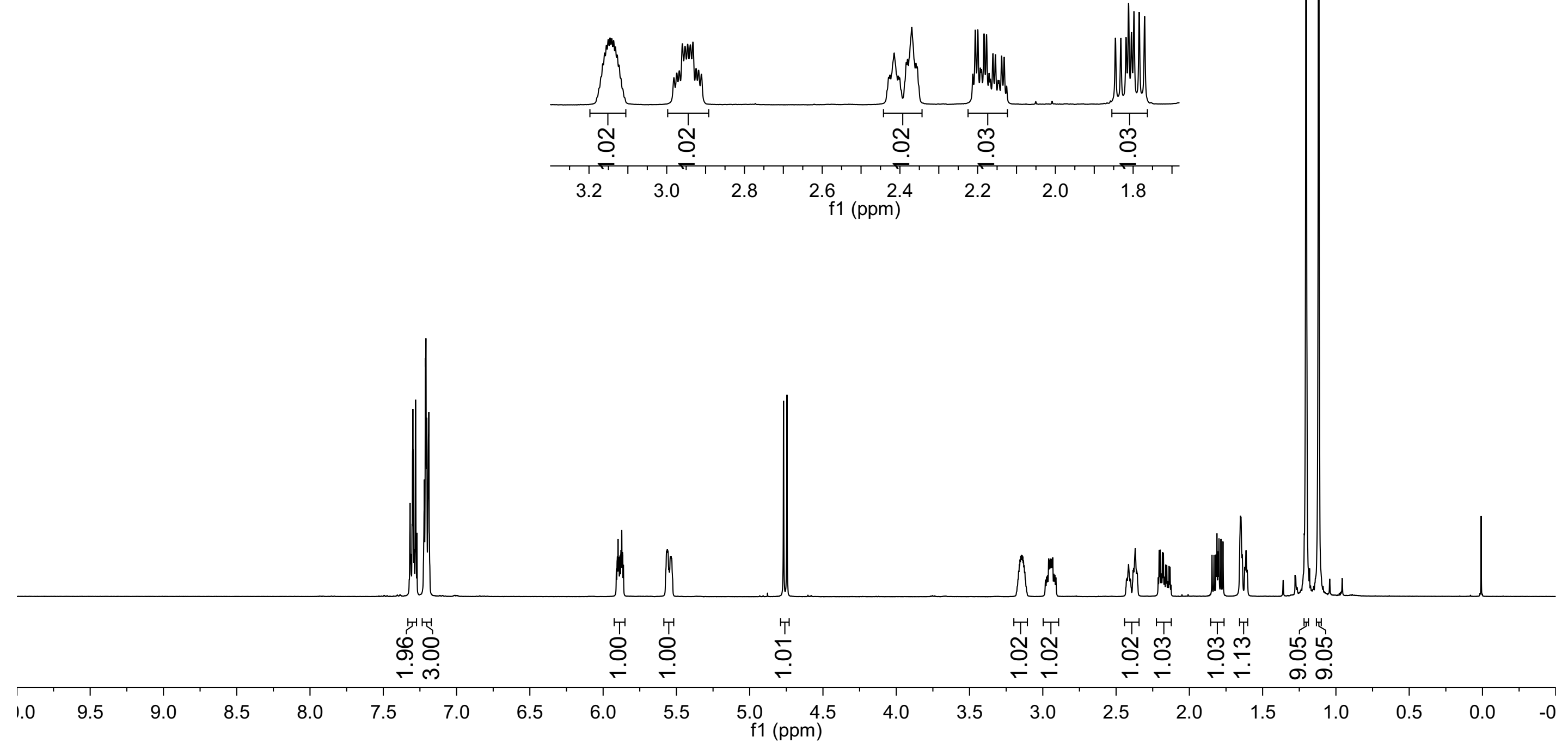
๙ิธ

穴

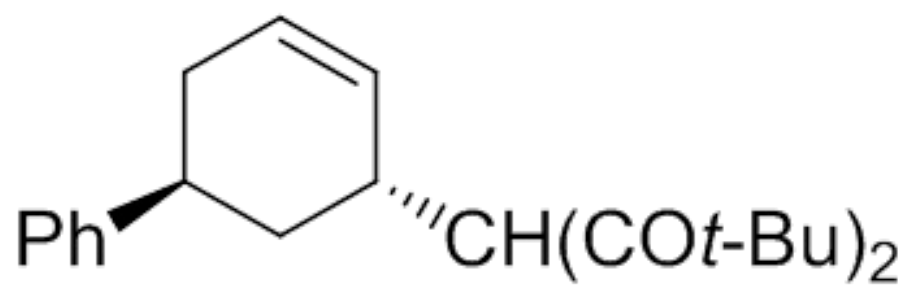

[3f]

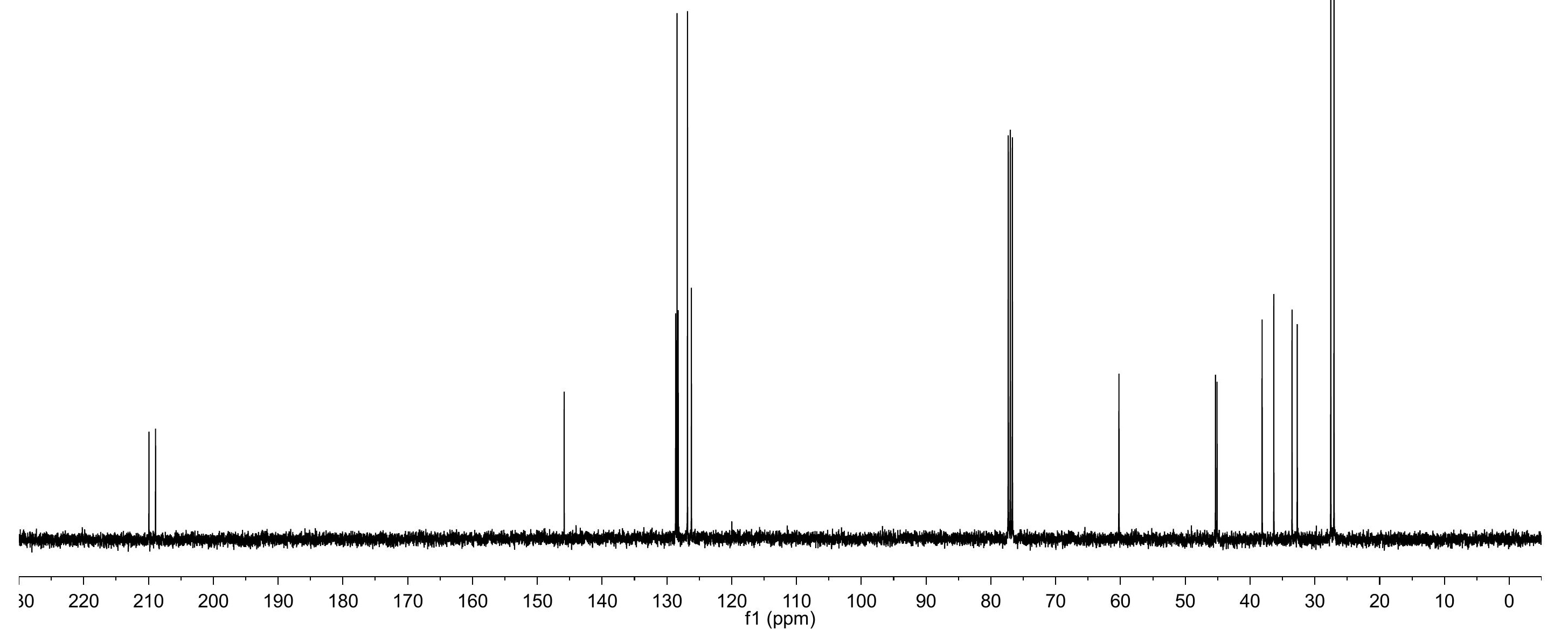




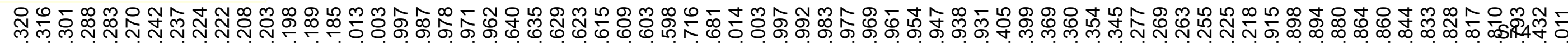

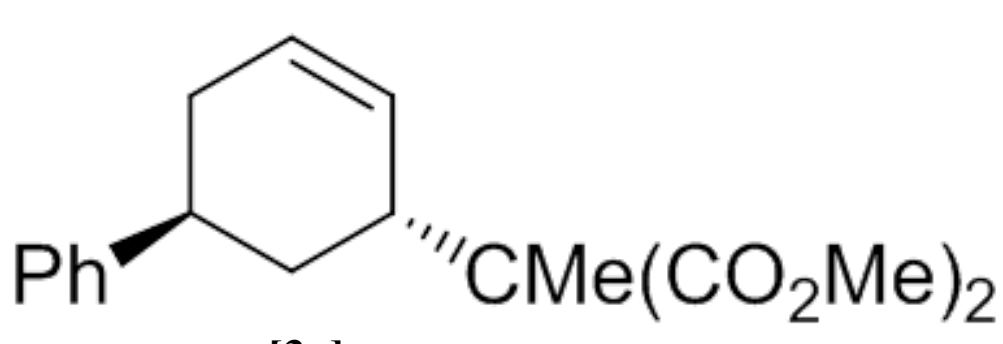

[3g]

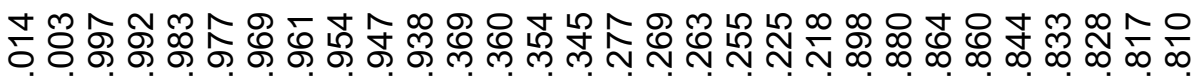

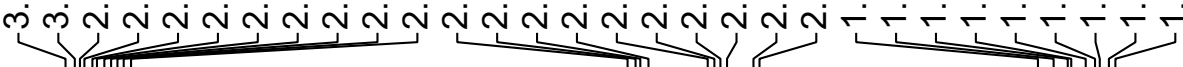
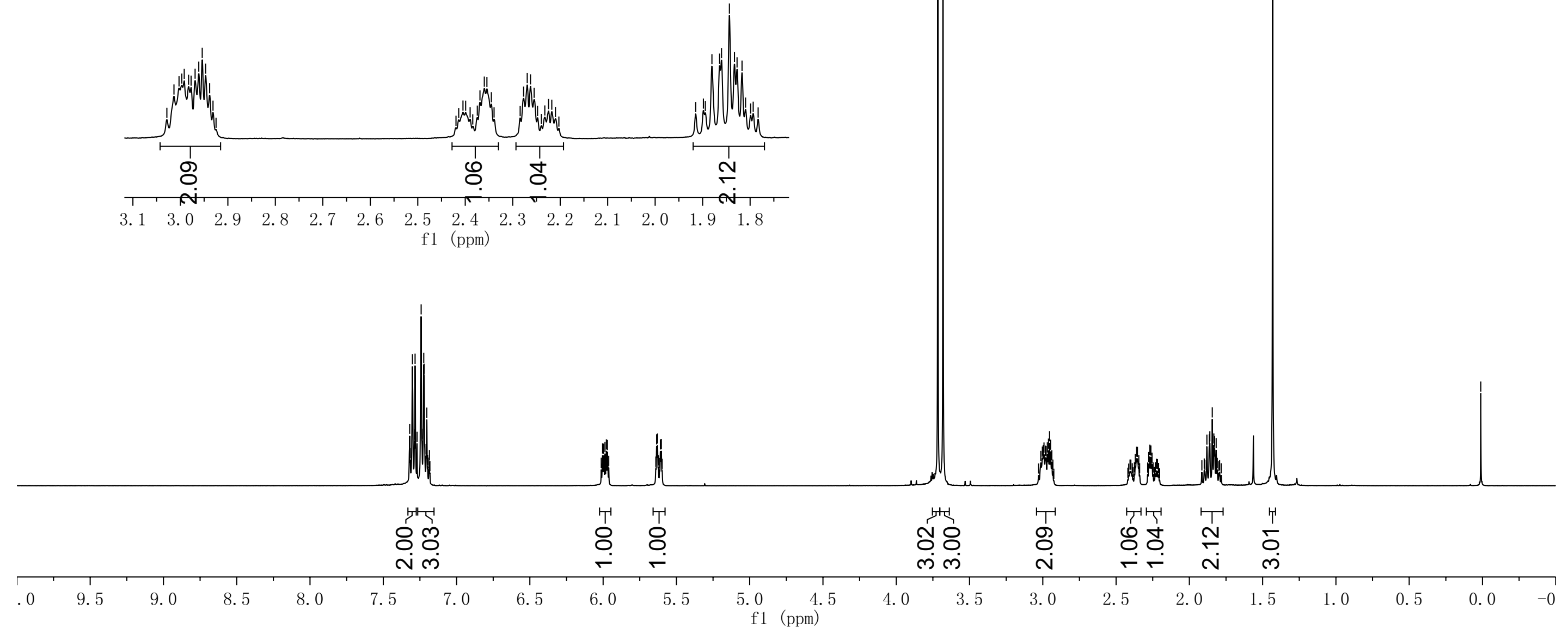


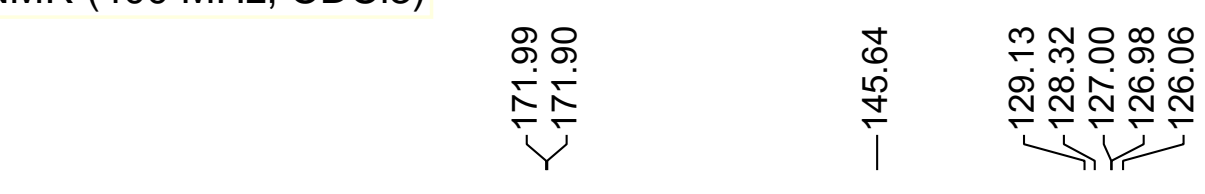

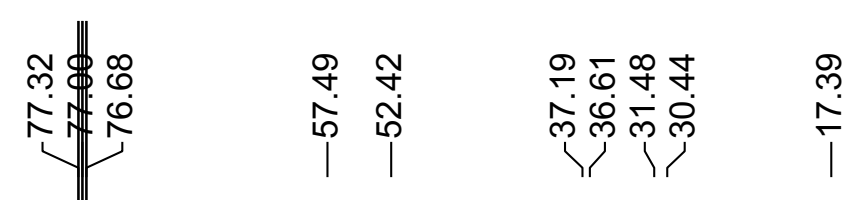

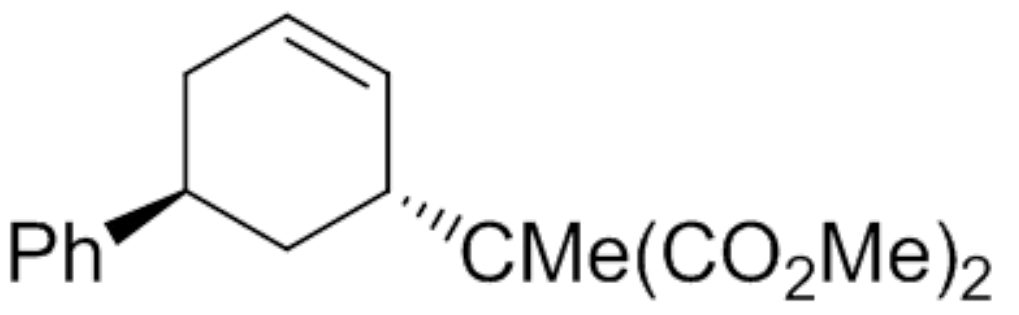

[3g]

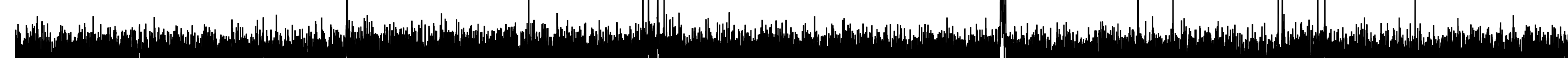

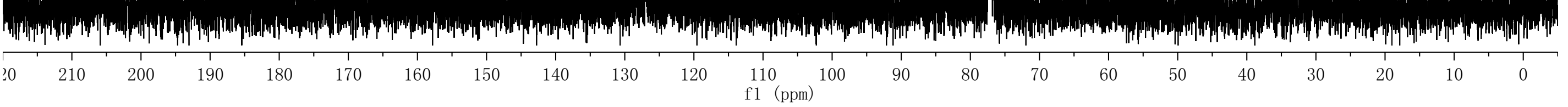



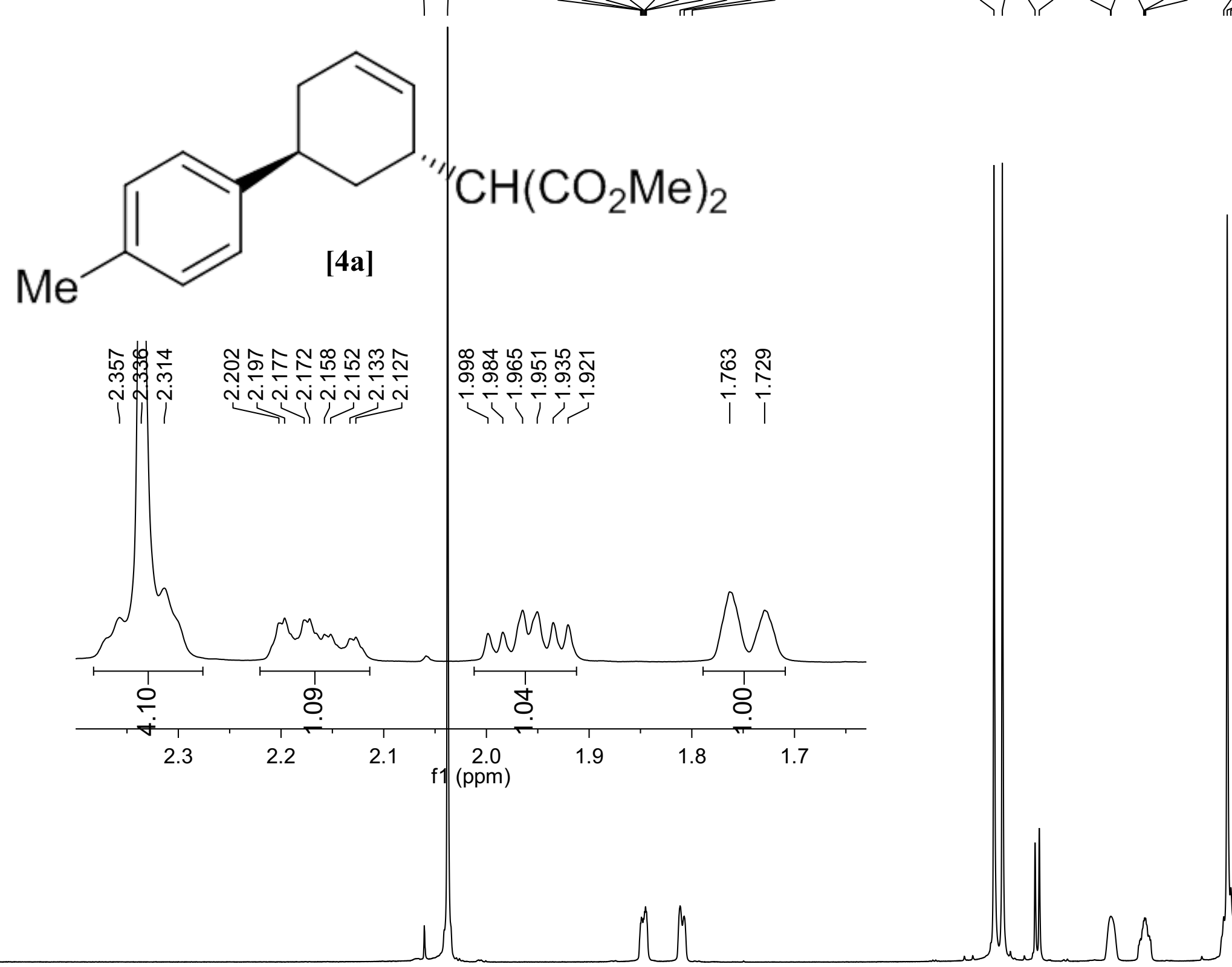

\begin{tabular}{|c|c|c|c|c|c|c|c|c|c|c|c|c|c|c|c|c|c|c|c|}
\hline & & & & & & $\begin{array}{l}\text { 'T' } \\
8 \\
\dot{+}\end{array}$ & & & & & & 䁬 & $\begin{array}{l}T^{\prime} \\
8 \\
8 \\
\end{array}$ & & 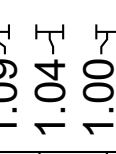 & & & & \\
\hline 1.0 & 9.5 & 9.0 & 8.5 & 8.0 & 7.5 & 7.0 & 6.5 & 6.0 & 5.5 & $\begin{array}{c}5.0 \quad 4.5 \\
\mathrm{f} 1(\mathrm{ppm})\end{array}$ & 4.0 & 3.5 & 3.0 & 2.5 & 2.0 & 1.5 & 1.0 & 0.5 & 0.0 \\
\hline
\end{tabular}




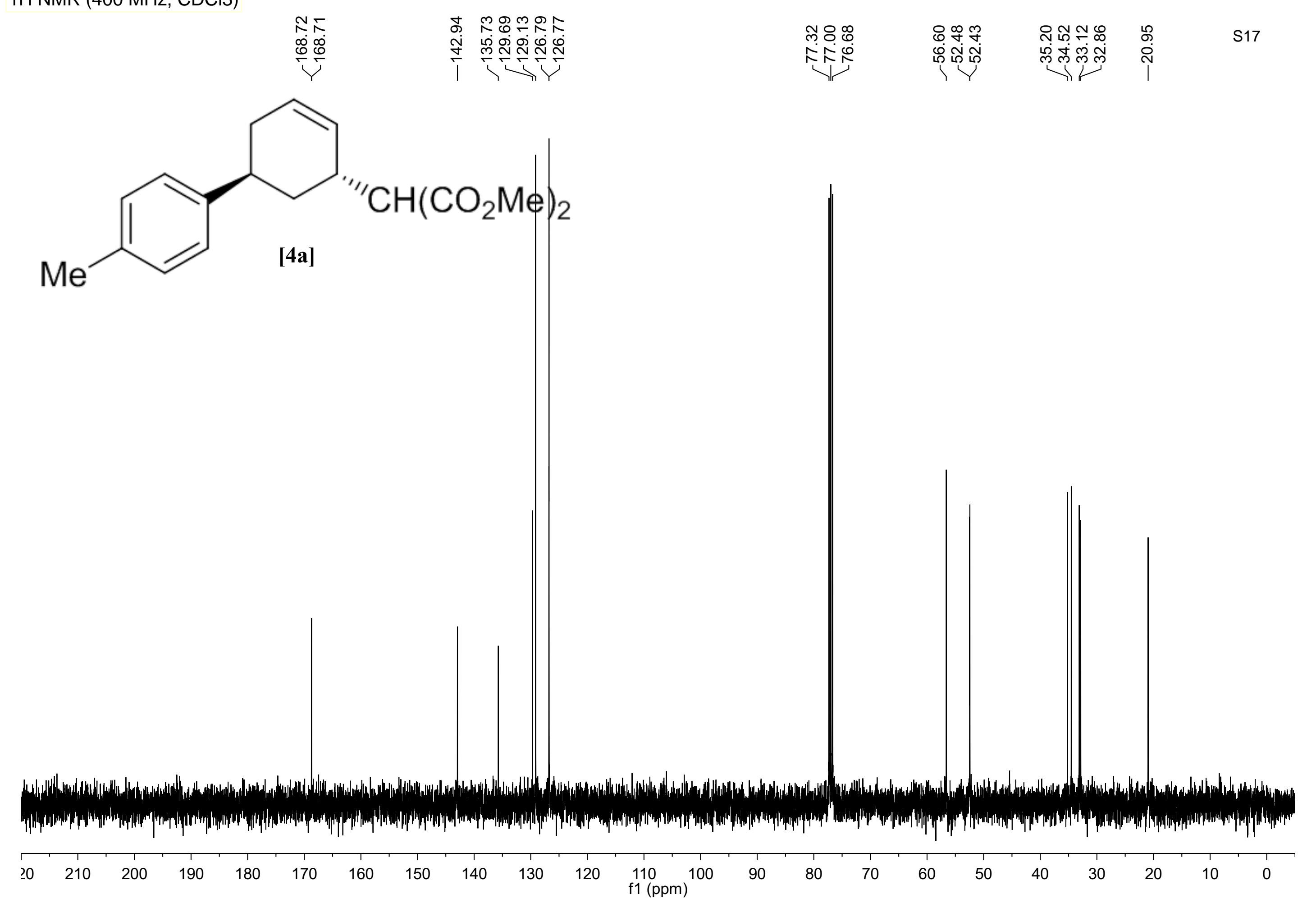




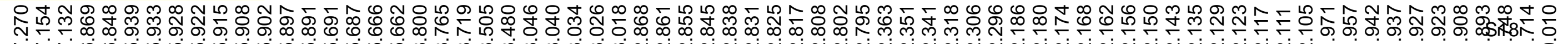

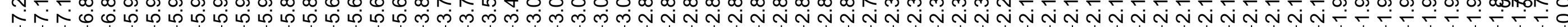

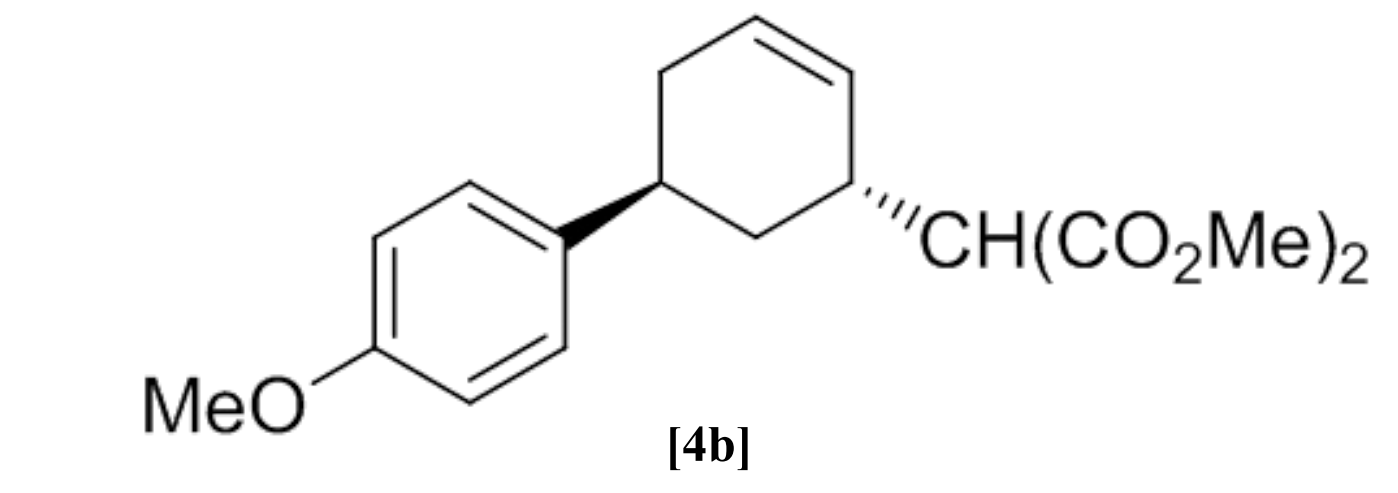

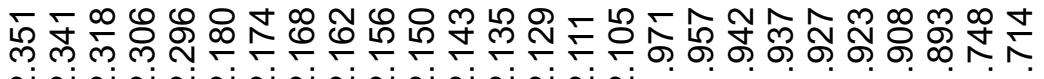
N N N N N N N N N N N N T T T T T T
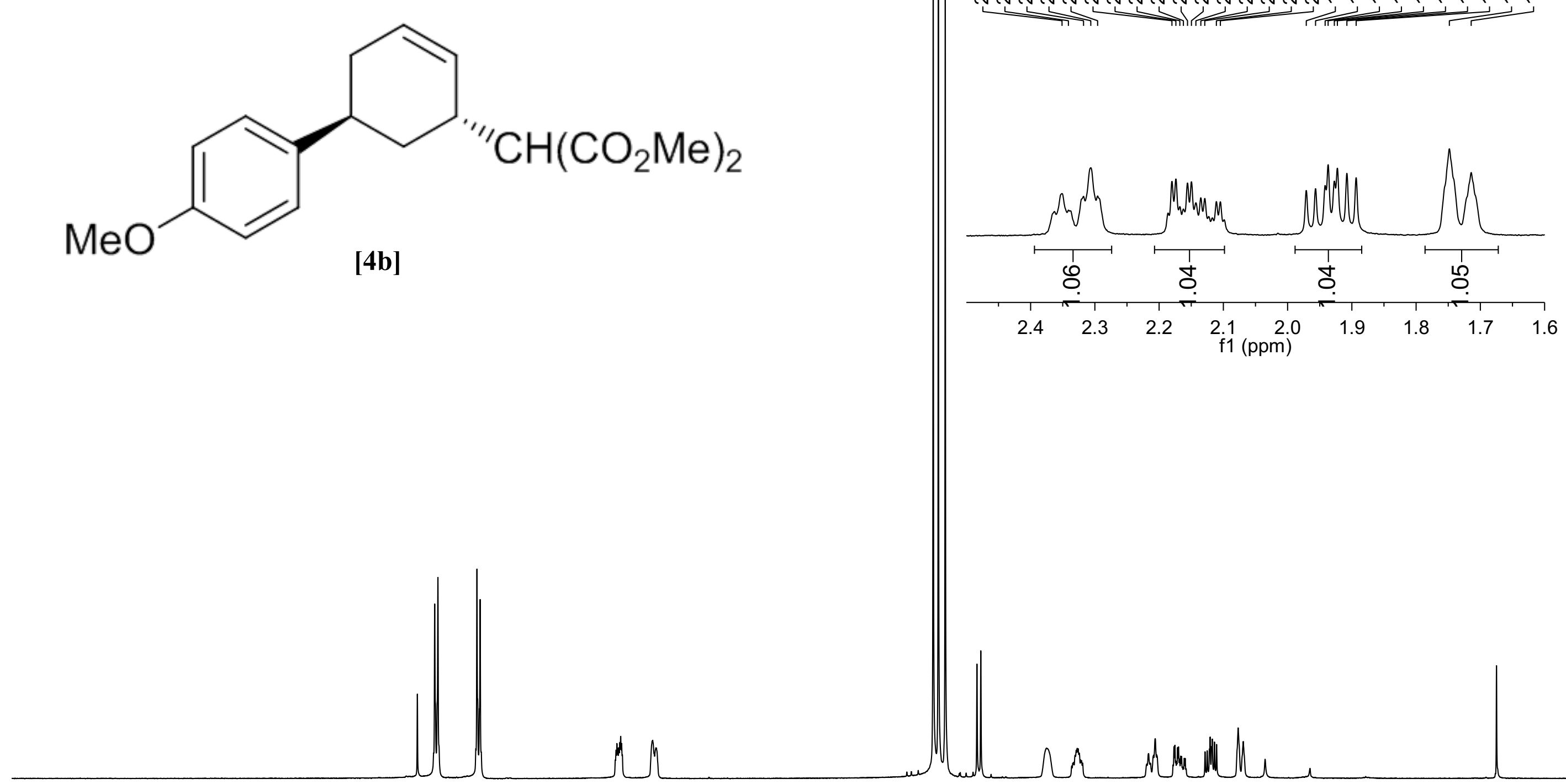

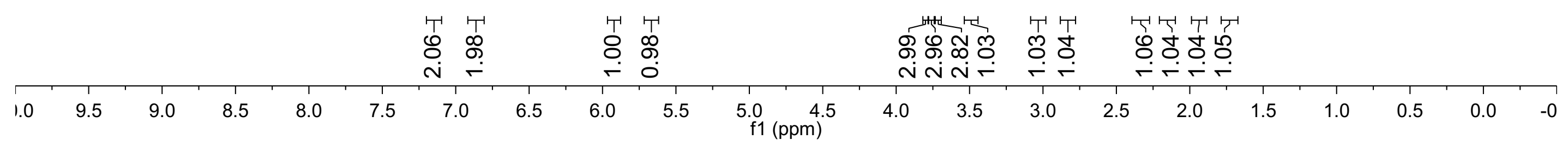


<smiles>COc1ccc([C@H]2CC=C[C@H](C(C)C)C2)cc1</smiles>

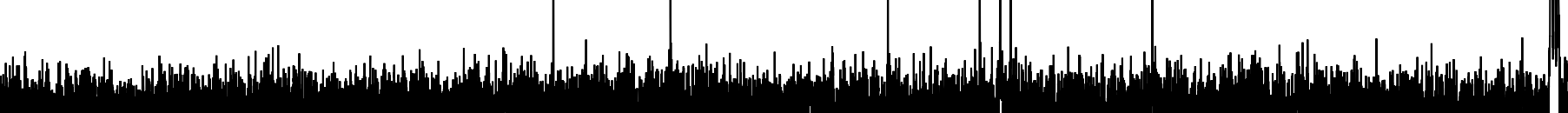

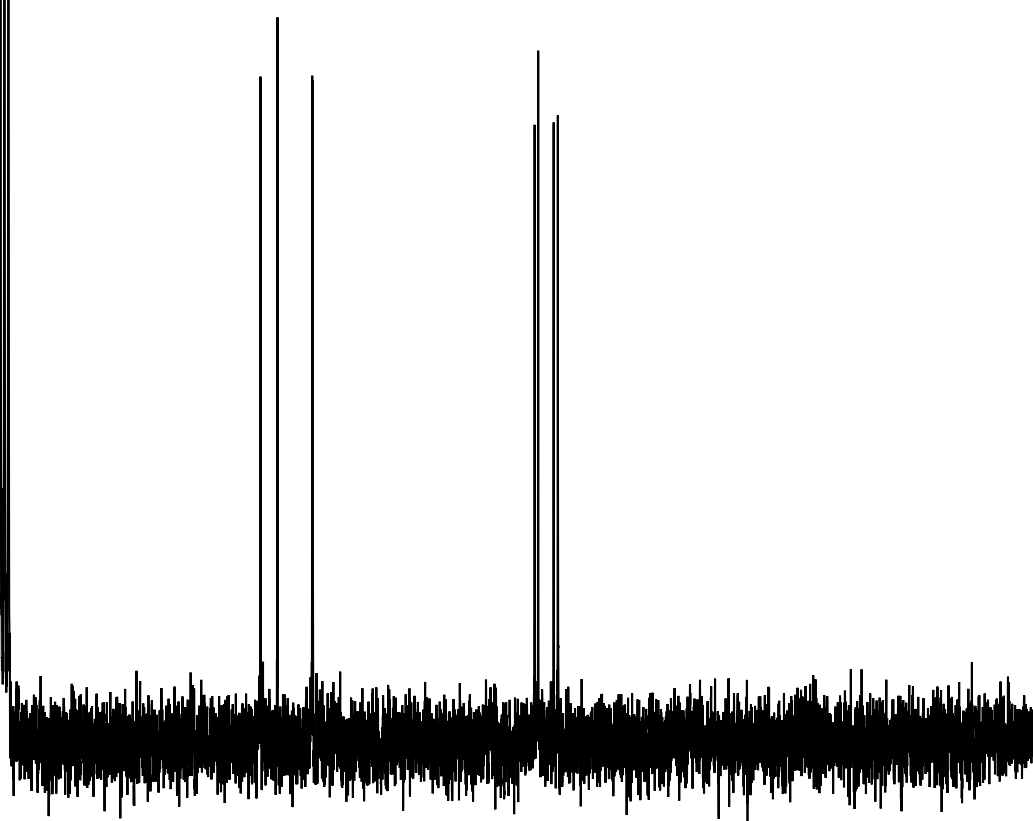

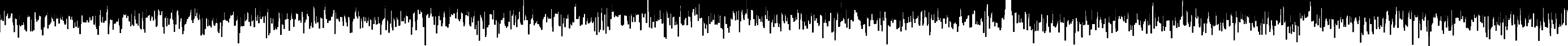




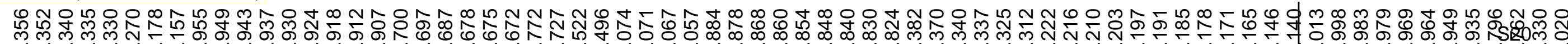

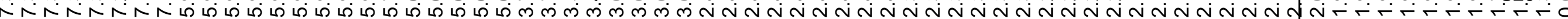

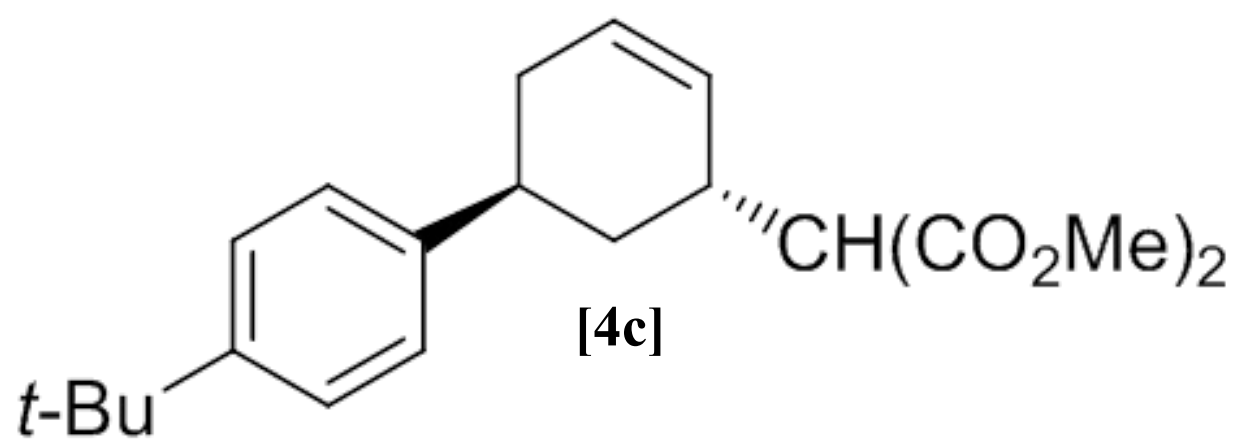

屃

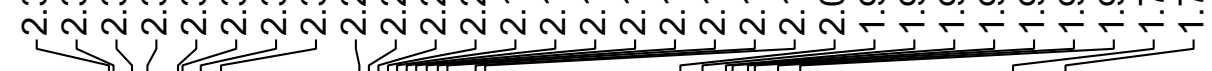
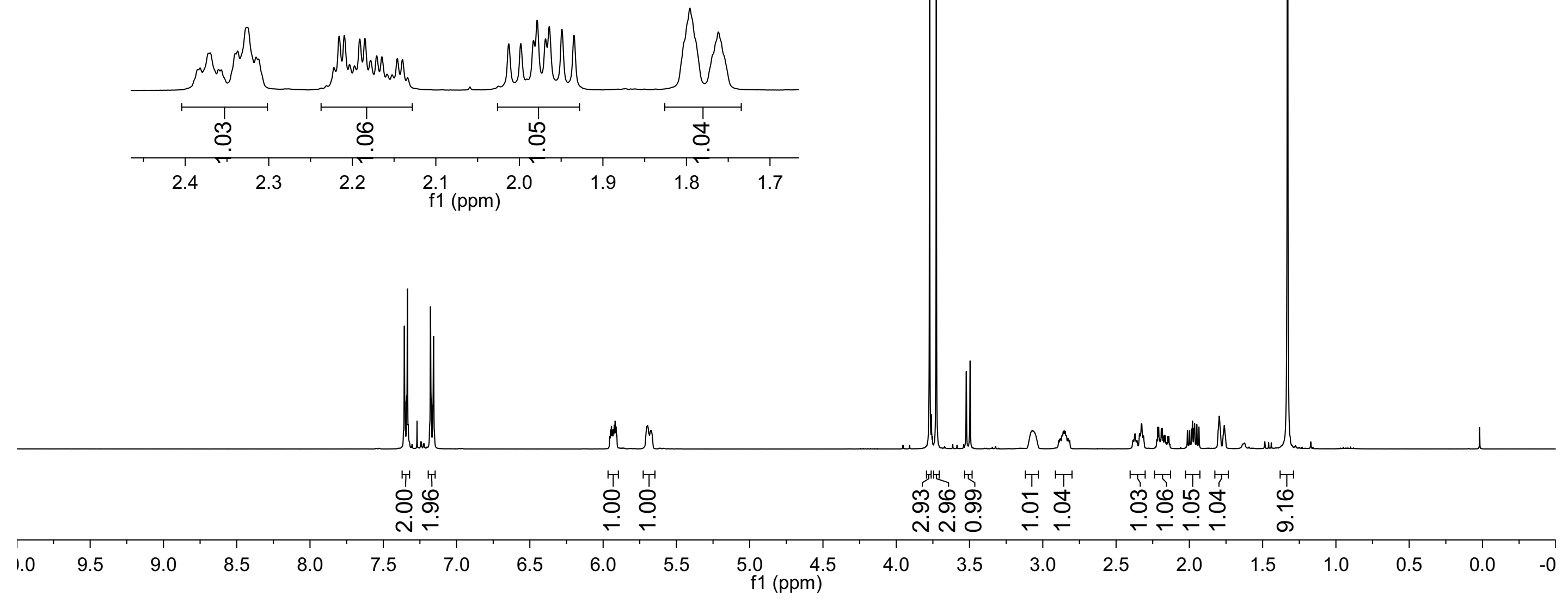

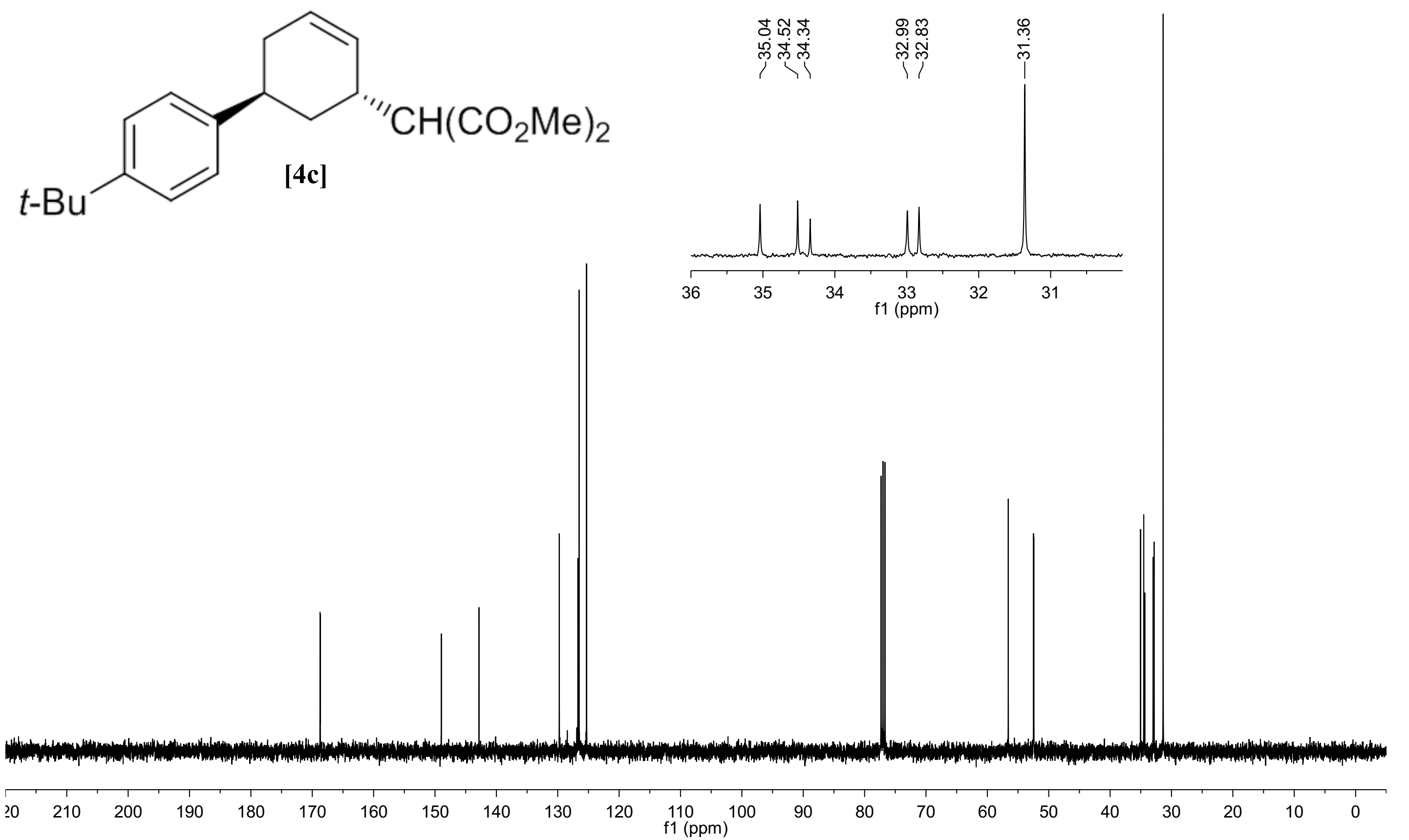


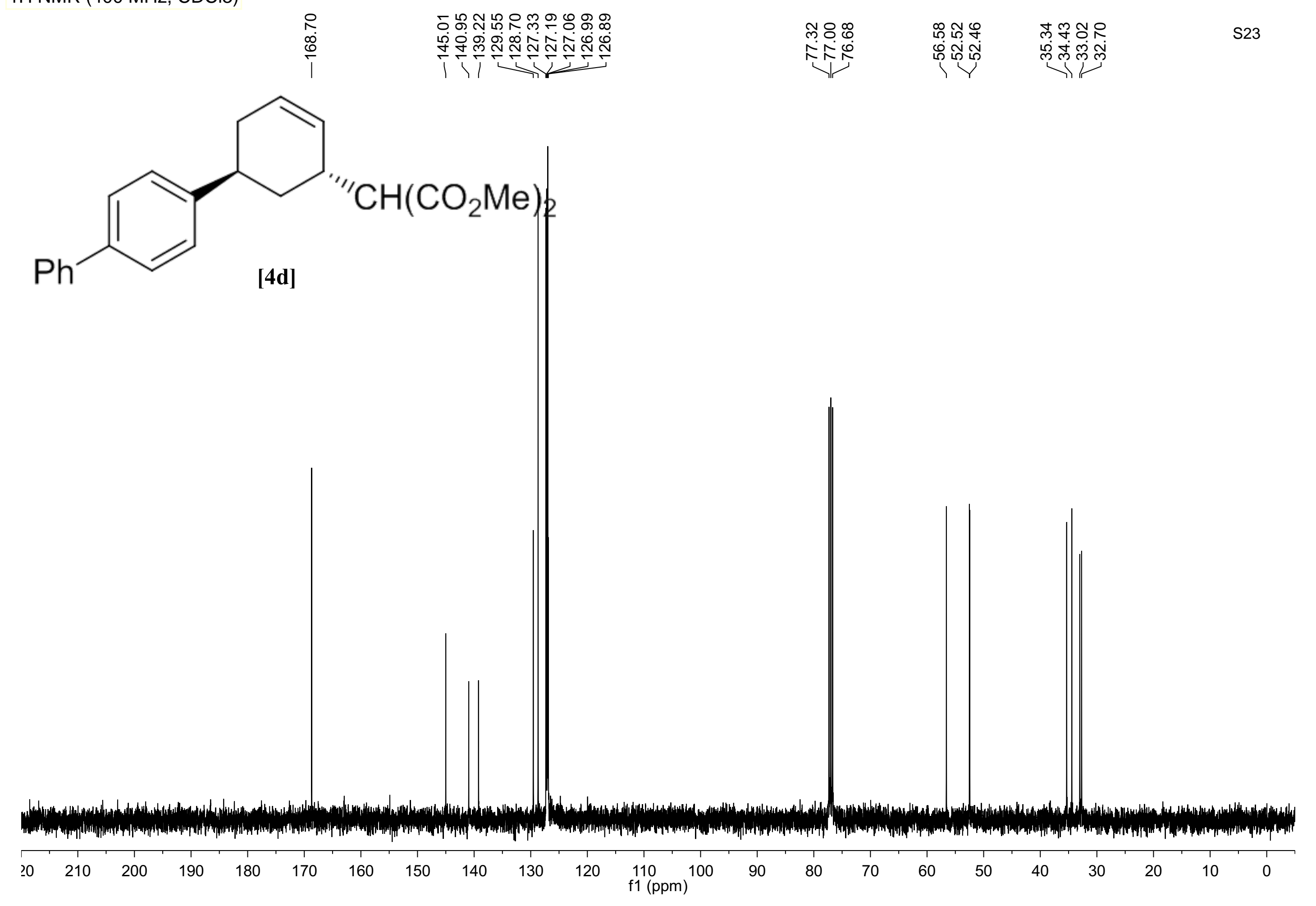




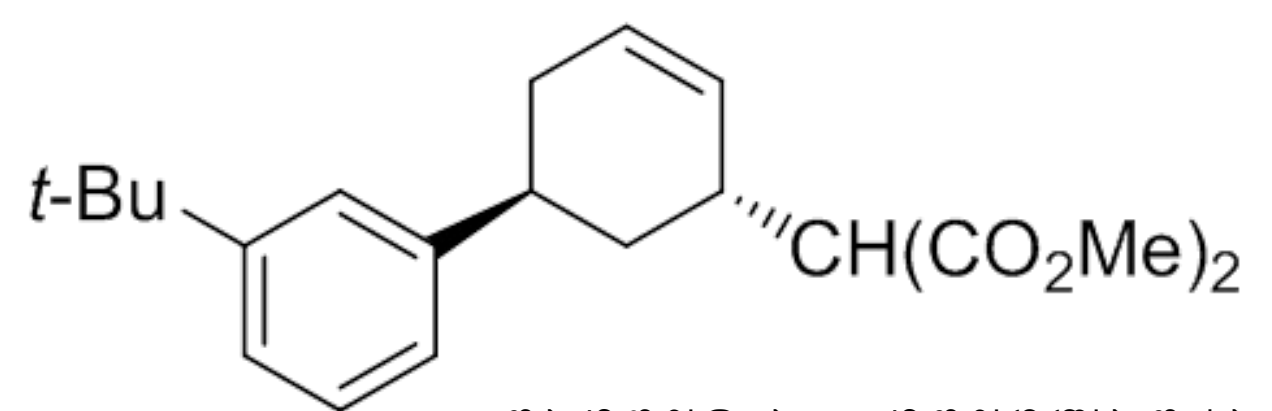

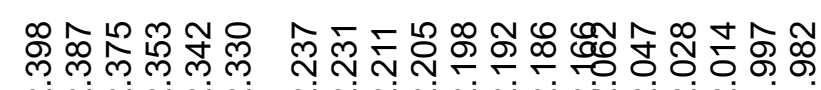

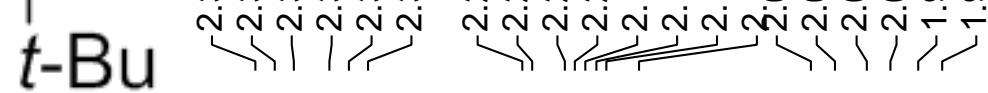

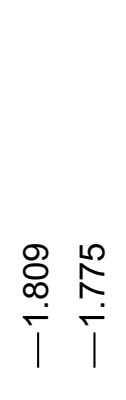

$[4 \mathrm{e}]$
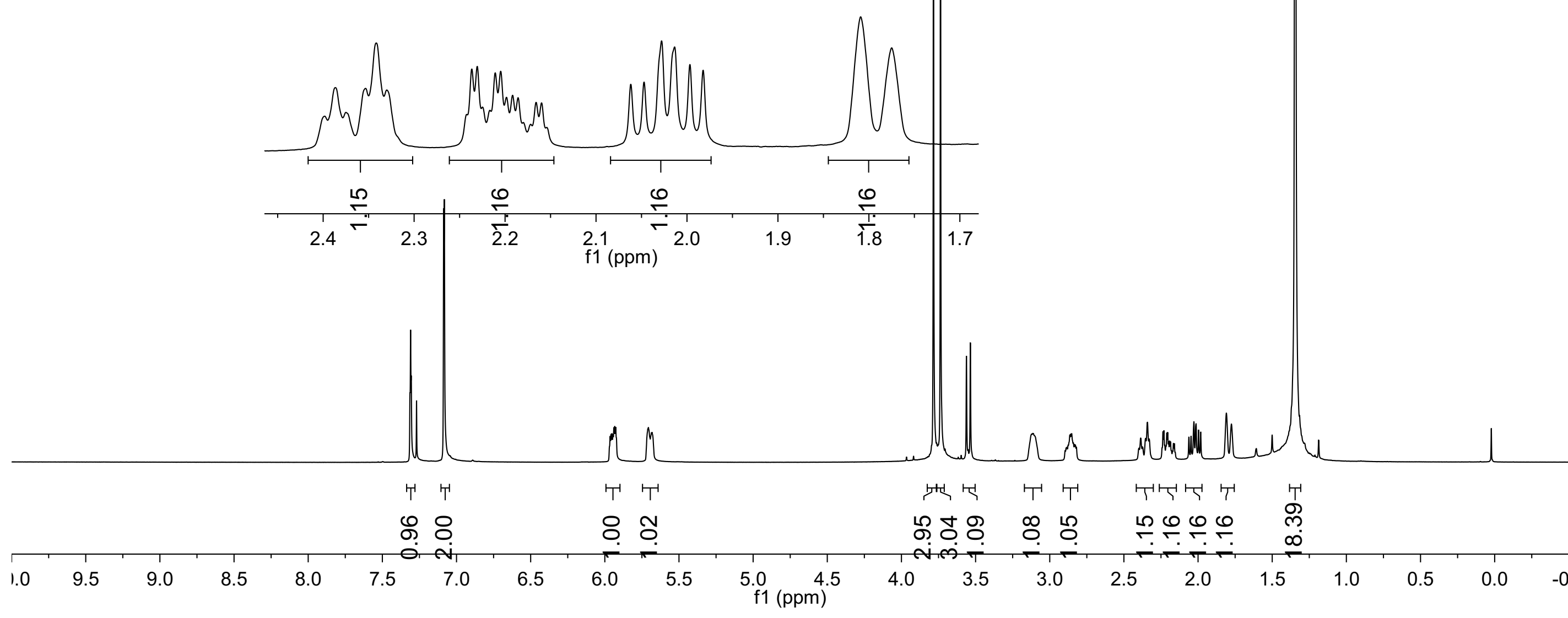


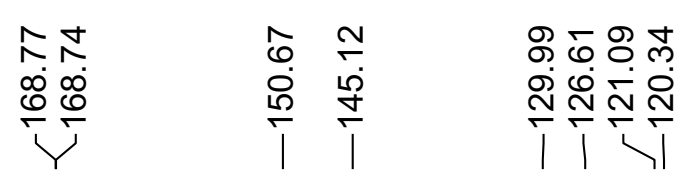

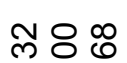

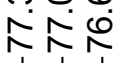

作

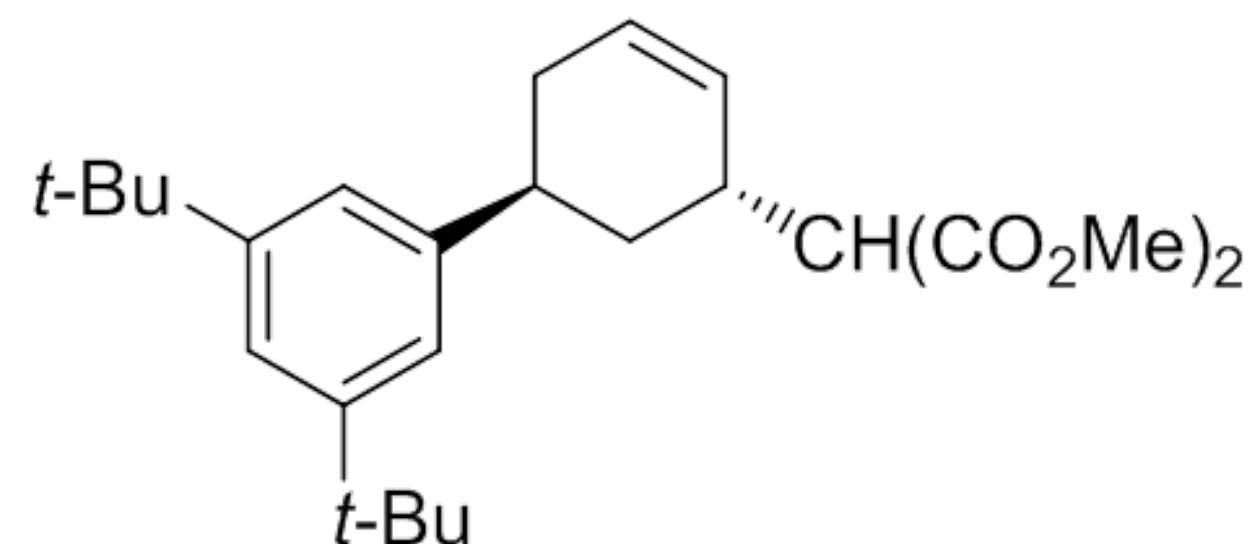

[4e]

Int. 


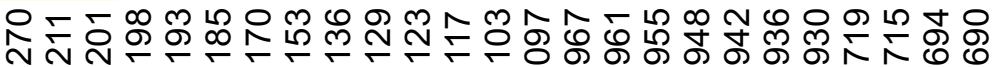

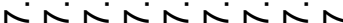

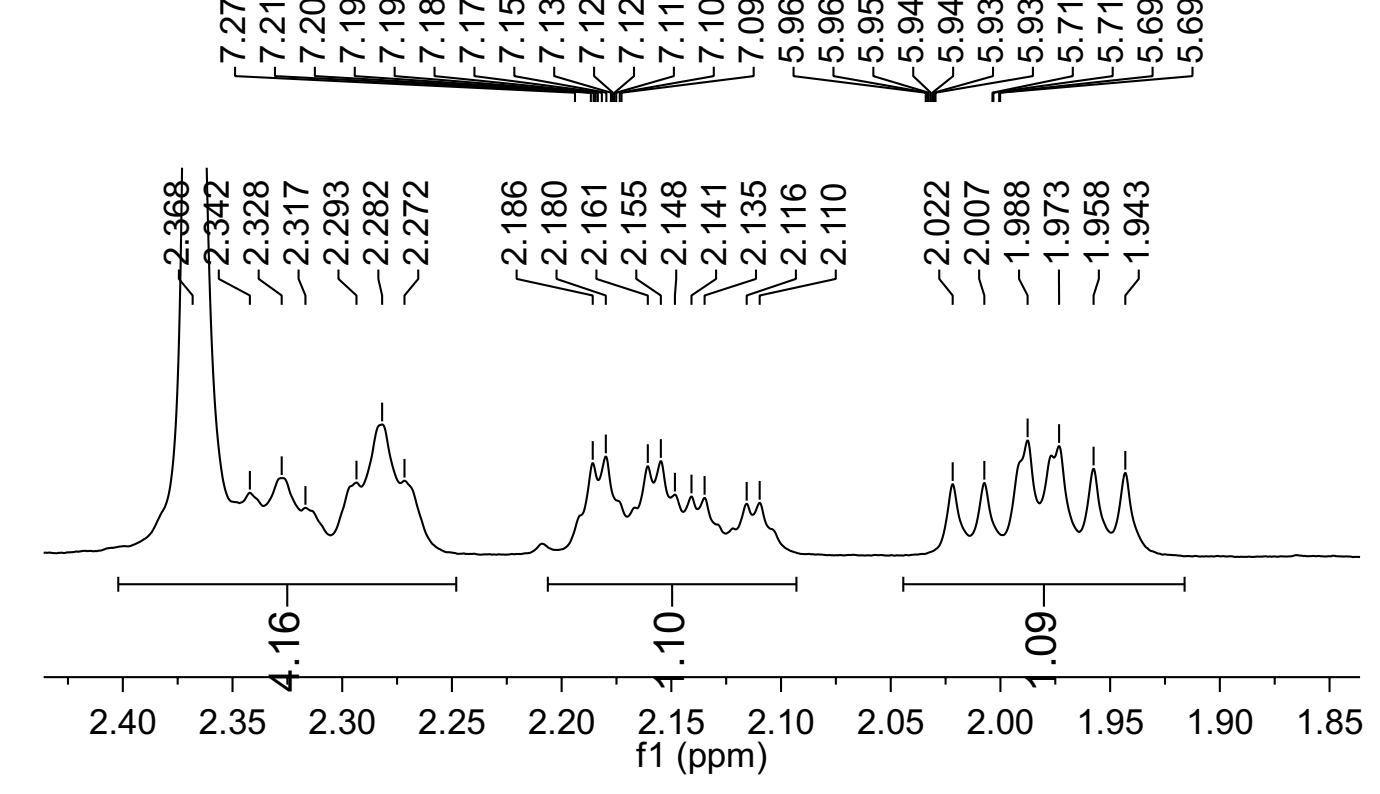

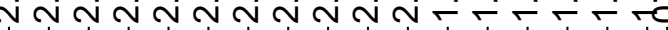
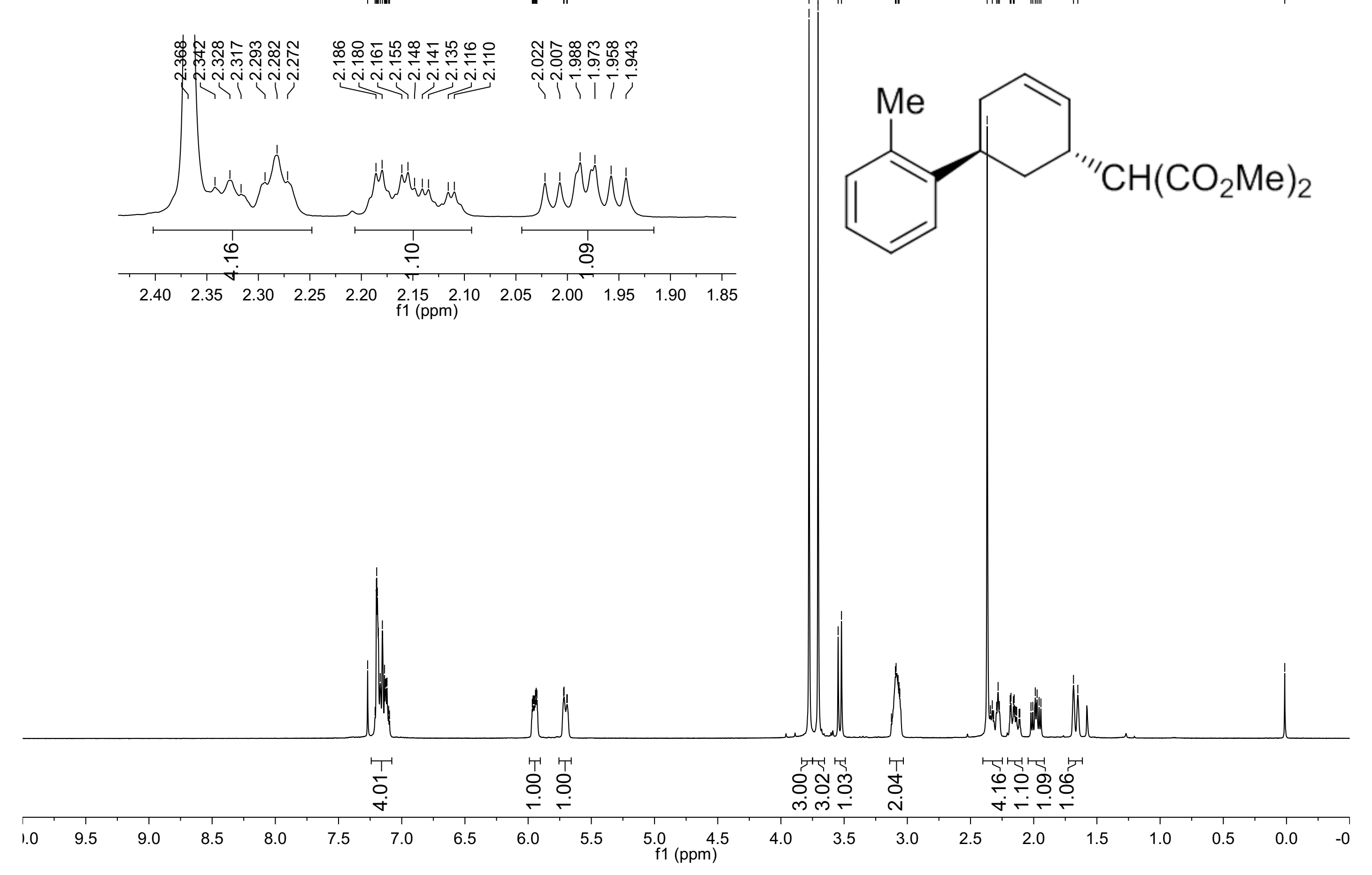


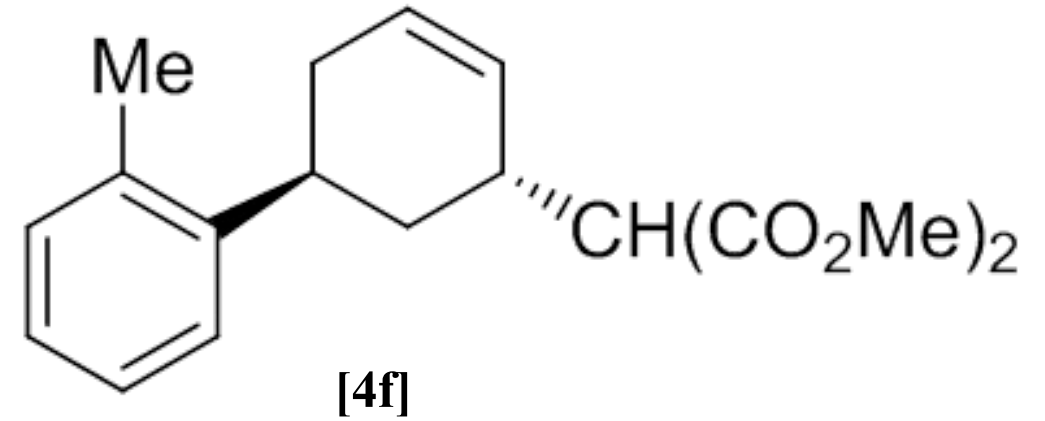

[4f]

$\|$

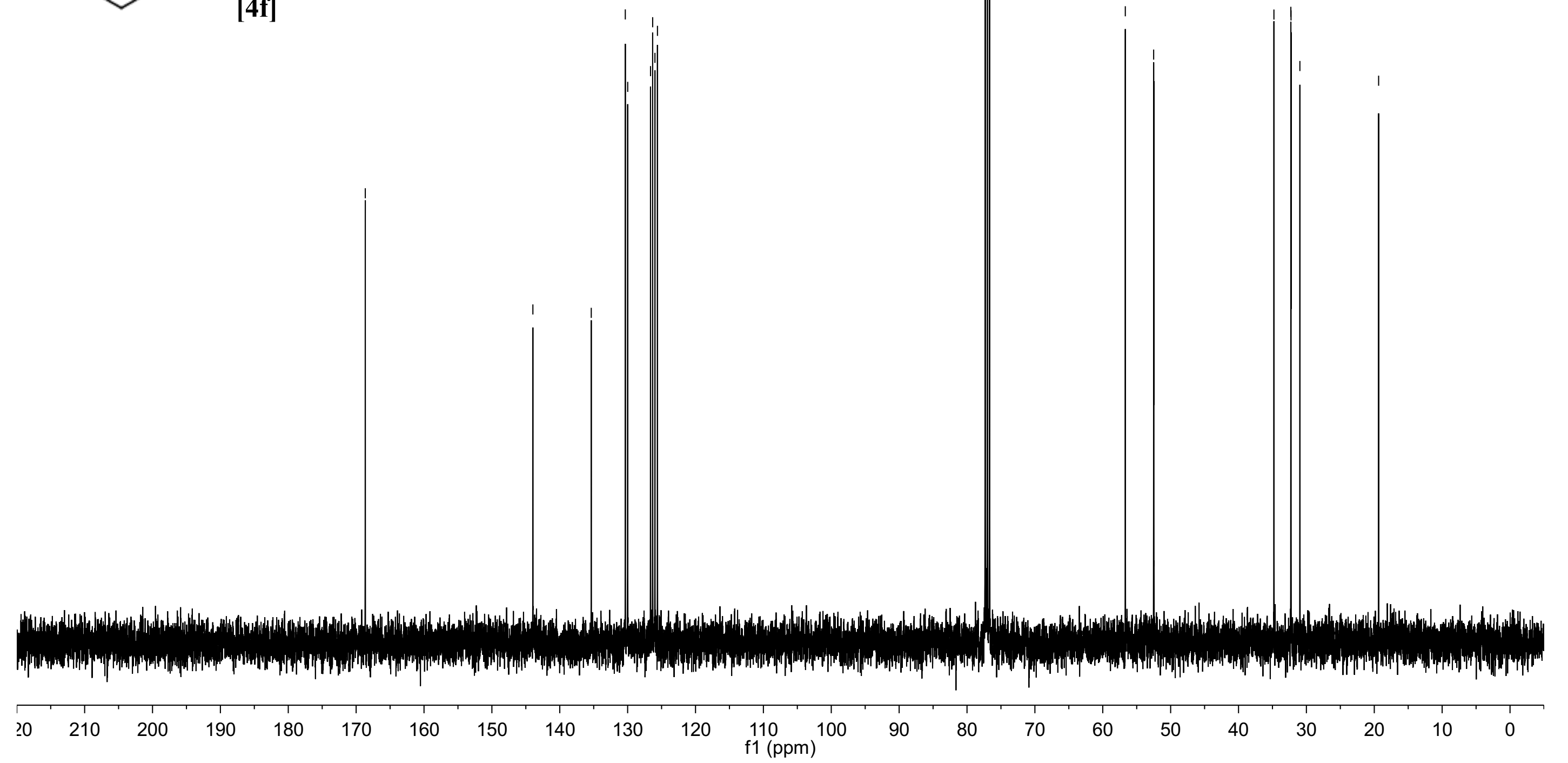




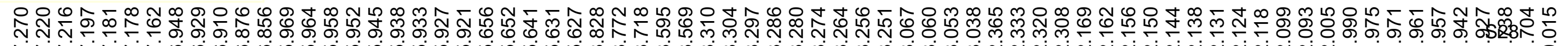

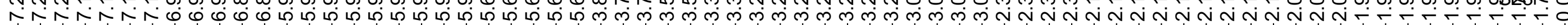

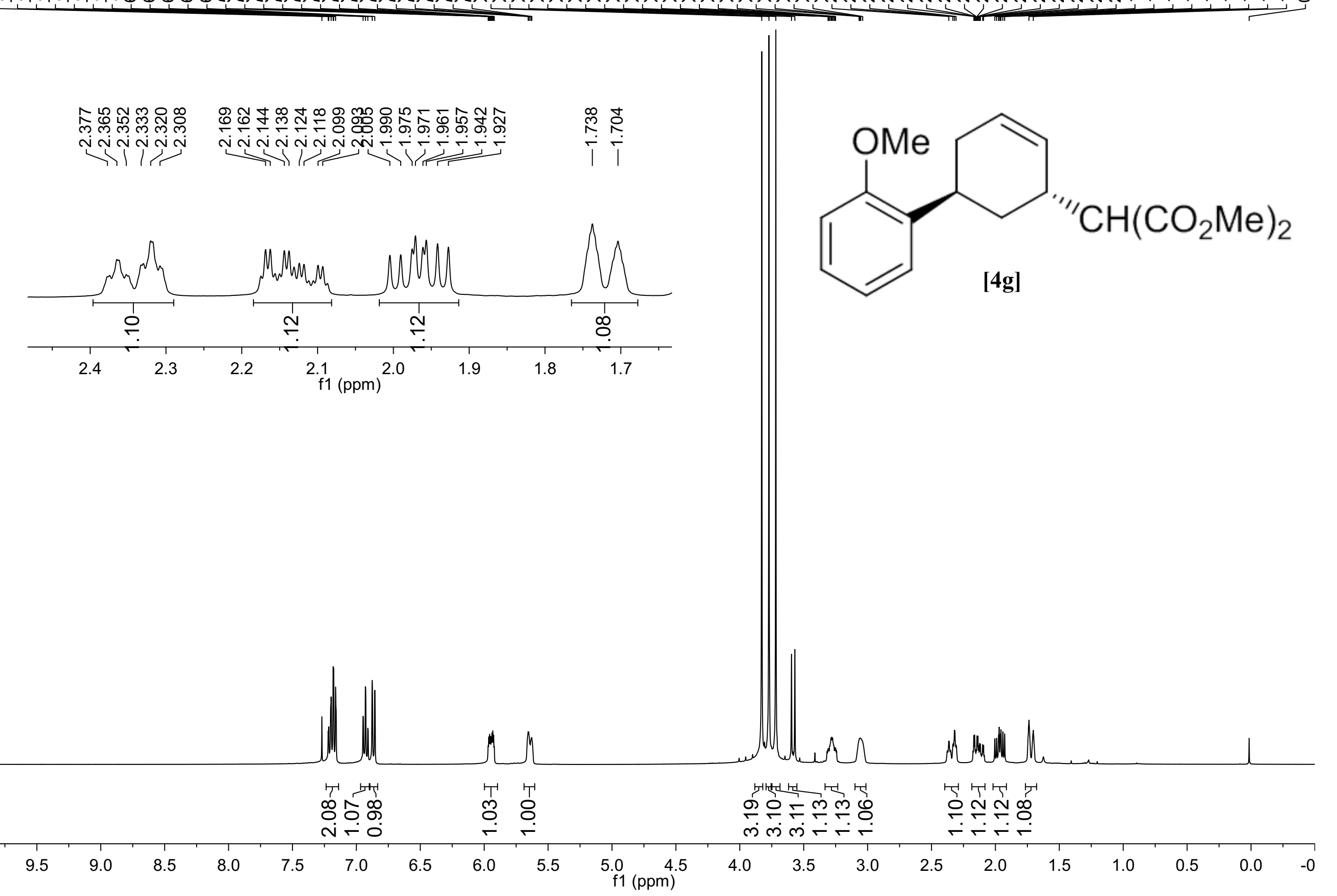




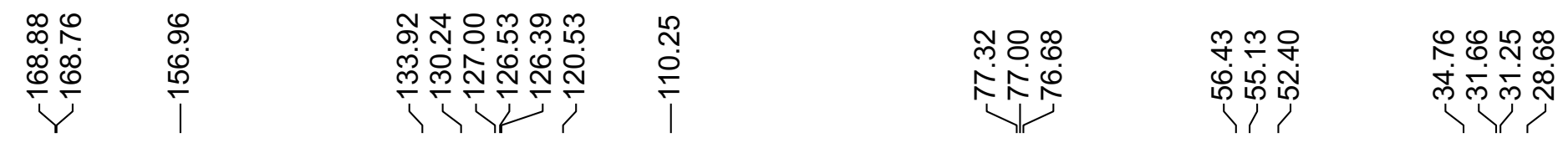

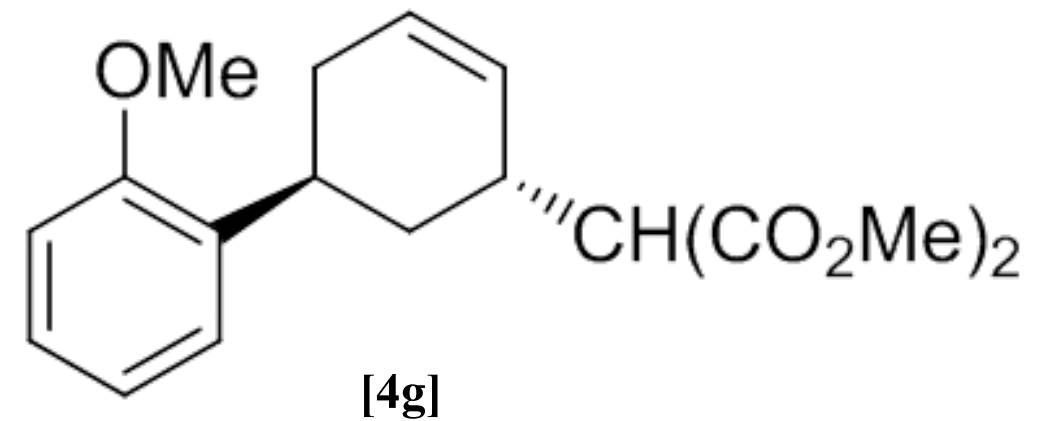
Int.

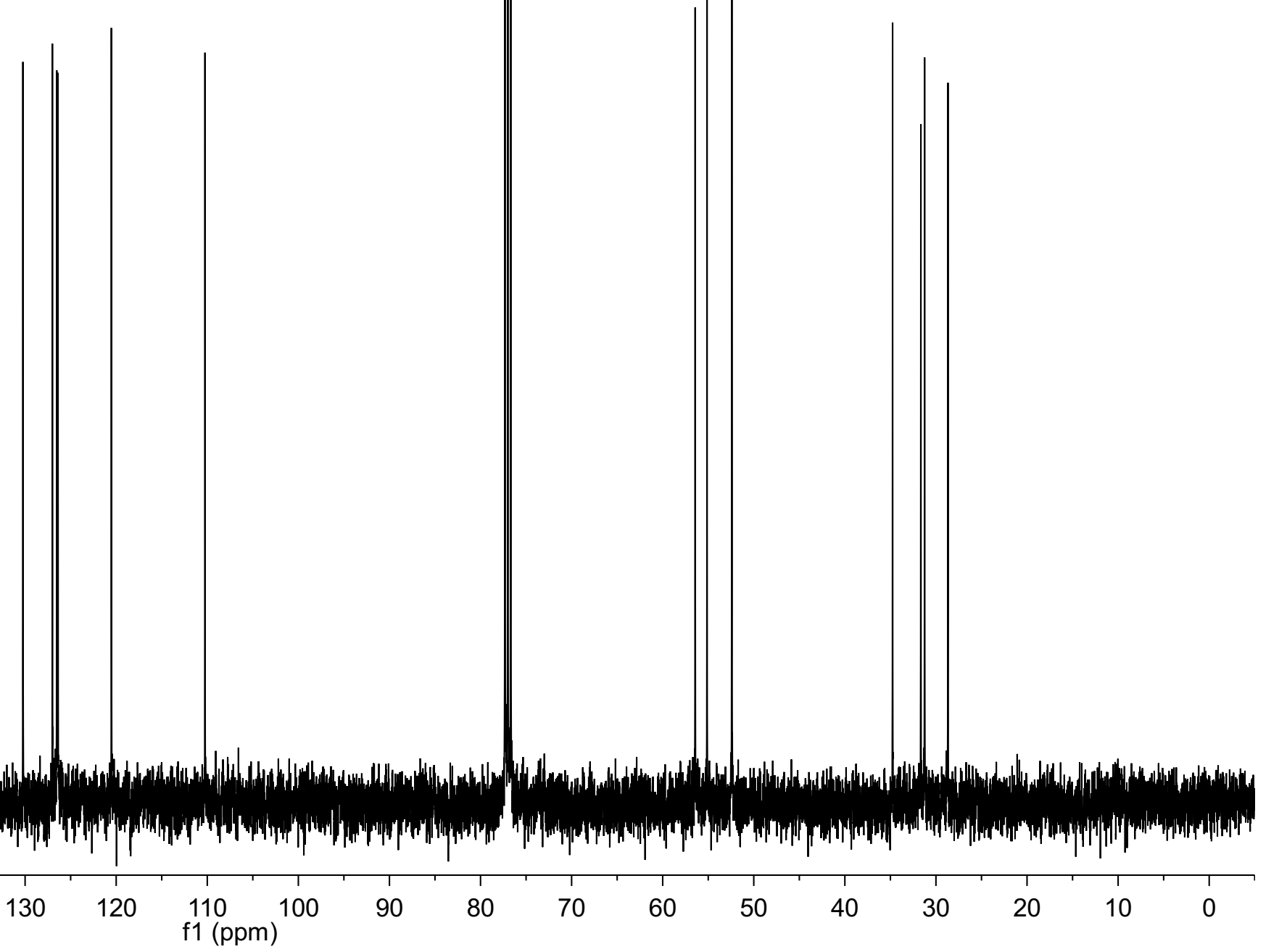

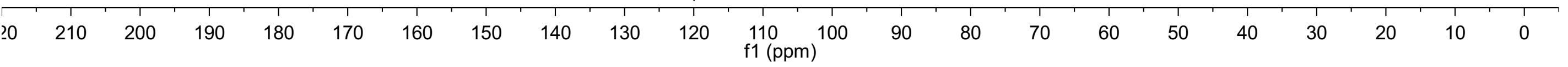



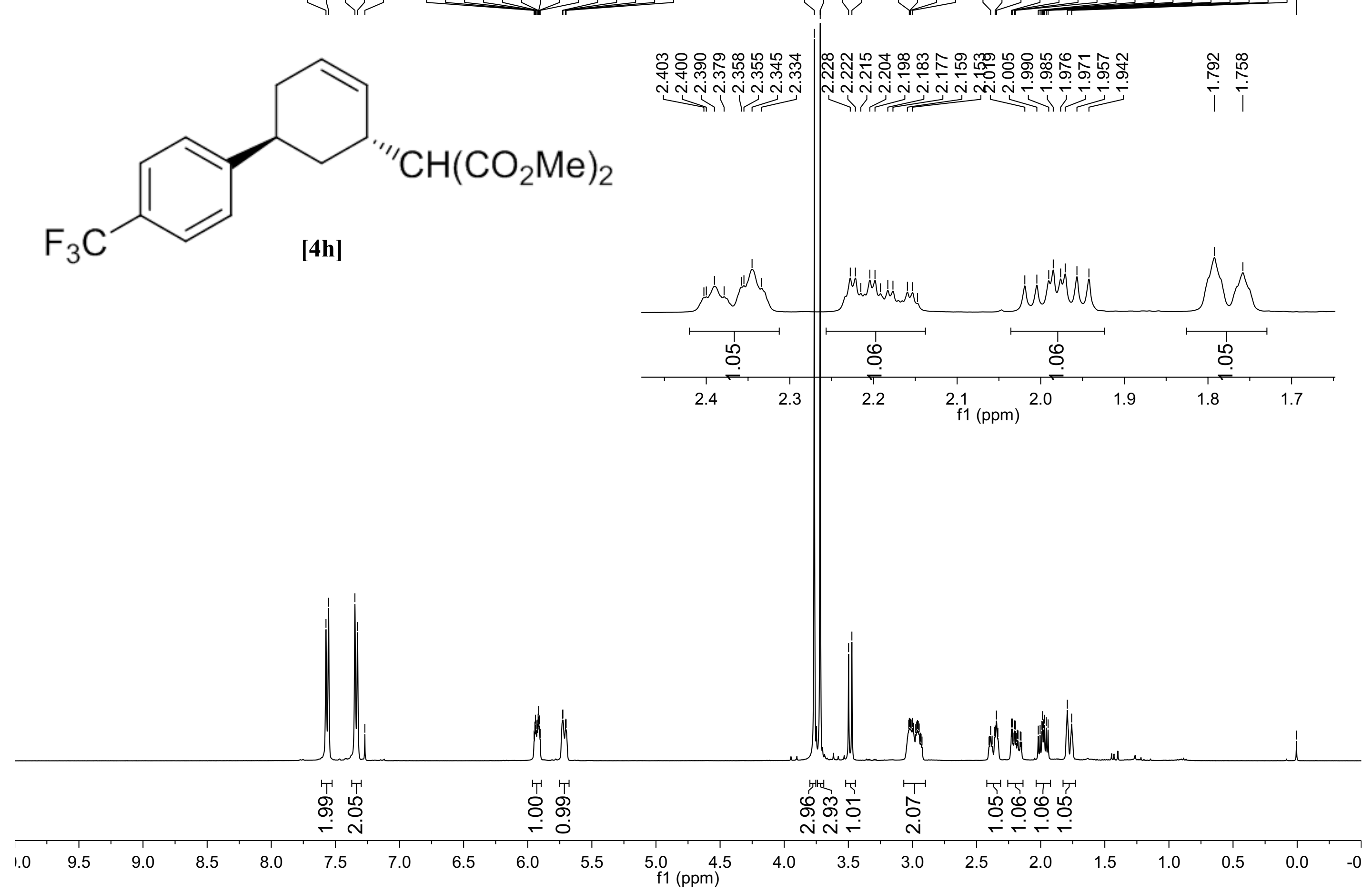


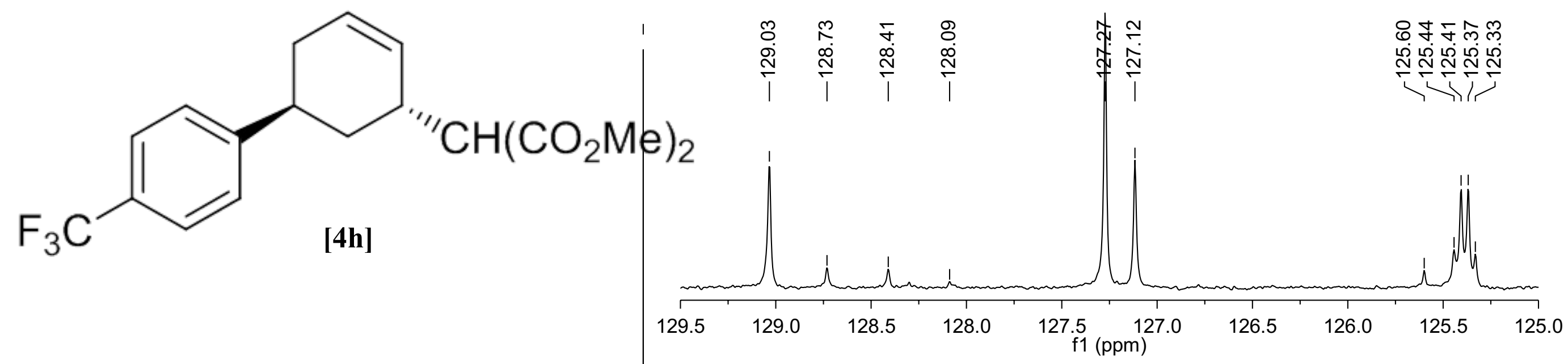

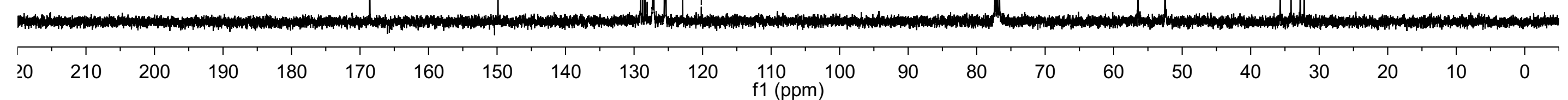


<smiles>COC(C)C1C=CC[C@@H](c2ccc(C(F)(F)F)cc2)C1</smiles>

\begin{tabular}{rllllllllllllllllllllll}
\hline 10 & 0 & -10 & -20 & -30 & -40 & -50 & -60 & -70 & -80 & -90 & -100 & -110 & -120 & -130 & -140 & -150 & -160 & -170 & -180 & -190 & -200 & -210
\end{tabular}




\section{${ }^{\prime \prime} \mathrm{CH}\left(\mathrm{CO}_{2} \mathrm{Me}\right)_{2}$}
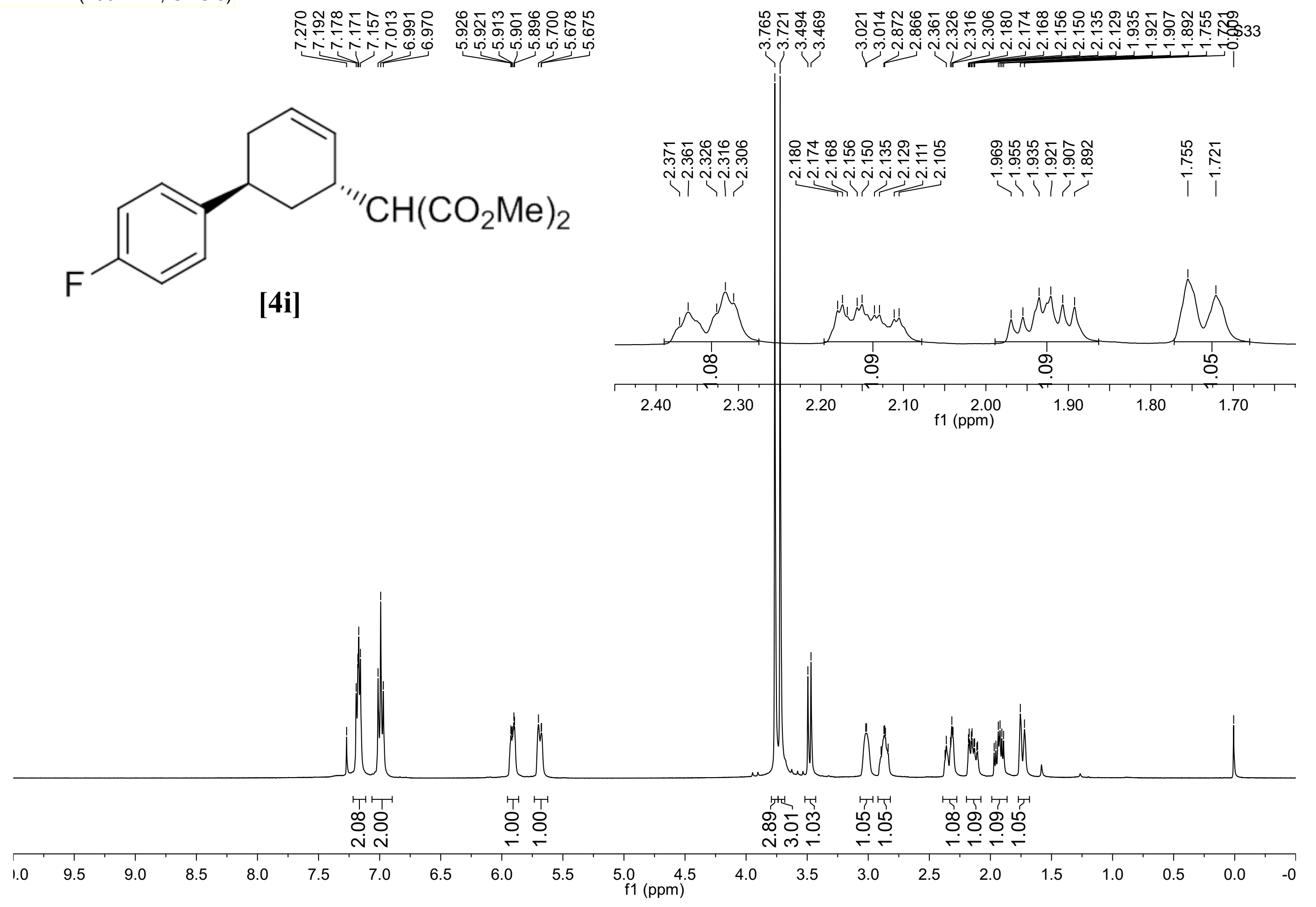


$$
\text { لj }
$$

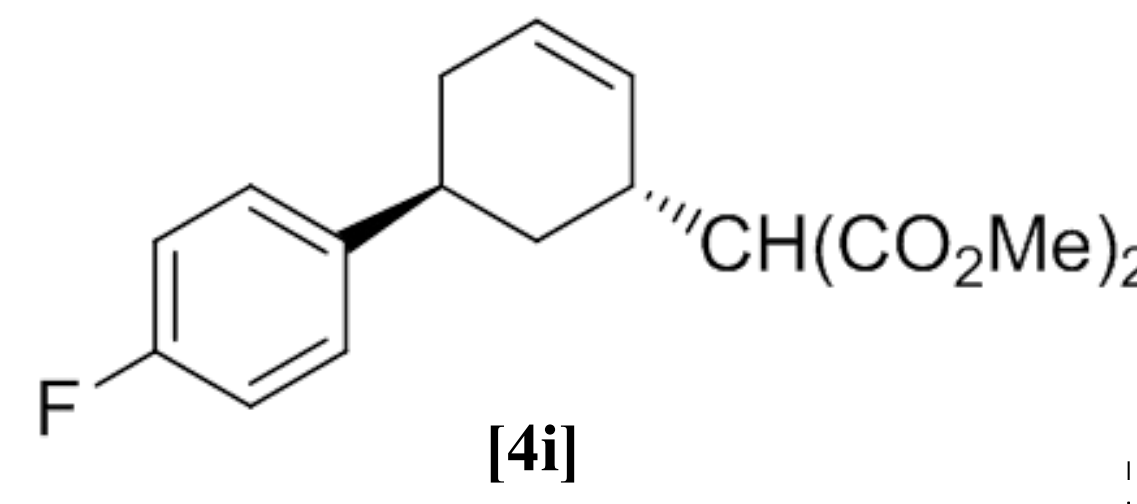

[4i]

$w^{\prime \prime}$

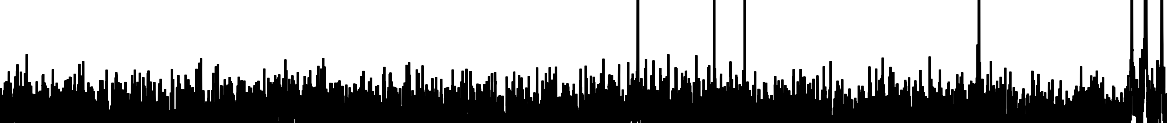




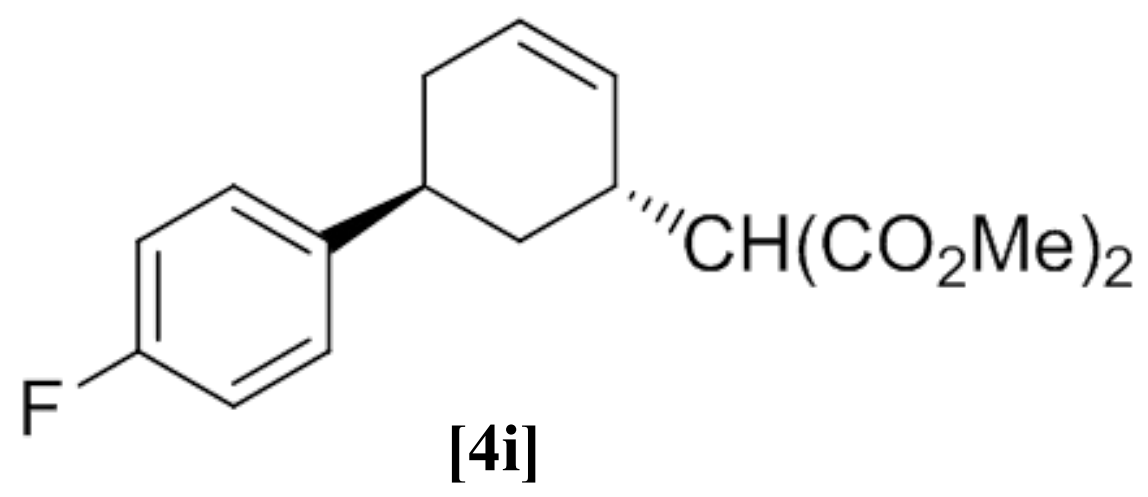

\begin{tabular}{lllllllllllllllllllllllll}
\hline 10 & 0 & -10 & -20 & -30 & -40 & -50 & -60 & -70 & -80 & -90 & -100 & -110 & -120 & -130 & -140 & -150 & -160 & -170 & -180 & -190 & -200 & -210 & &
\end{tabular}




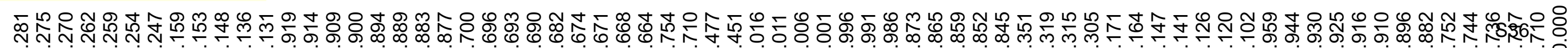

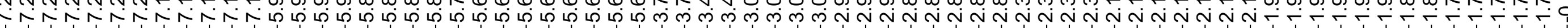

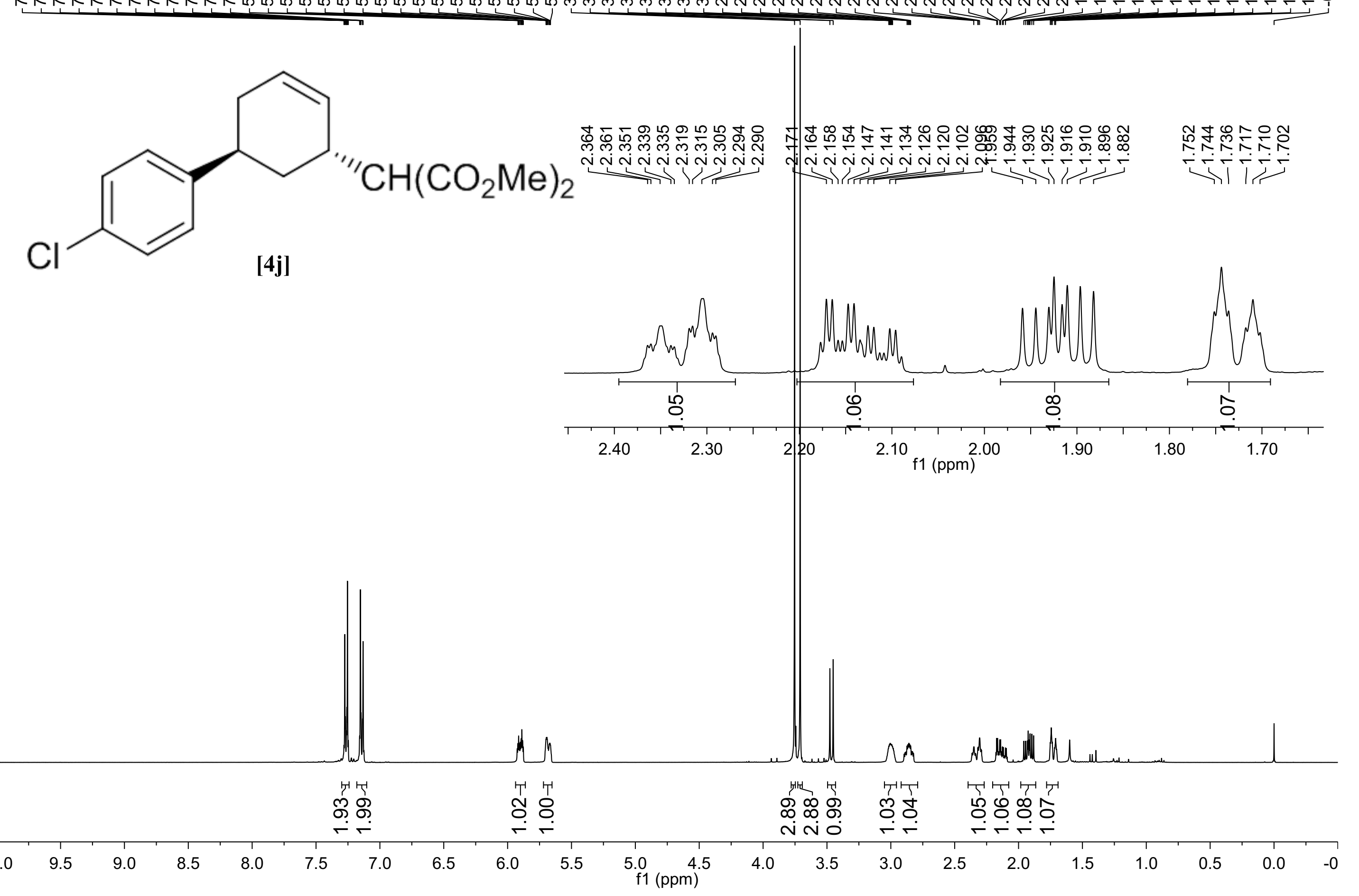


<smiles>COC(C)[C@H]1C=CC[C@@H](c2ccc(Cl)cc2)C1</smiles>

[4j]
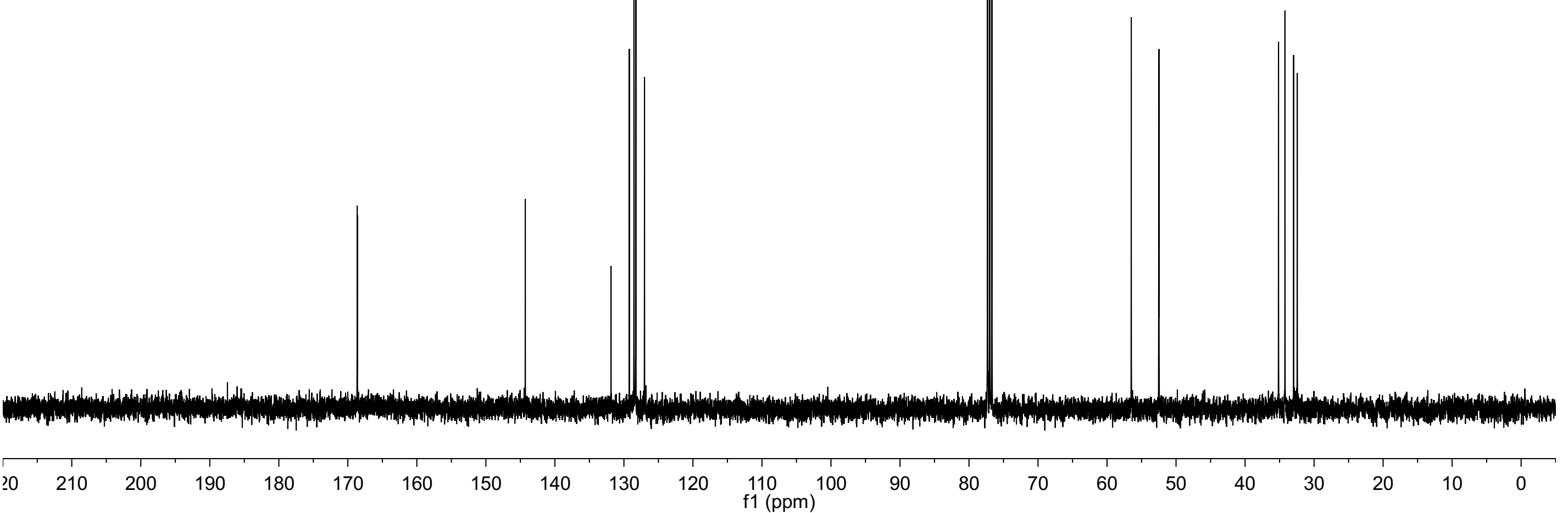


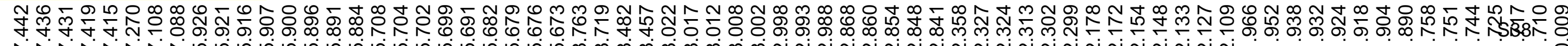

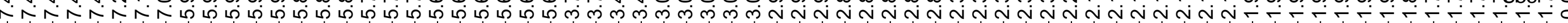

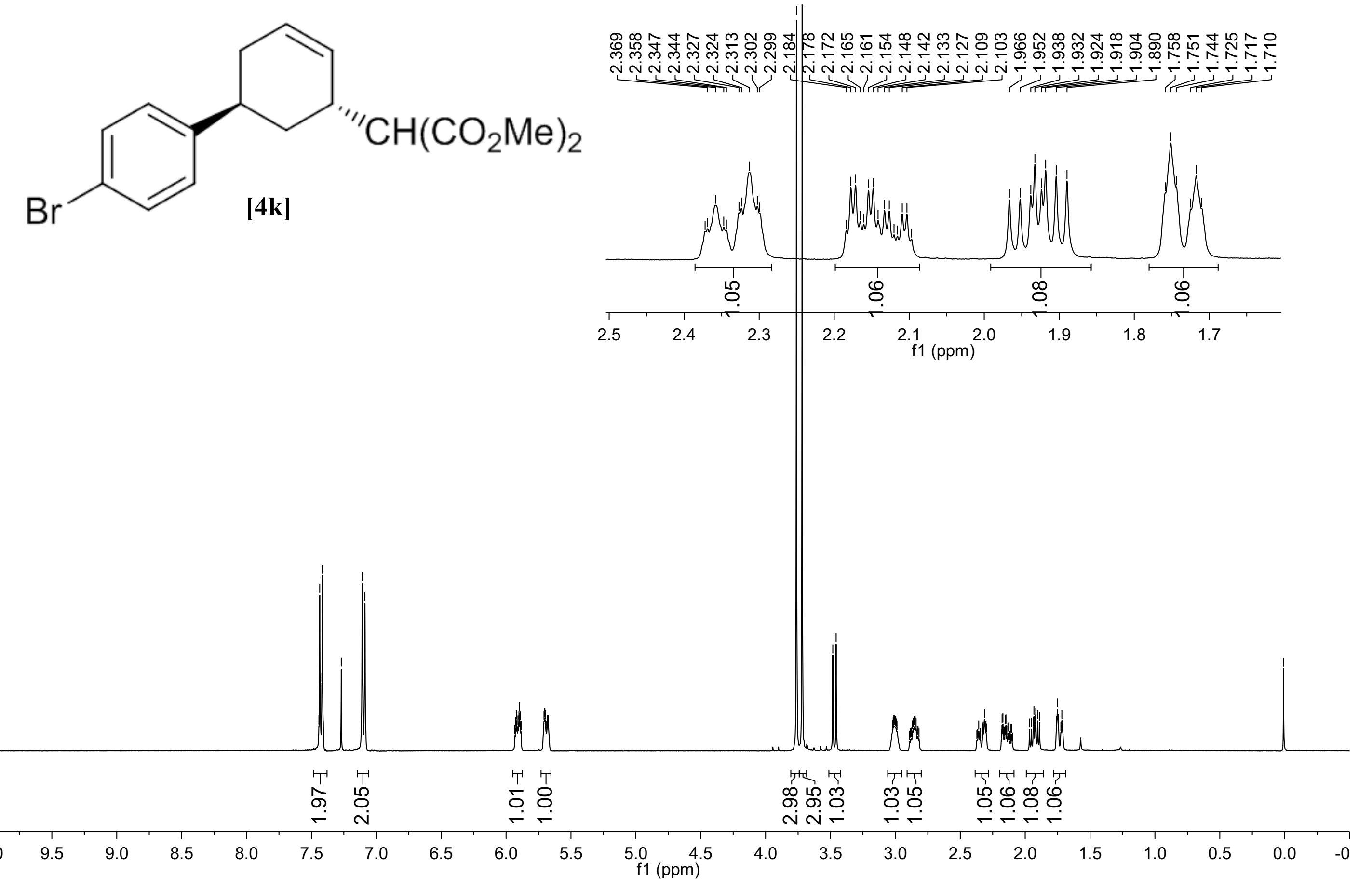




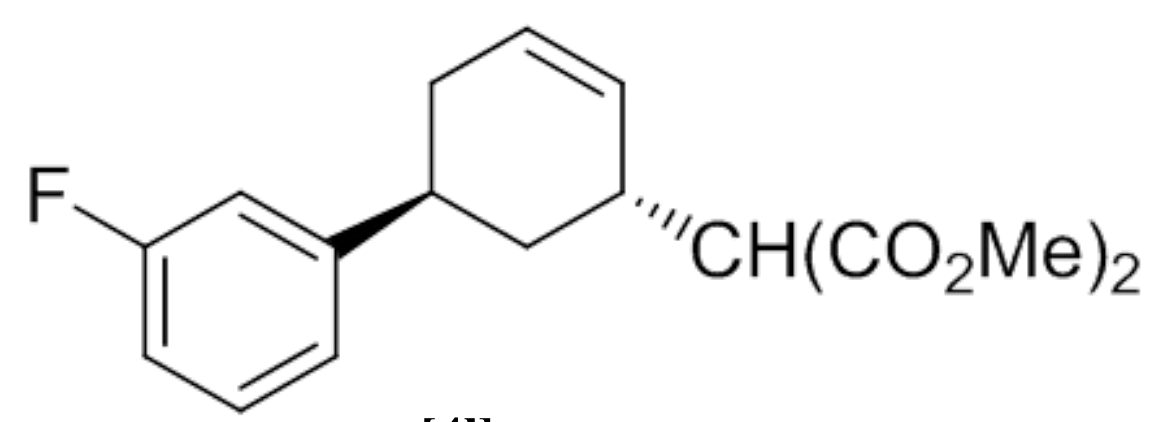

[4I]

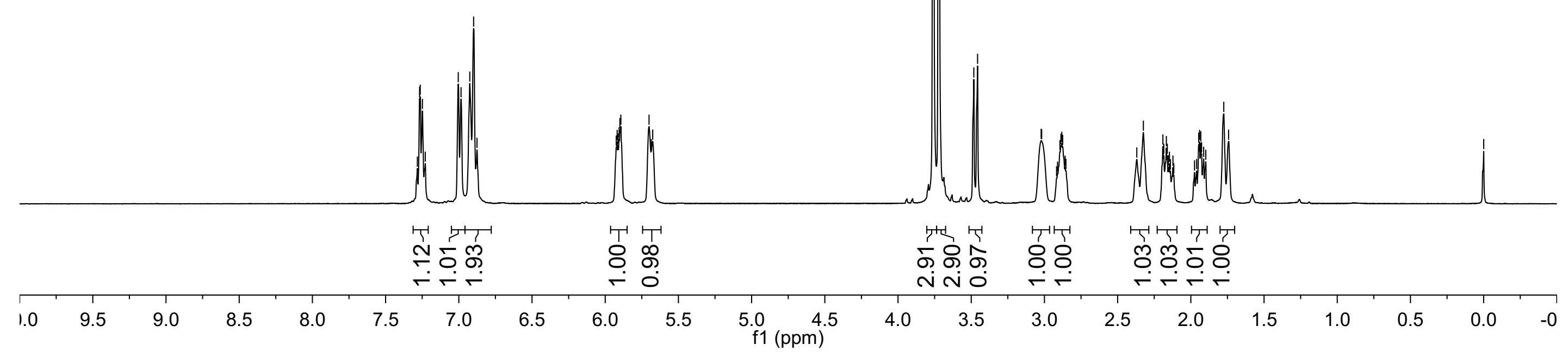


<smiles>COC(C)[C@H]1C=CC[C@@H](c2cccc(F)c2)C1</smiles>

[41]

whlth

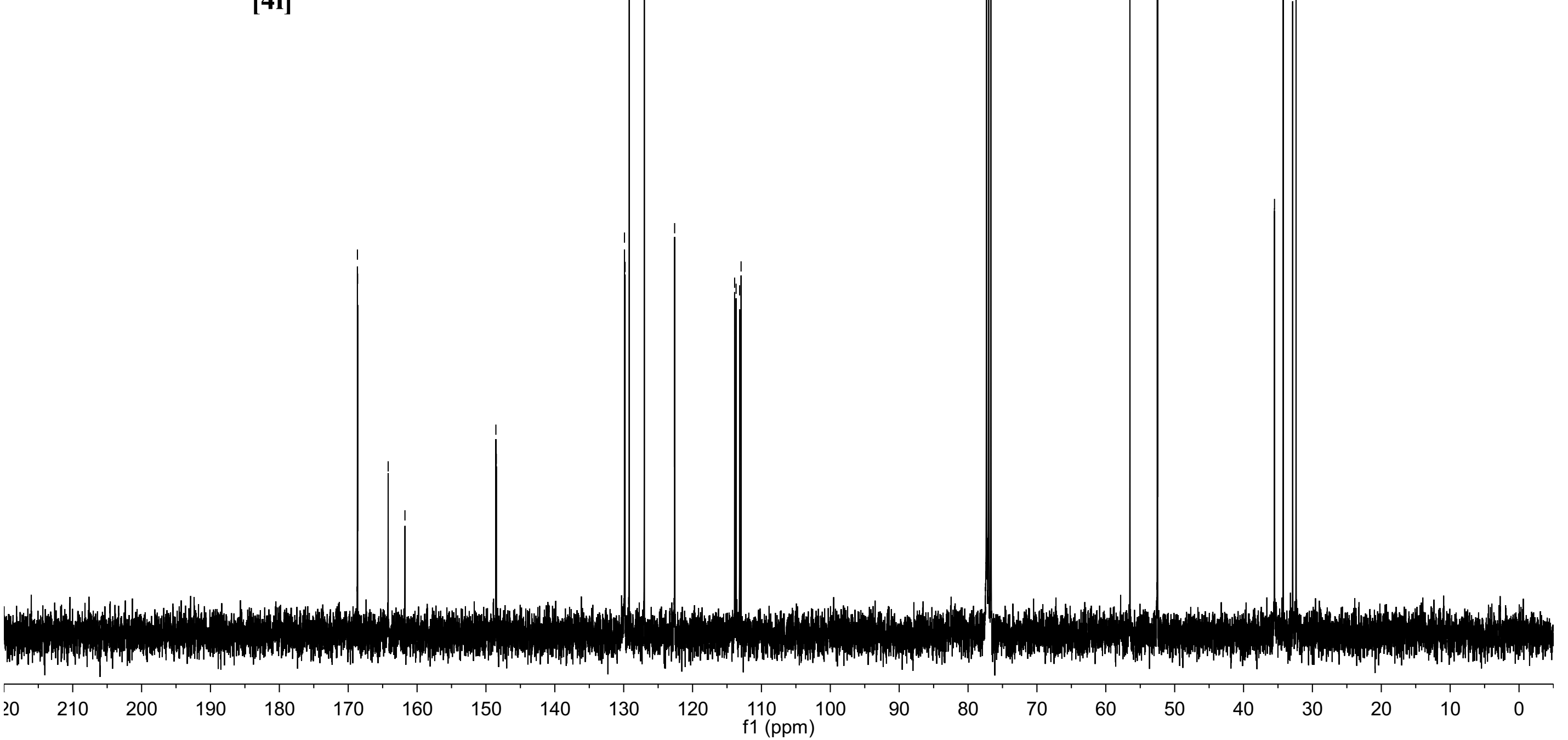

\section{|}


<smiles>COC(=O)[C@H]1C=CC[C@H](c2cccc(F)c2)C1</smiles>

[4I]

\begin{tabular}{rlllllllllllllllllllllllll}
\hline 10 & 0 & -10 & -20 & -30 & -40 & -50 & -60 & -70 & -80 & -90 & -100 & -110 & -120 & -130 & -140 & -150 & -160 & -170 & -180 & -190 & -200 & -210 &
\end{tabular}




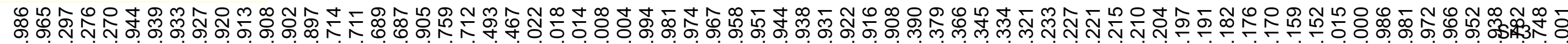

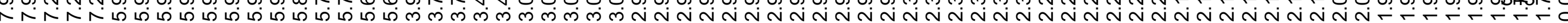

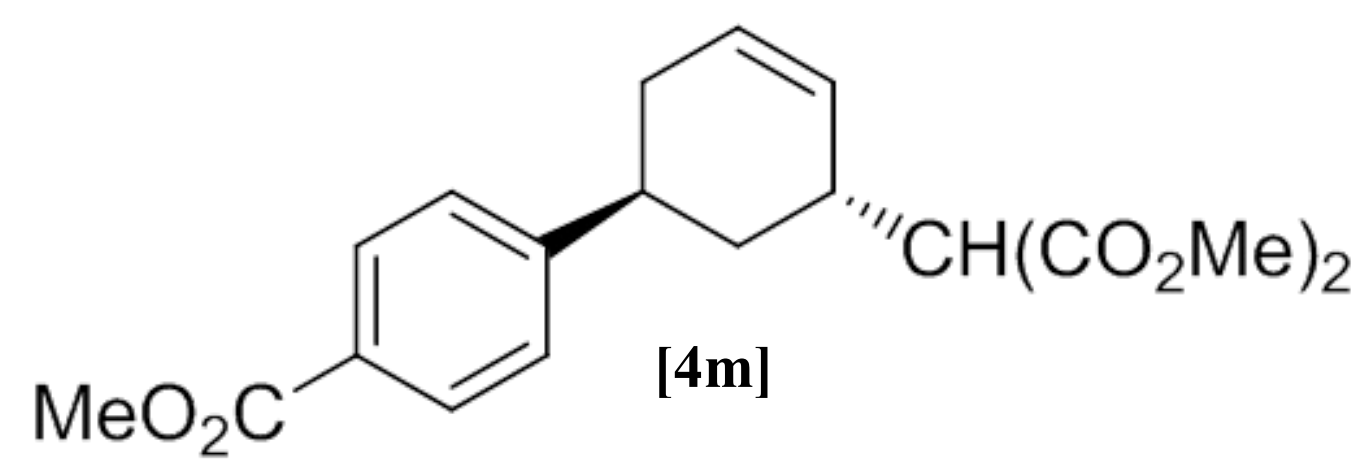

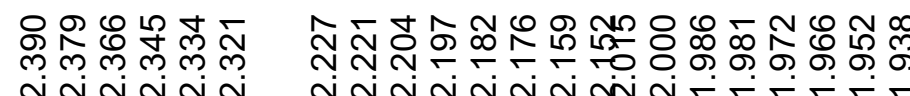

\11\%

Niก

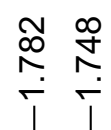
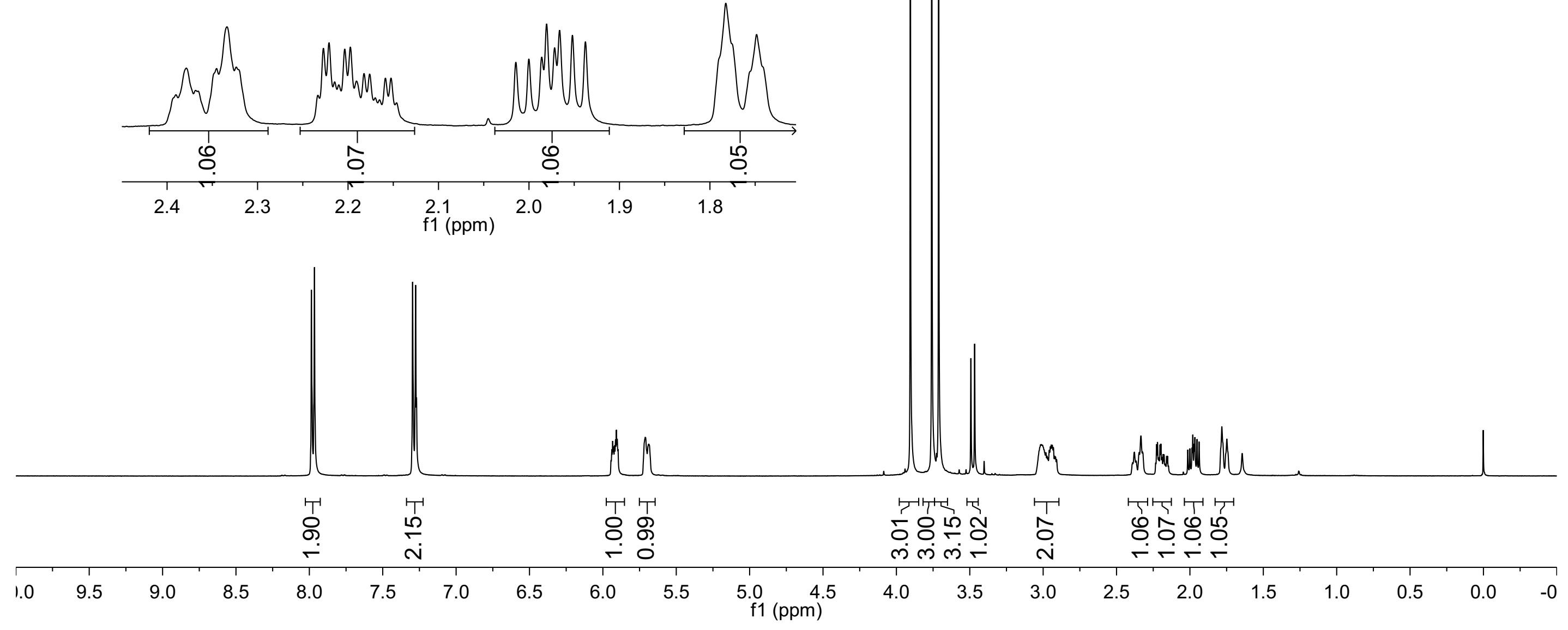
<smiles>COC(C)[C@H]1C=CC[C@@H](c2ccc(C(=O)O)cc2)C1</smiles>

\section{$\mathrm{MeO}_{2} \mathrm{C} \quad[4 \mathrm{~m}]$}




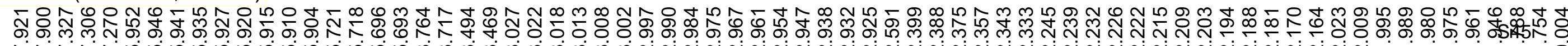

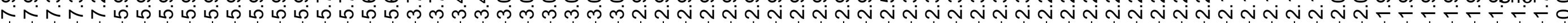

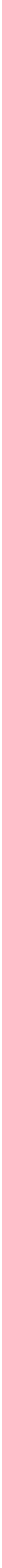



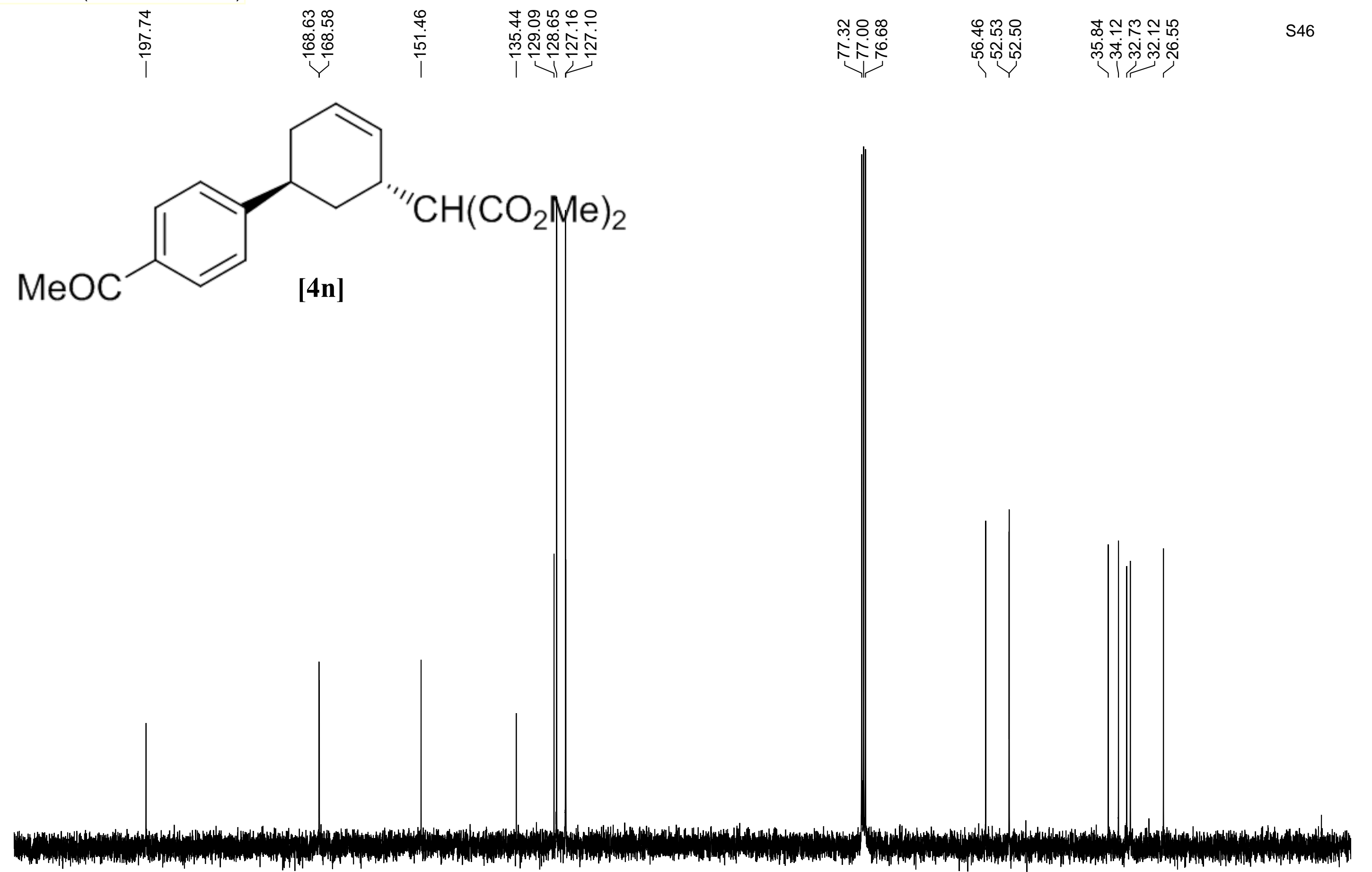
$\stackrel{\infty}{\circ}$

i

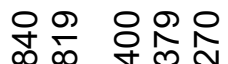

仿

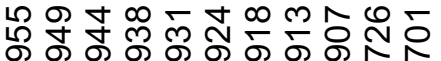

ம

\section{${ }^{\prime \prime} \mathrm{CH}\left(\mathrm{CO}_{2} \mathrm{Me}\right)_{2}$}

\section{[4o]}

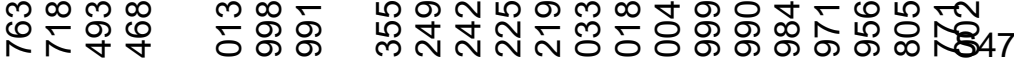

ก่

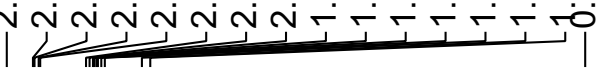

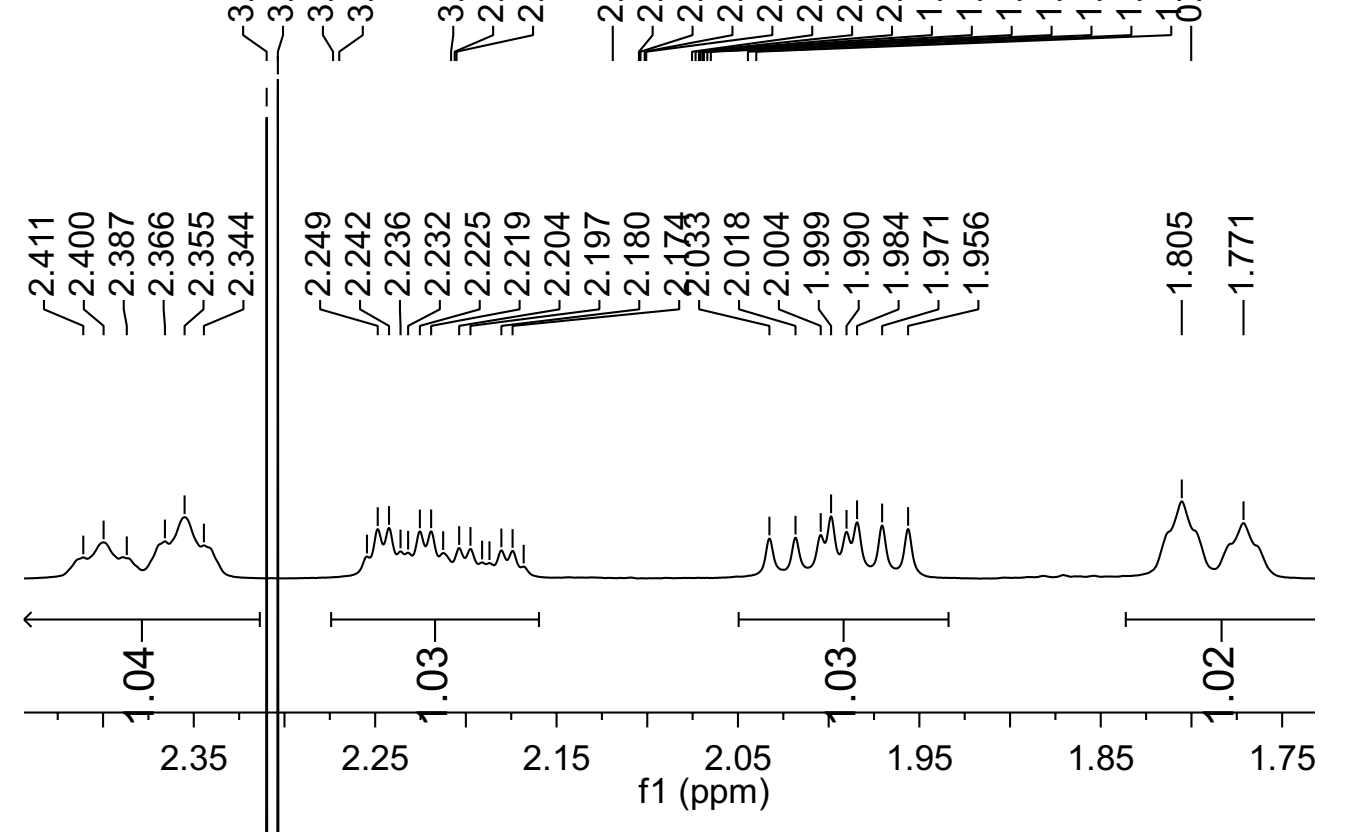

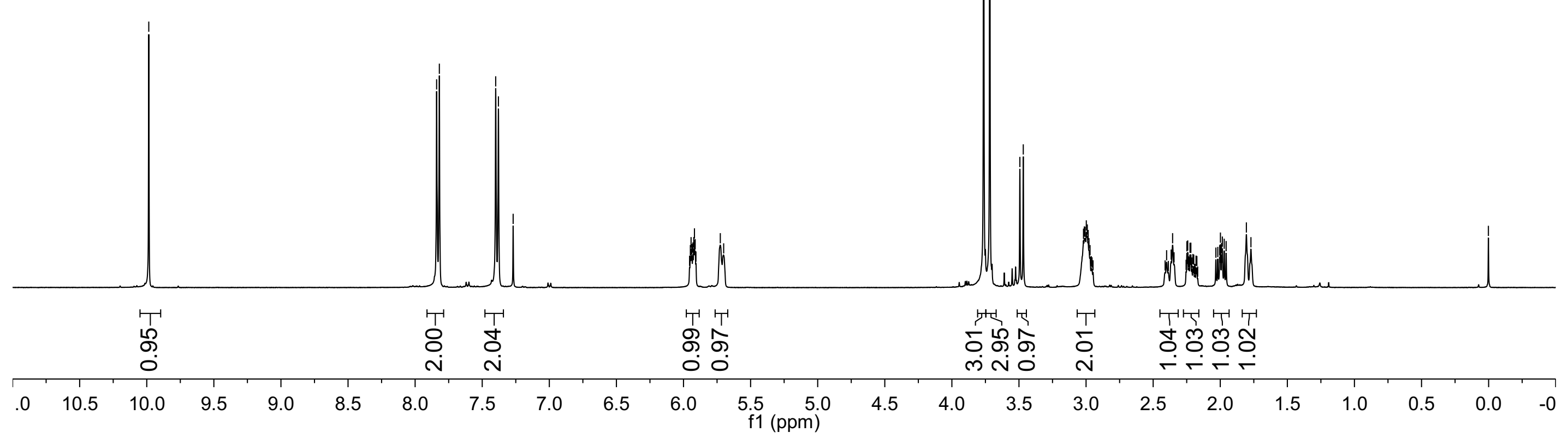




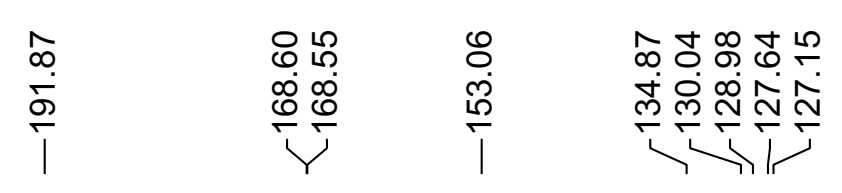

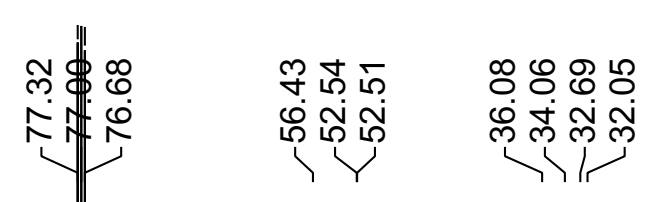

${ }^{\prime \prime} \mathrm{CH}\left(\mathrm{CO}_{2} \mathrm{Me}\right)_{2}$

[4o]

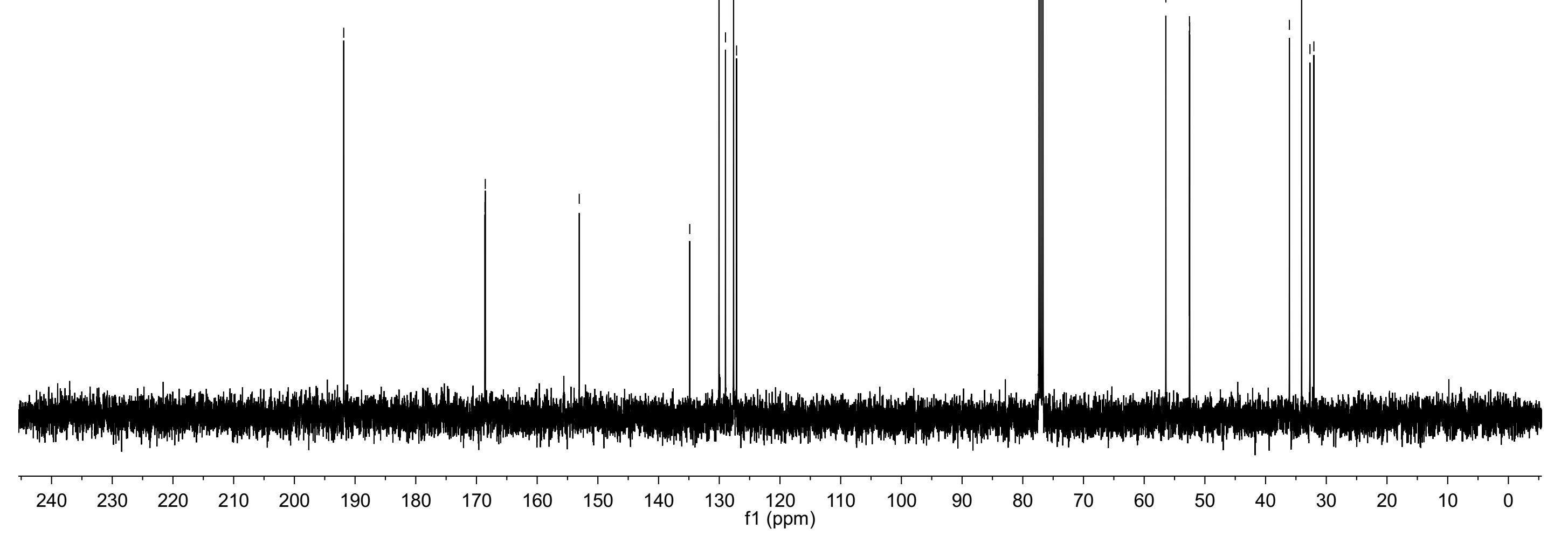




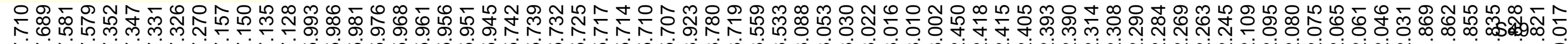

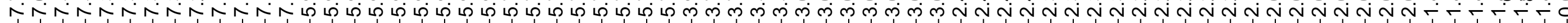

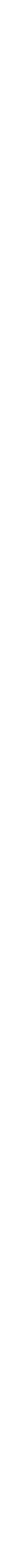


<smiles>COc1ccc2cc([C@@H]3CC=C[C@H](C(C)=O)C3)ccc2c1</smiles>

[4p]

낭으으.

촗요

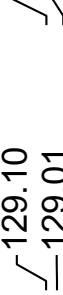

पi

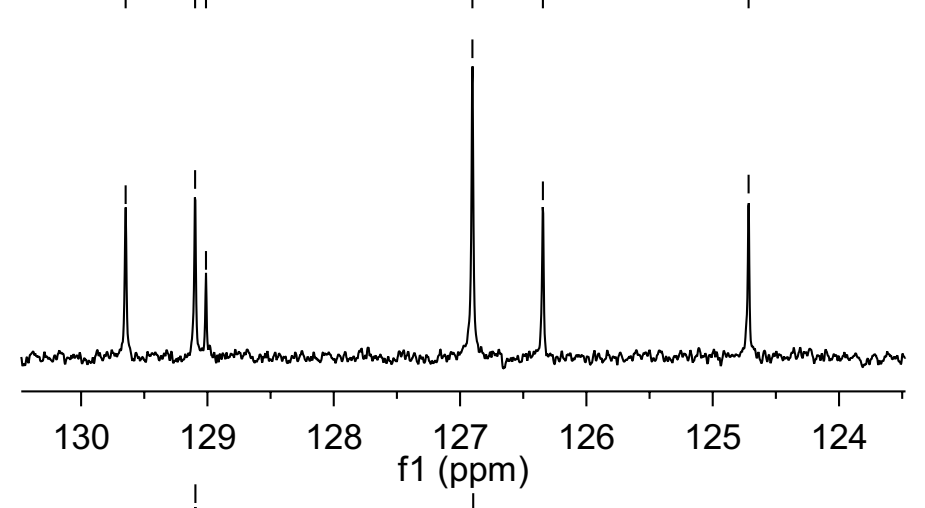

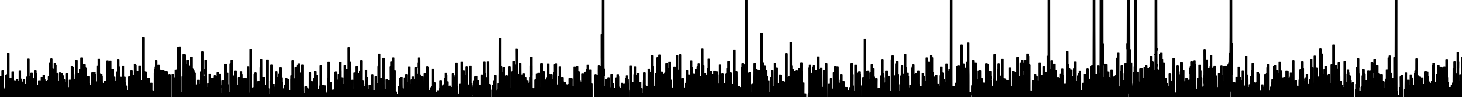

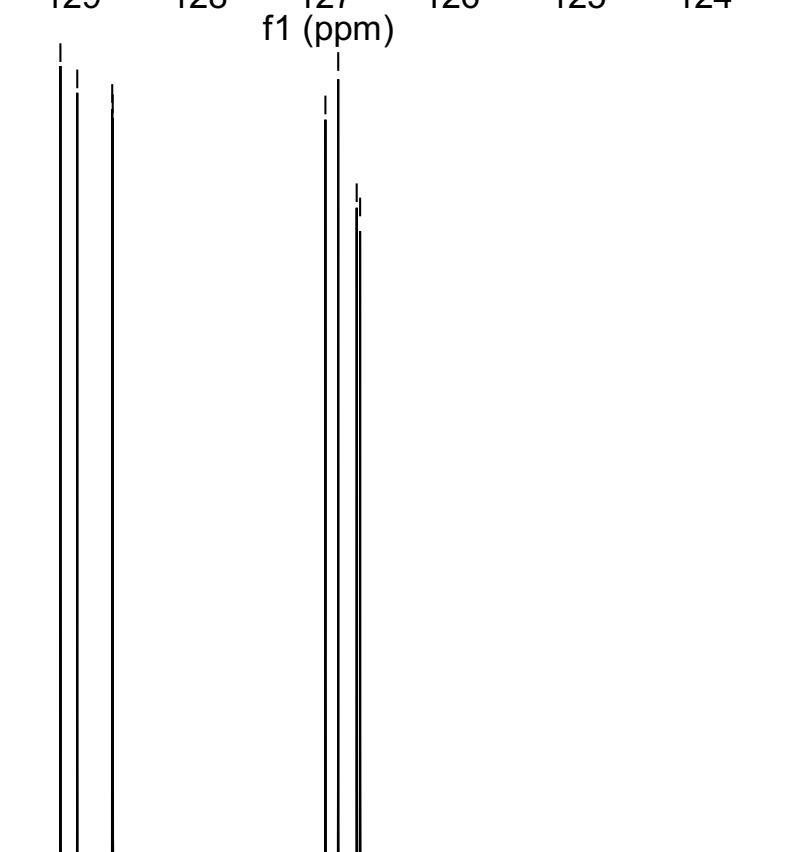

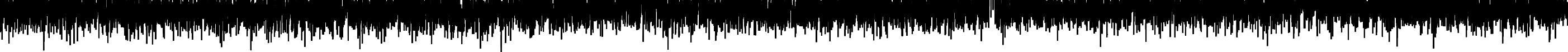




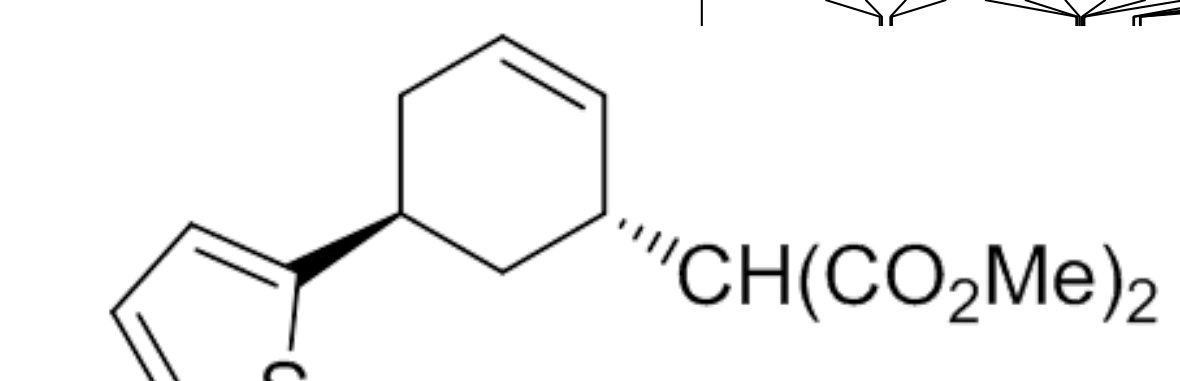

$[4 \mathbf{q}]$

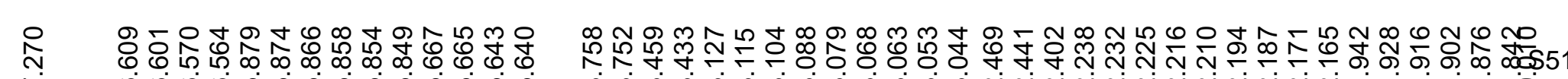
Q

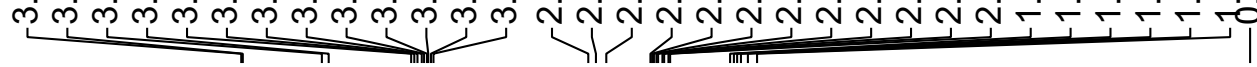
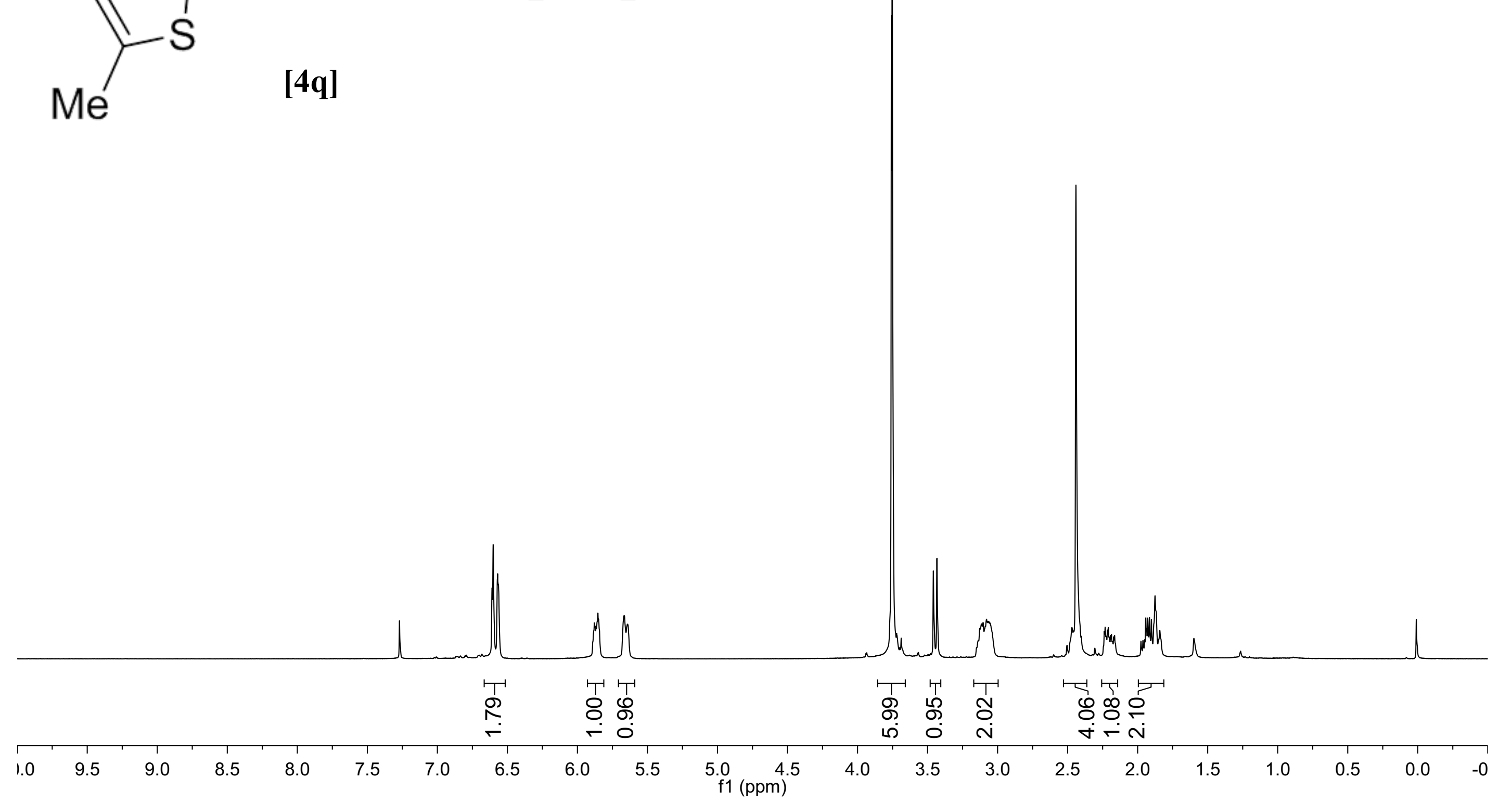


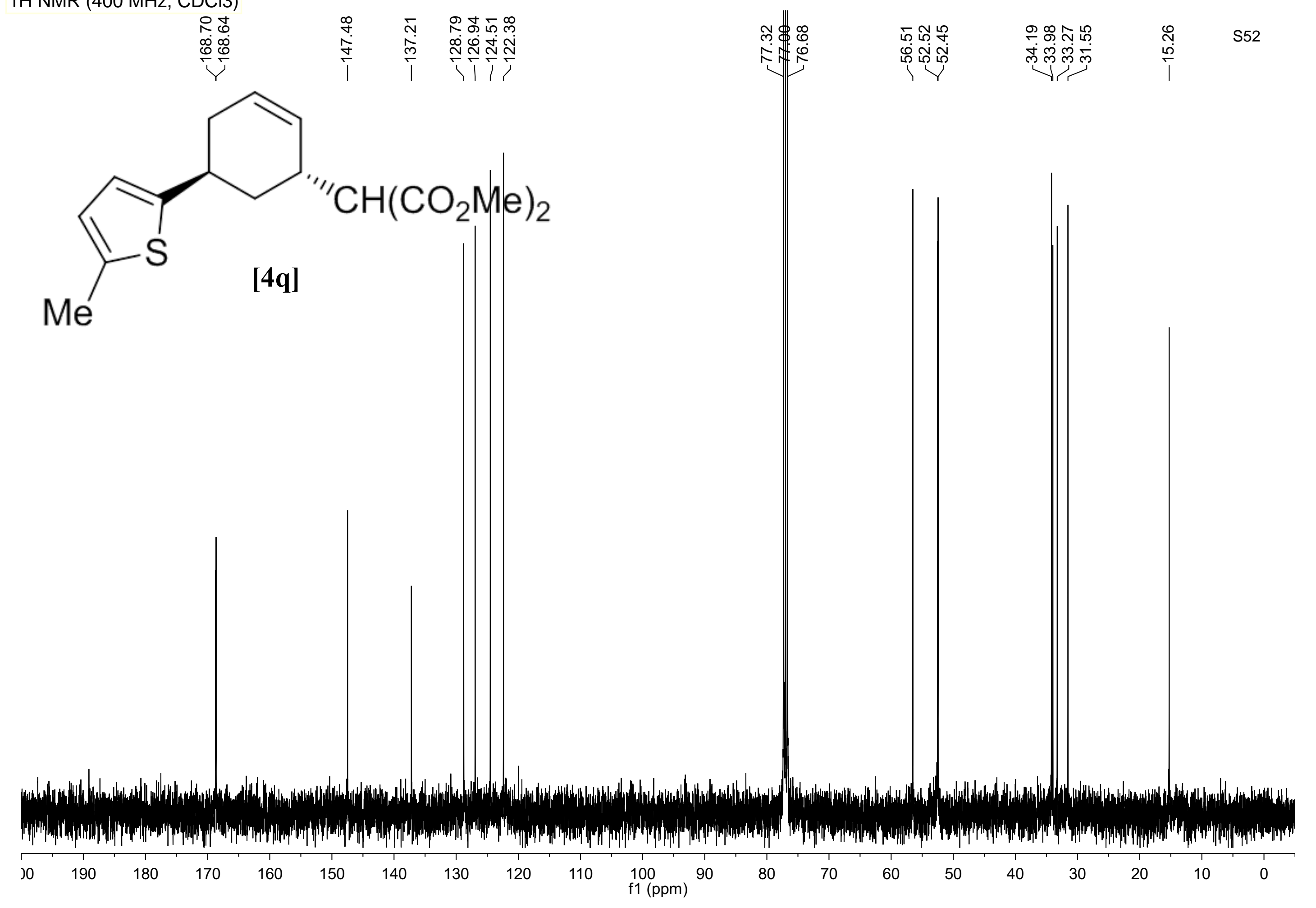




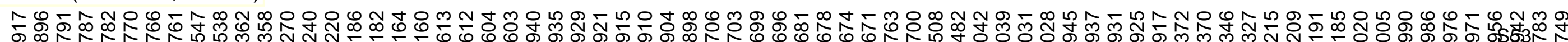

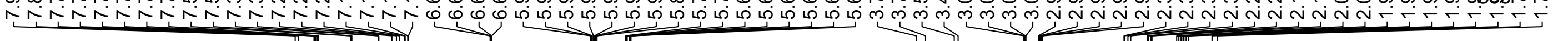
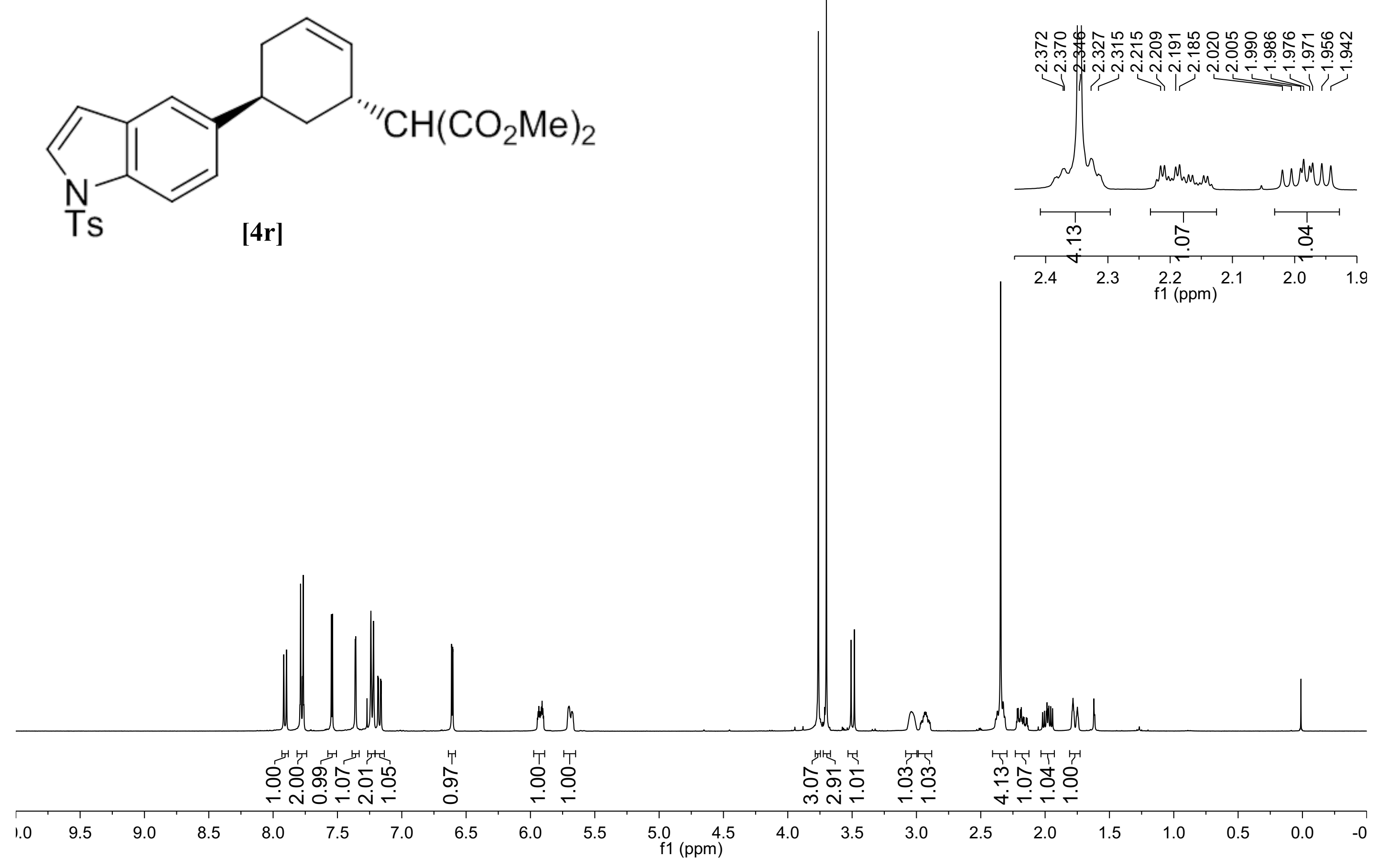

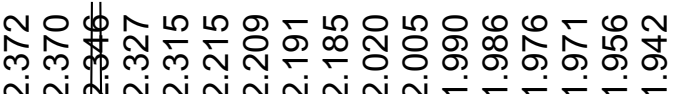

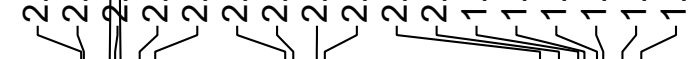
f1 (ppm) 2. 


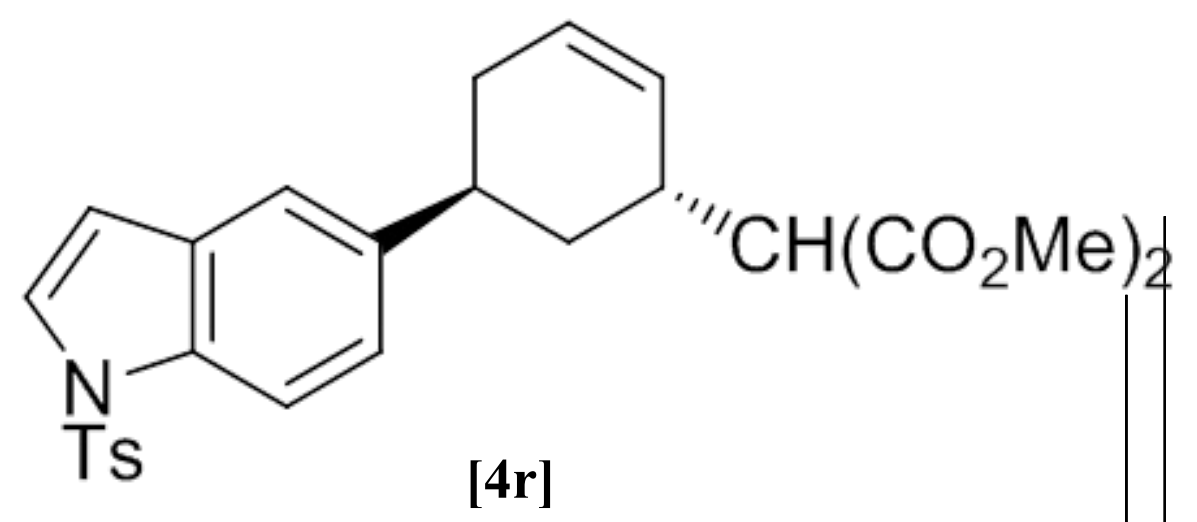

[4r]

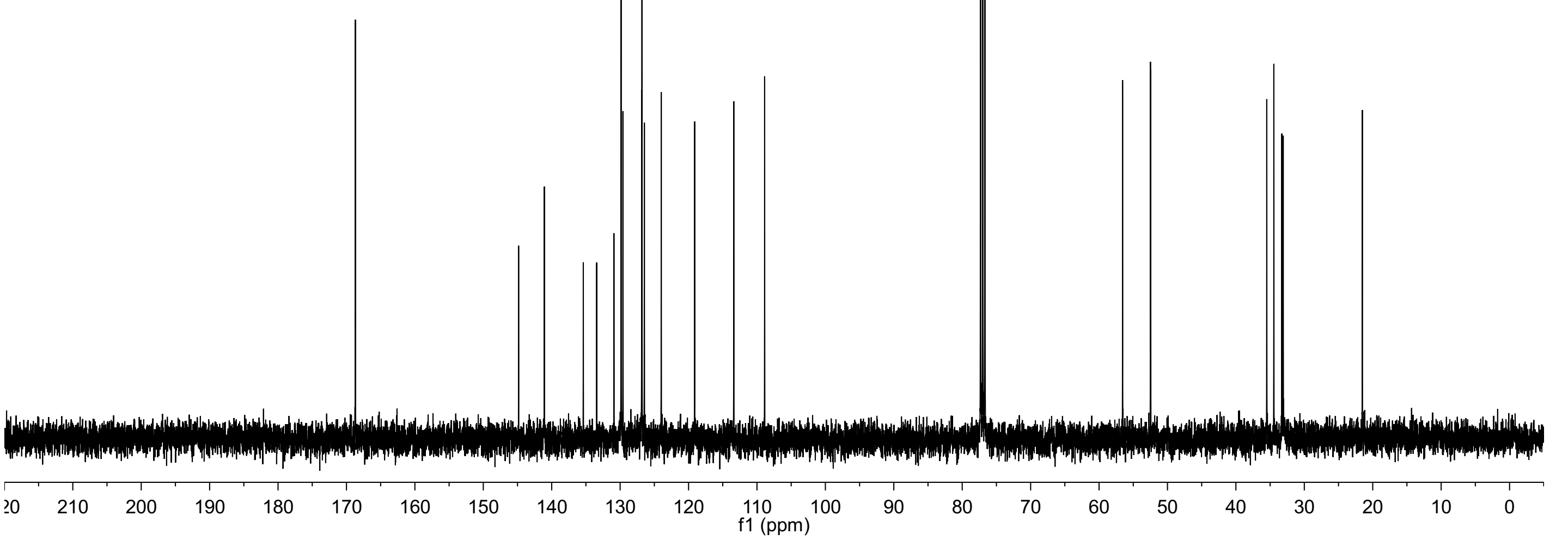




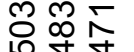

$\infty \infty \infty$

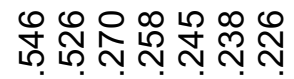

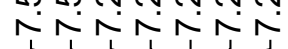

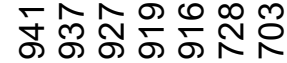

(0)

(1)

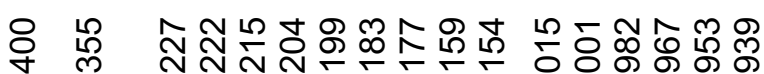

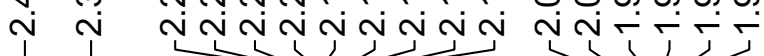

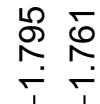
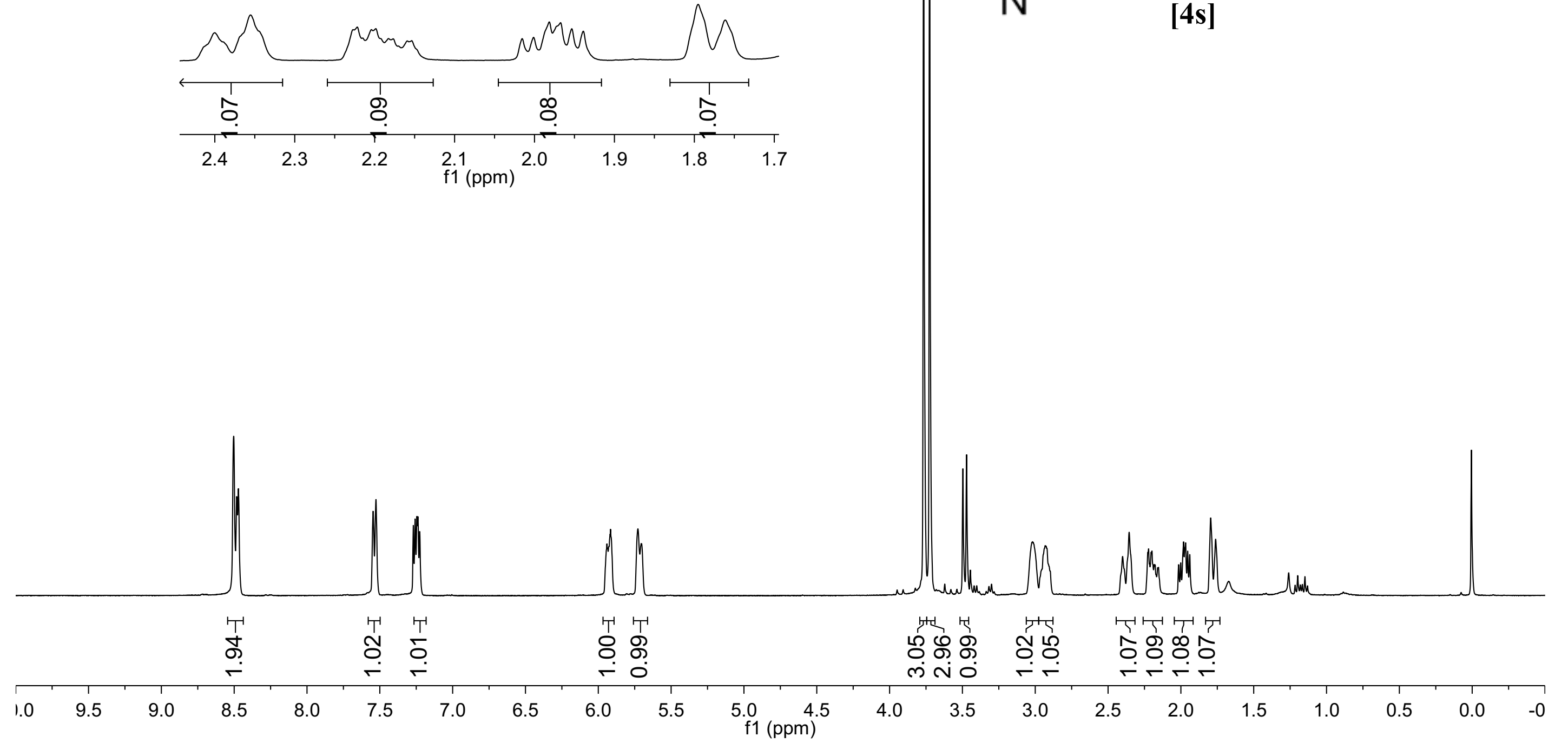

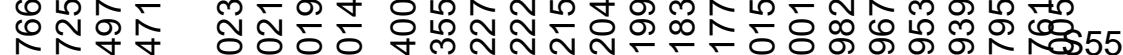

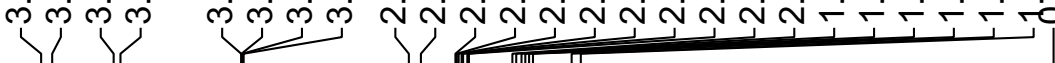

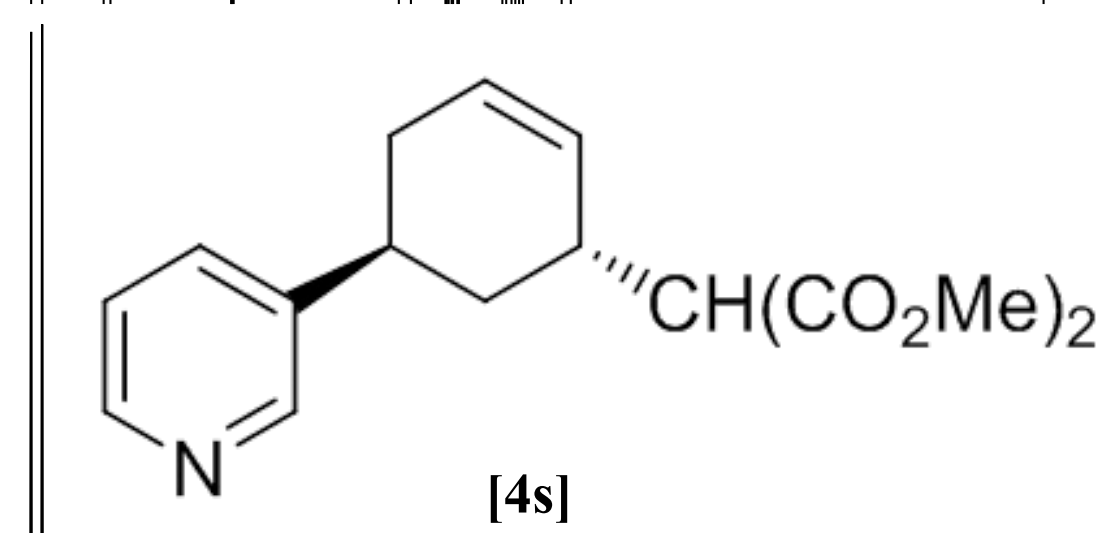




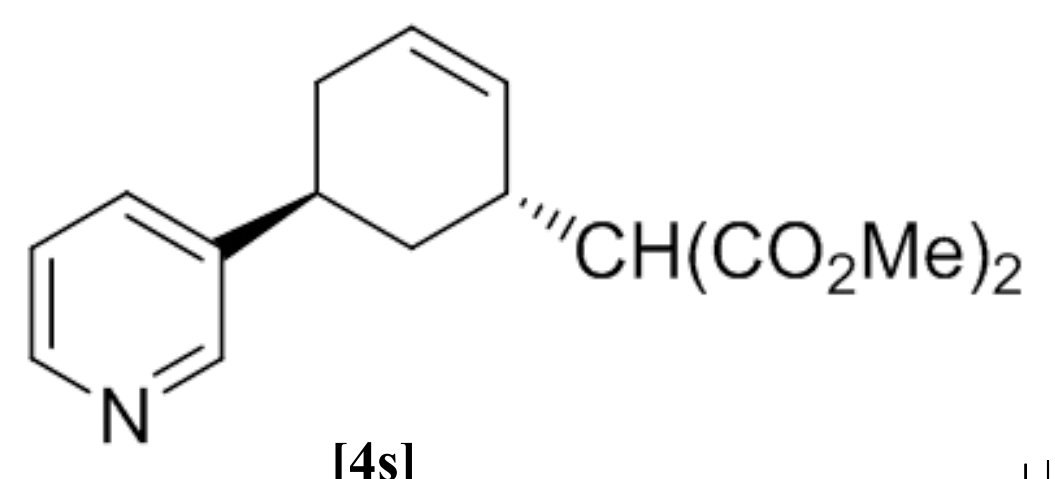

$[4 s]$ 

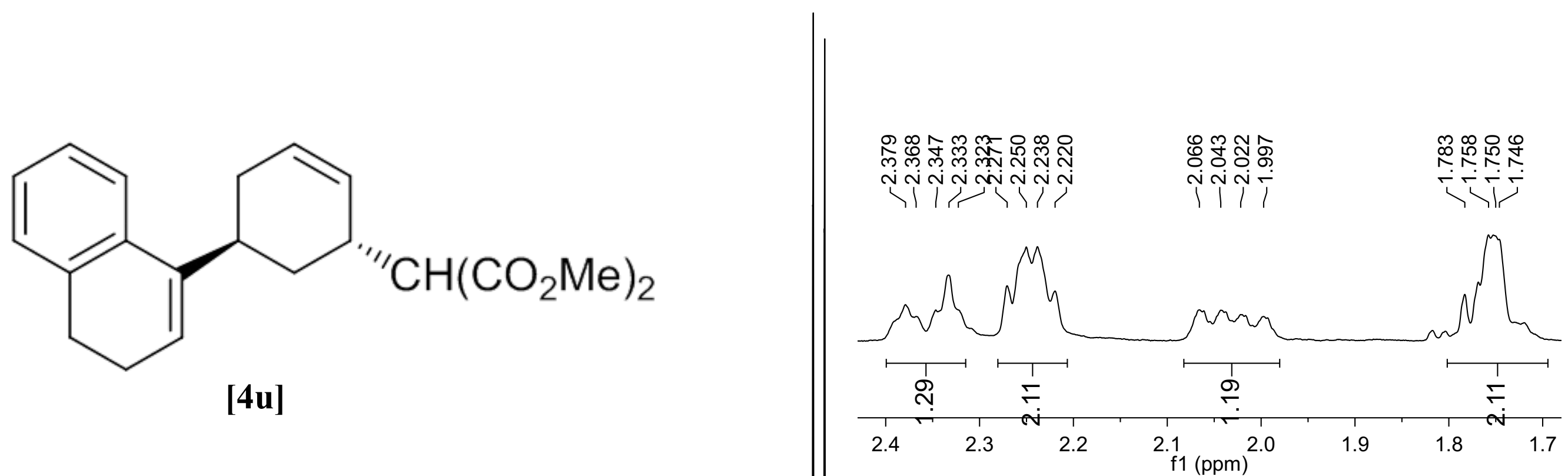

[4u]

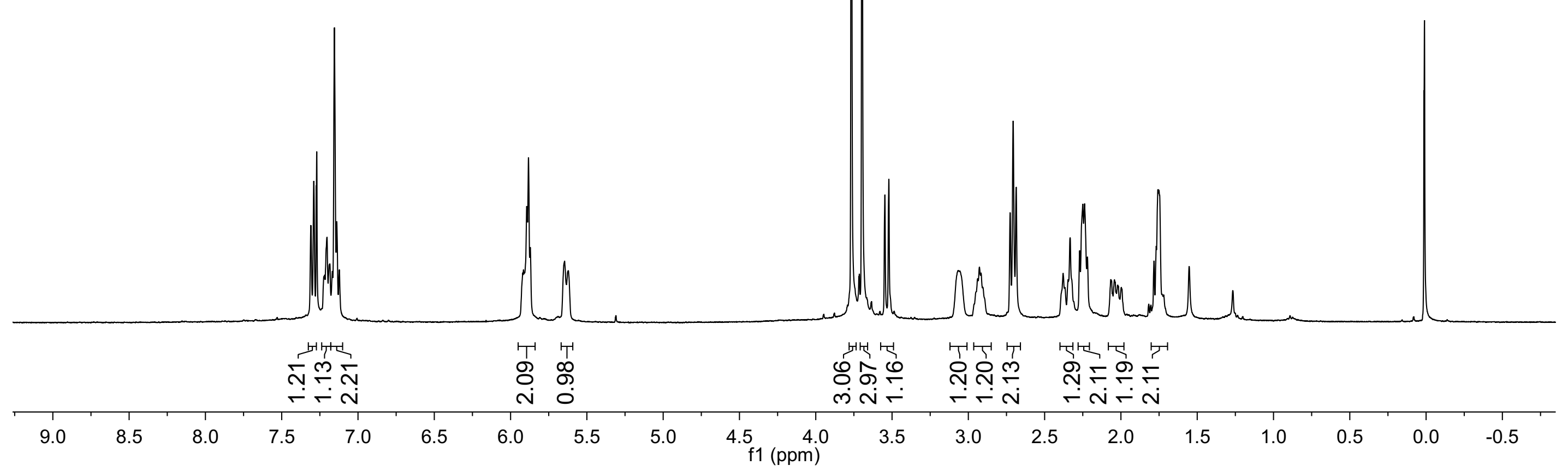




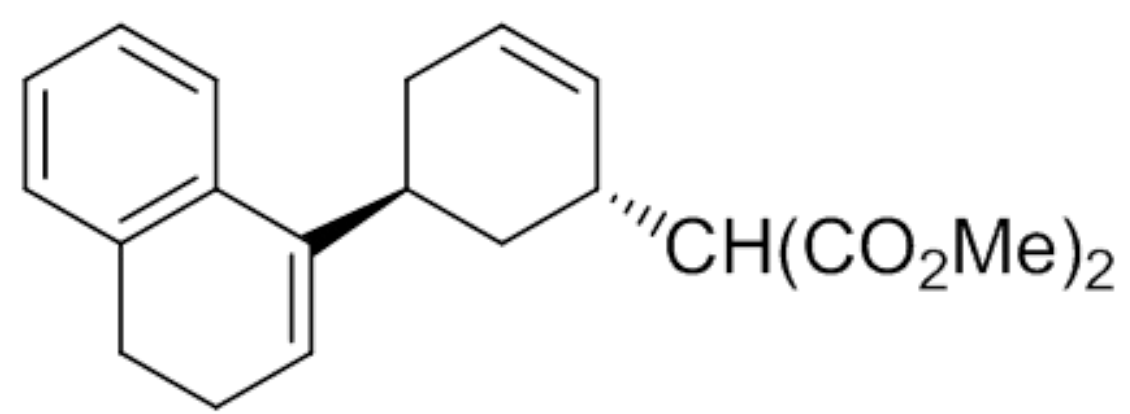

[4u]

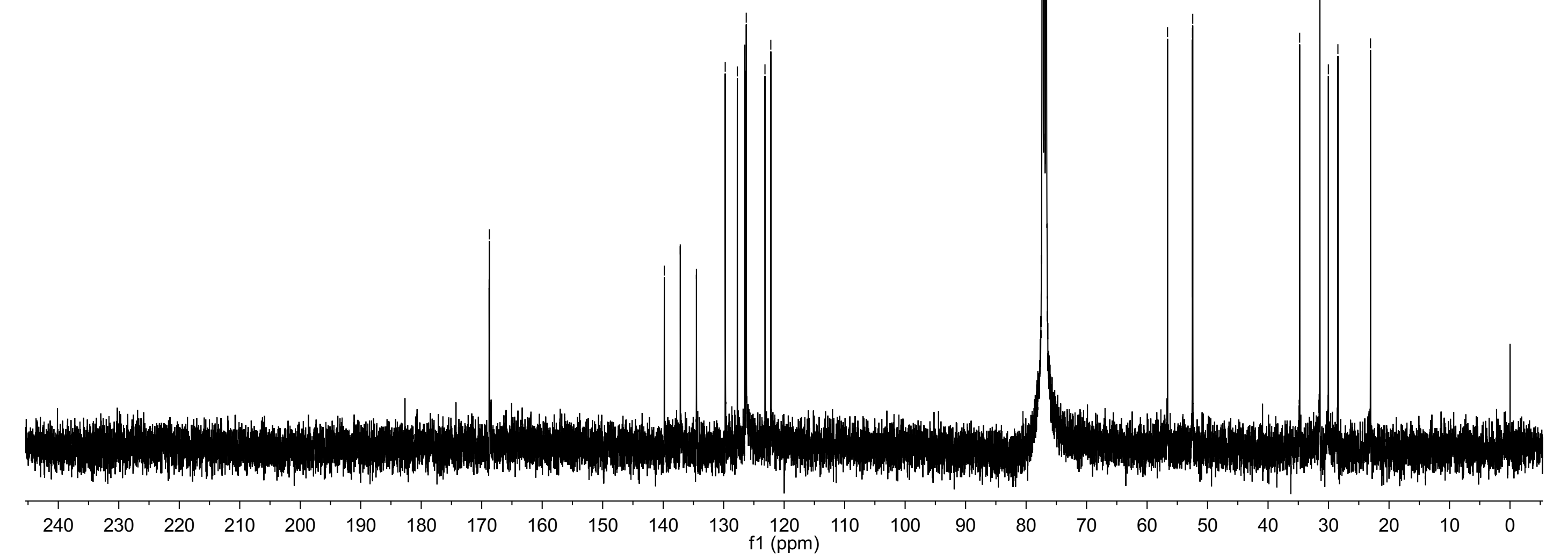




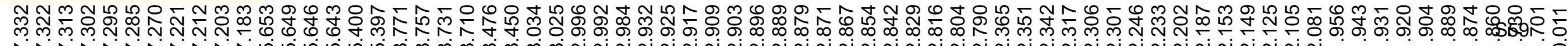

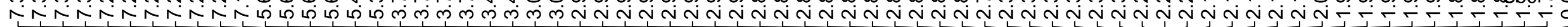

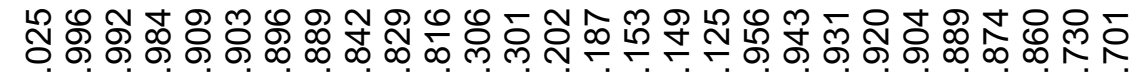

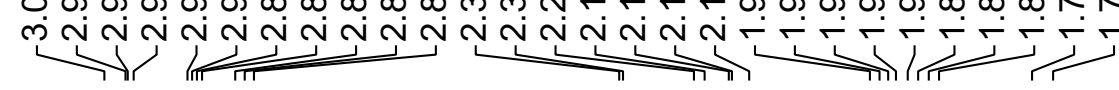
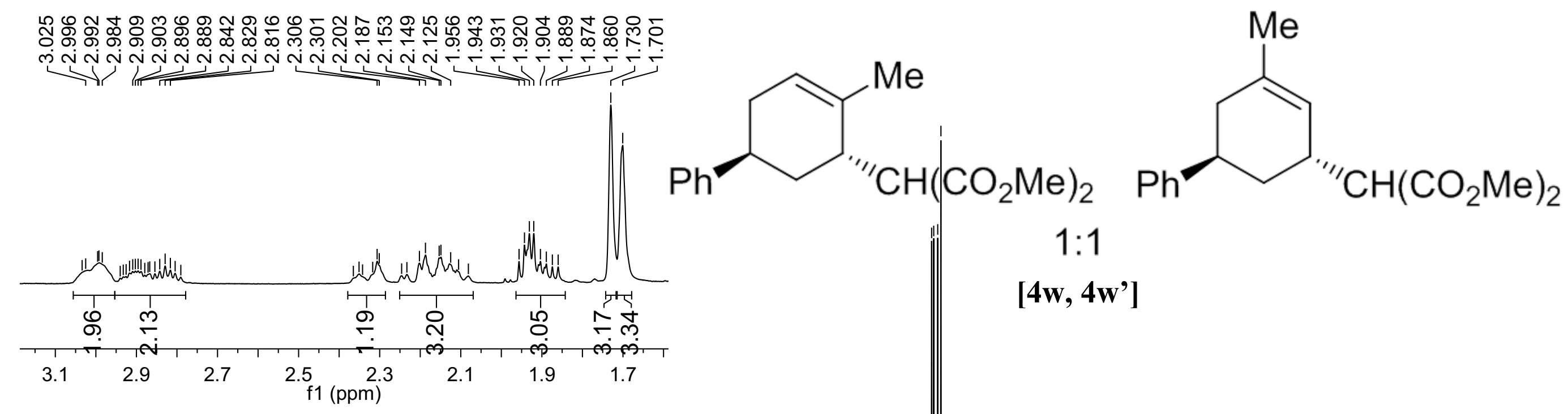

$\left[4 \mathbf{w}, 4 w^{\prime}\right]$
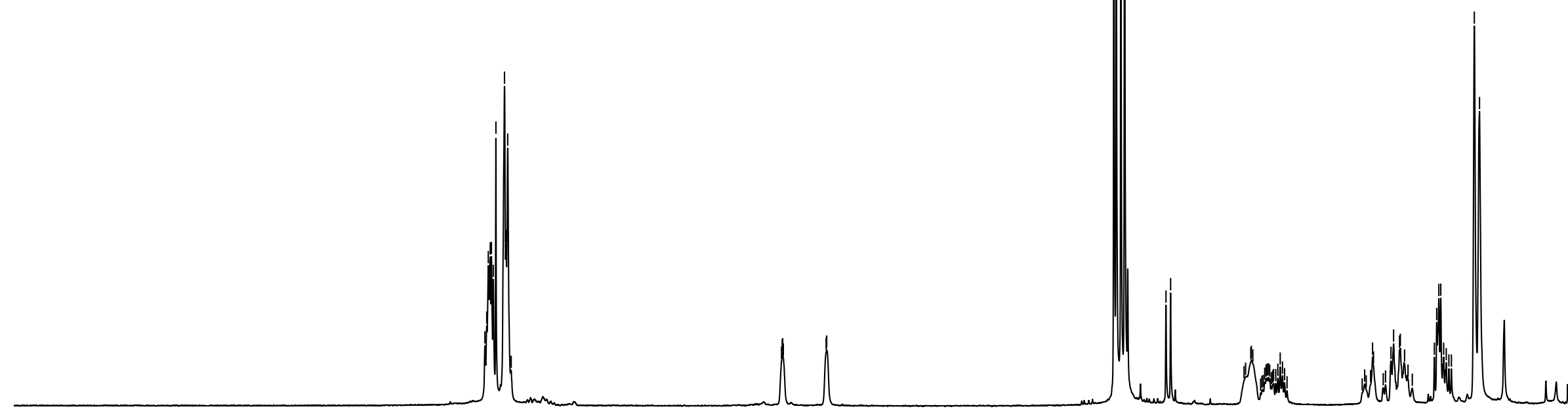

\begin{tabular}{|c|c|c|c|c|c|c|c|c|c|c|}
\hline & & & & & 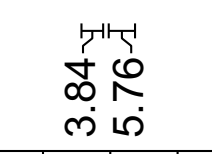 & & & $\begin{array}{ll} \\
\\
\end{array}$ & & \\
\hline & 9.5 & 9.0 & 8.5 & 8.0 & 7.5 & 6.5 & 6.0 & 5.5 & $\begin{array}{c}5.0 \quad 4.5 \\
\text { f1 (ppm) }\end{array}$ & 4.0 \\
\hline
\end{tabular}

胡故

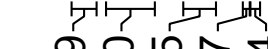
îं

$\begin{array}{llll}3.5 & 3.0 & 2.5 & 2.0\end{array}$

$\begin{array}{lllll}1.5 & 1.0 & 0.5 & 0.0 & -0\end{array}$




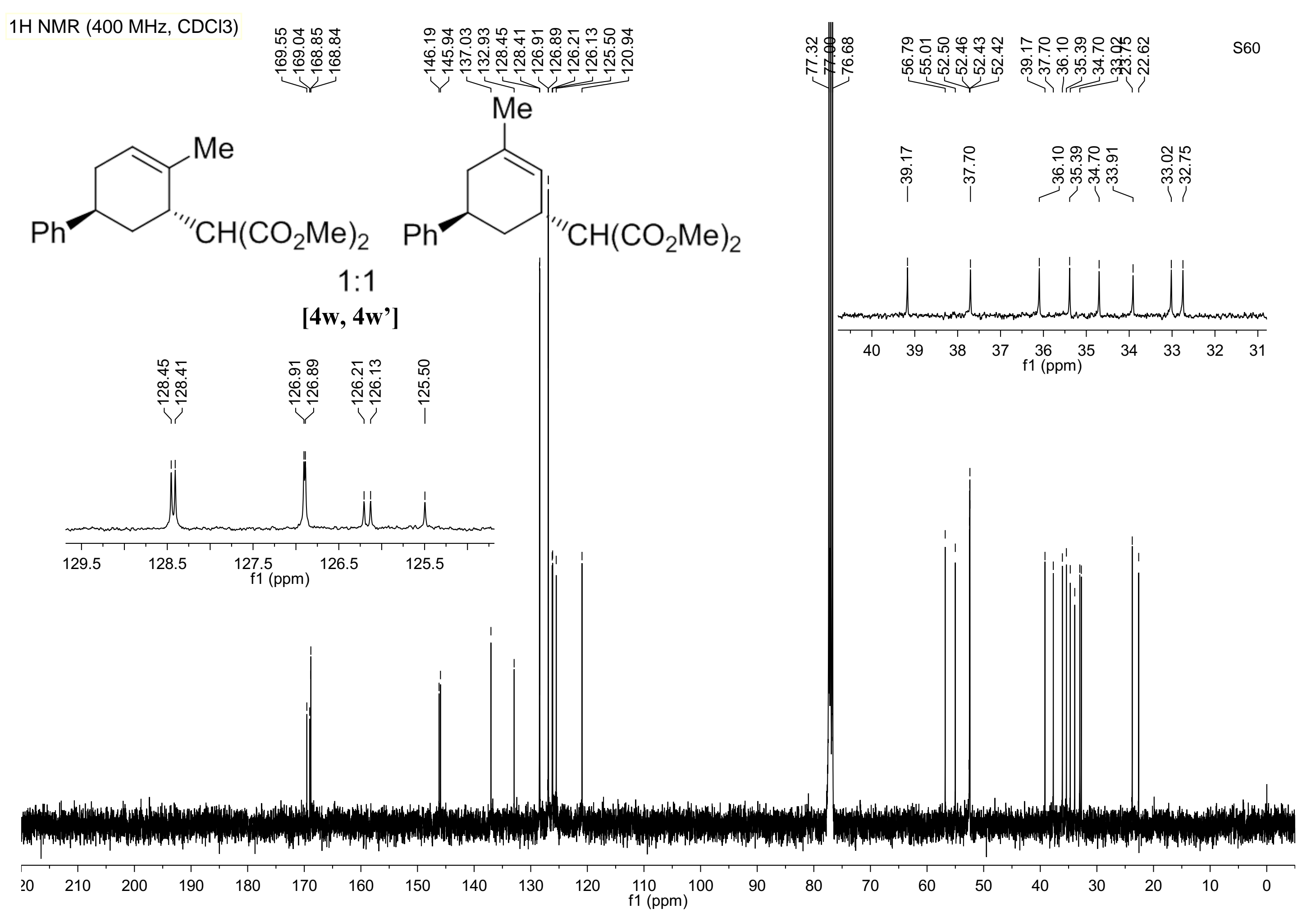




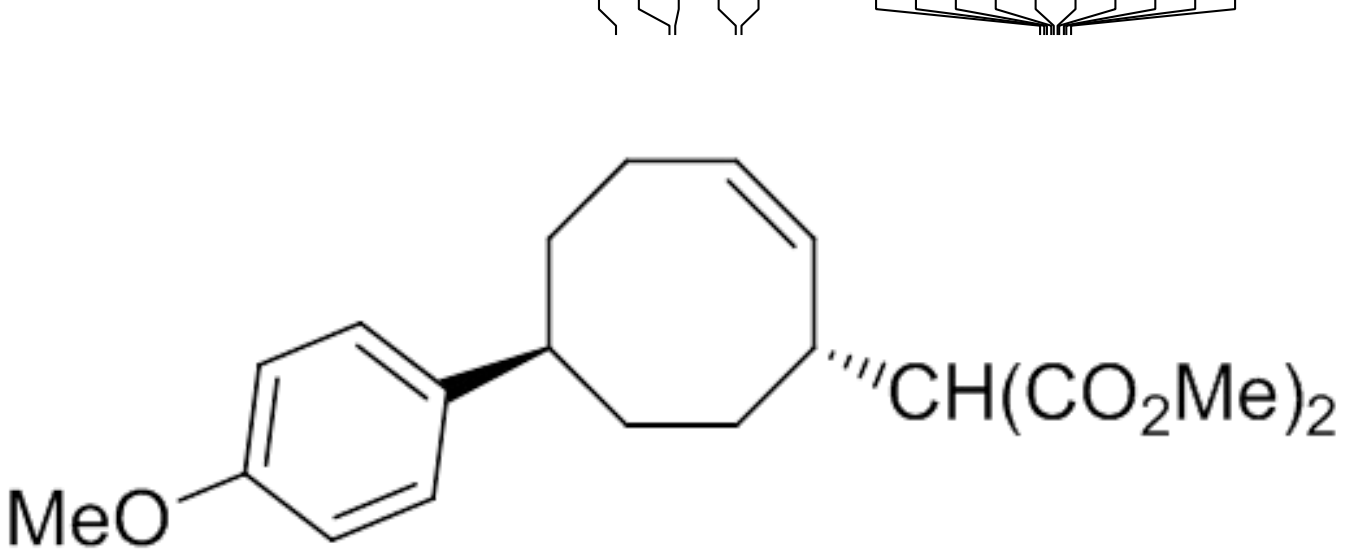

[5a]

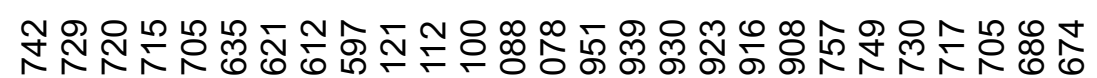

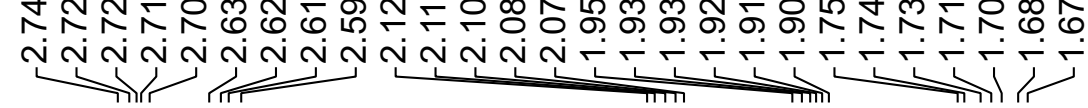

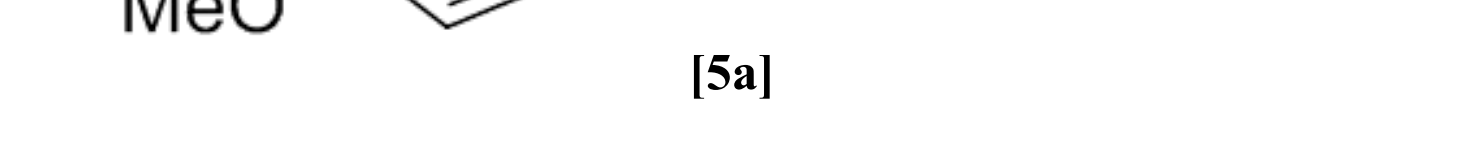

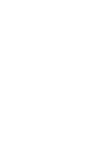
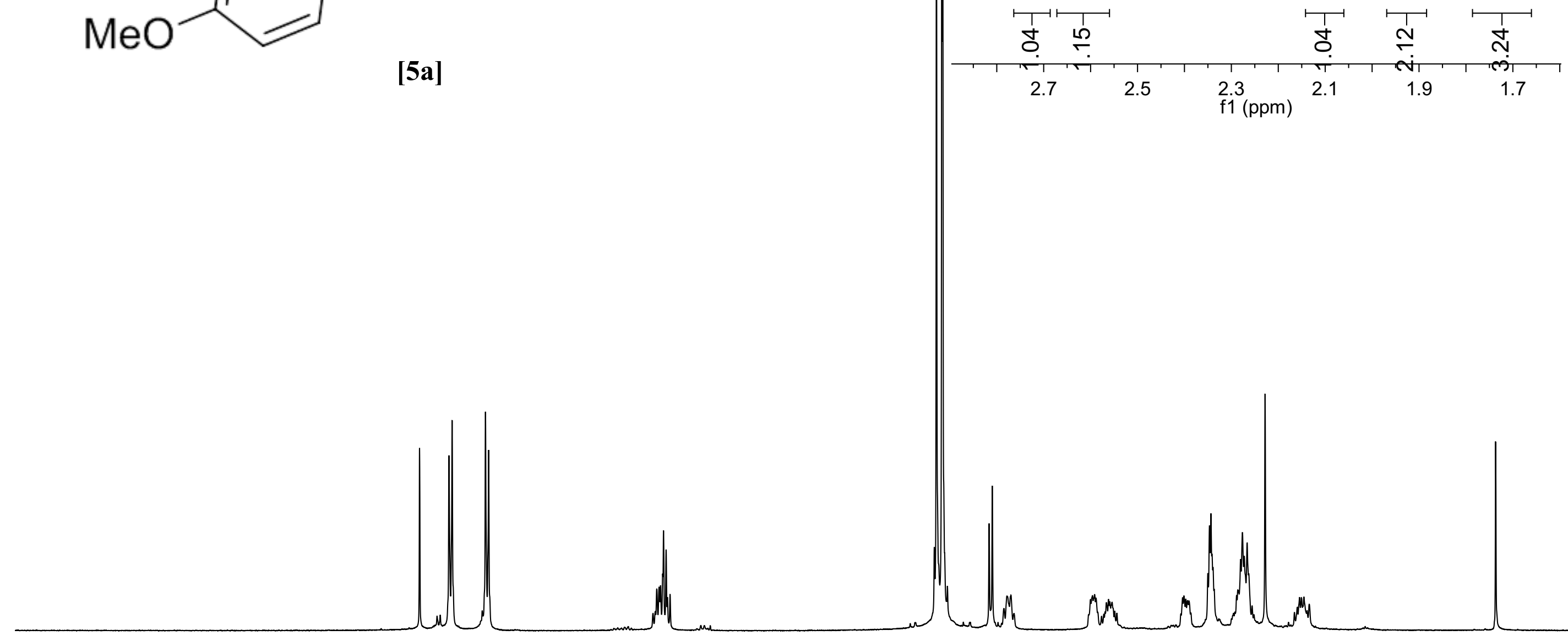

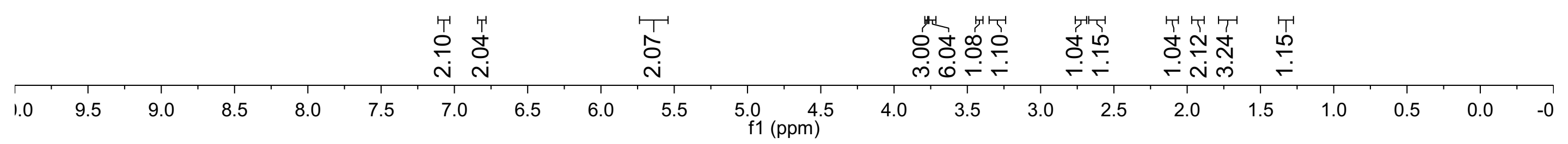




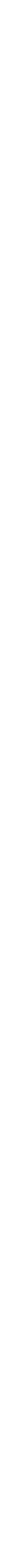




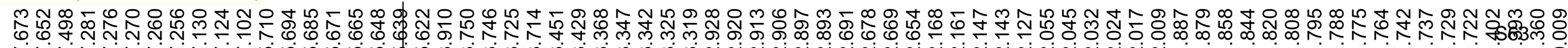

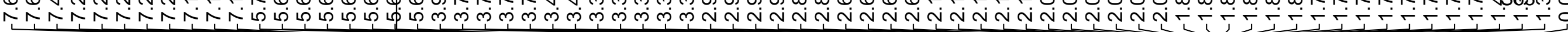

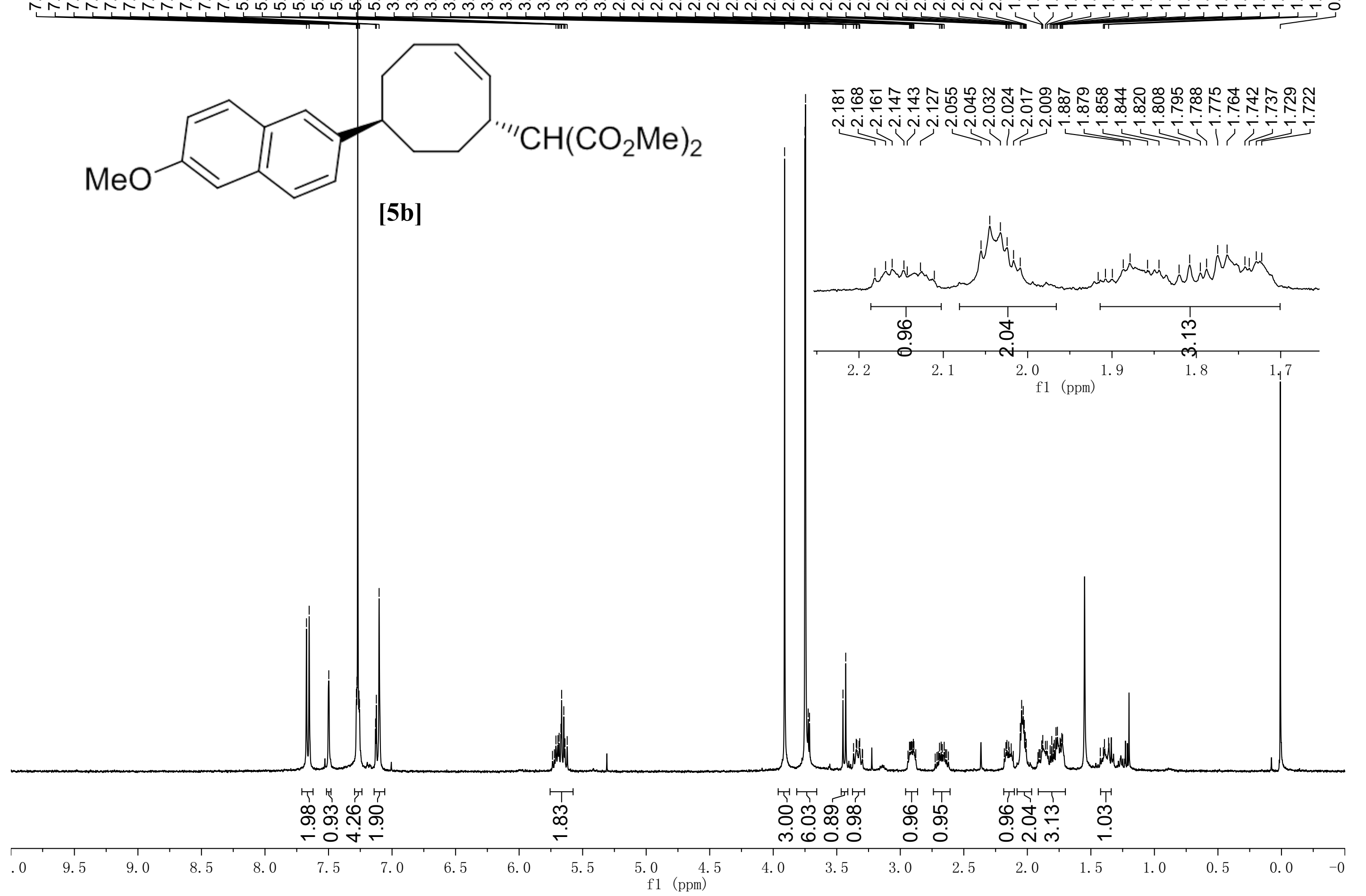




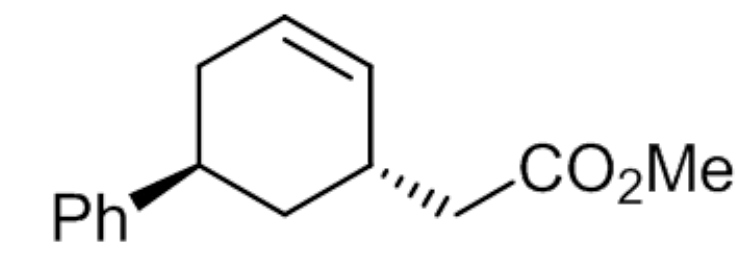

[6a]

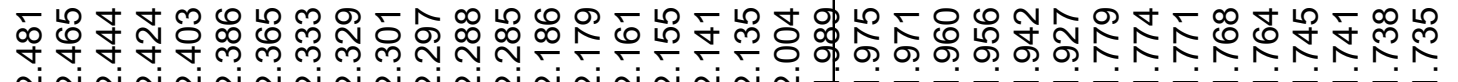

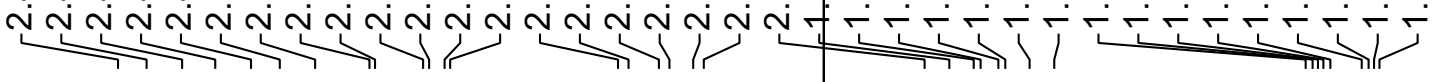

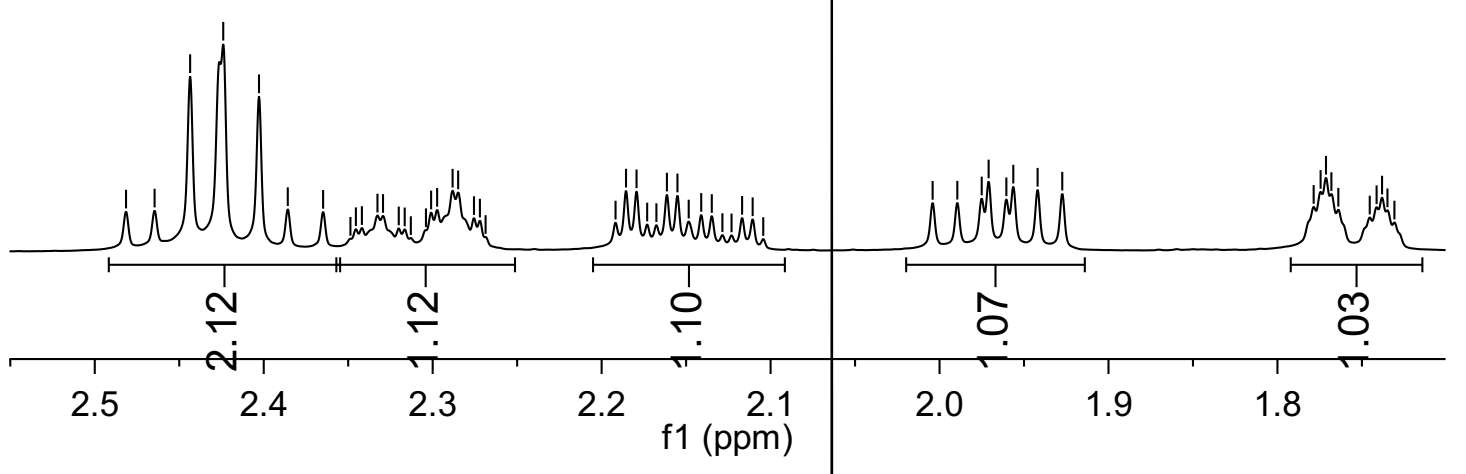

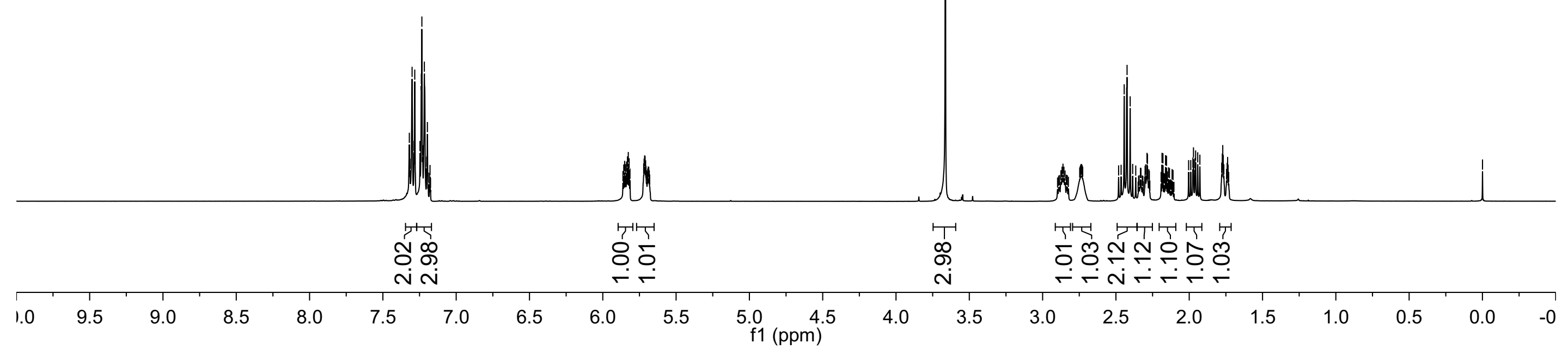


<smiles>CC(=O)C[C@@H]1C=CC[C@H](c2ccccc2)C1</smiles>

[6a]

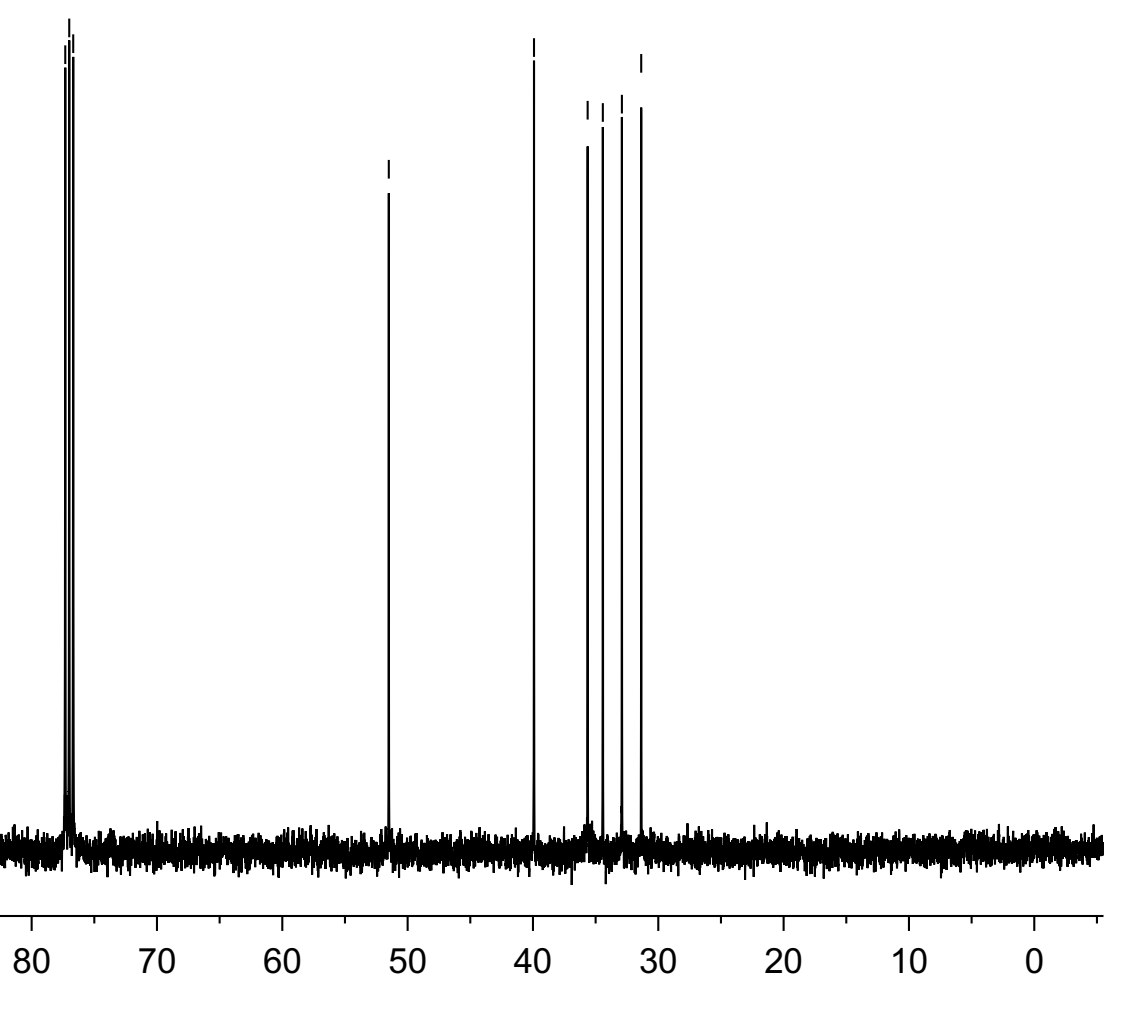




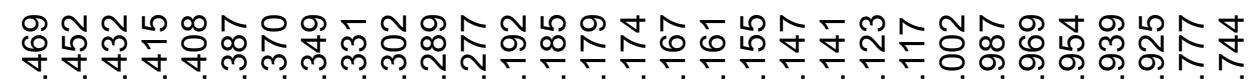

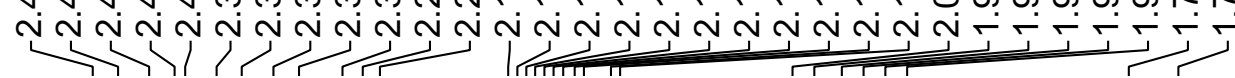

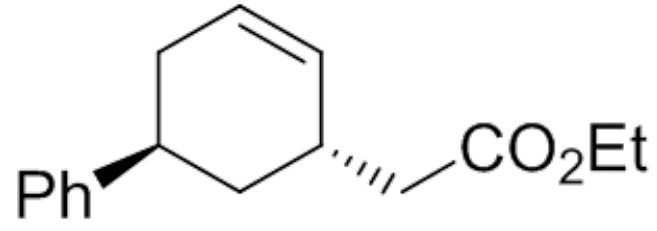

[6b]
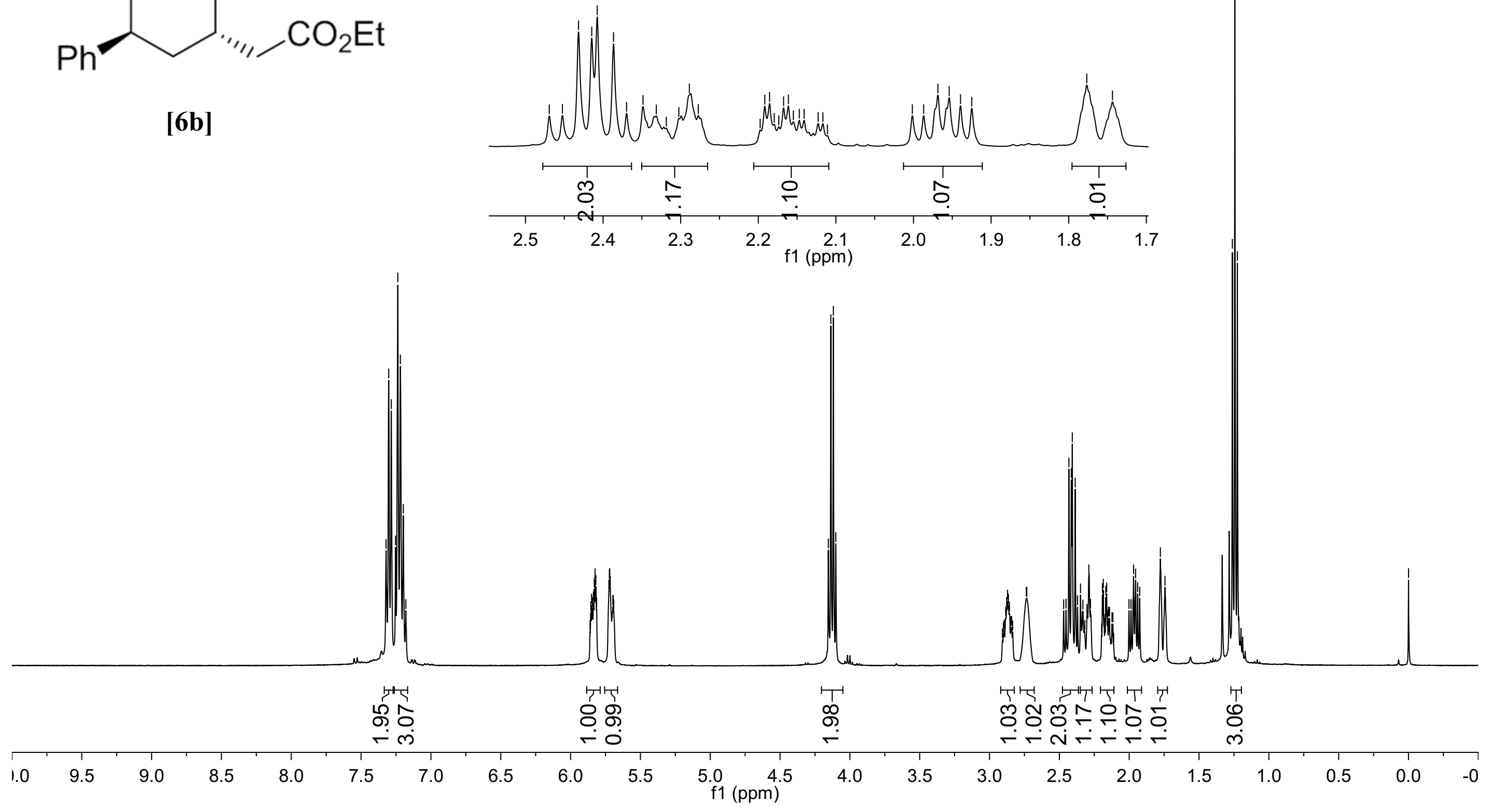
<smiles>CCOC(=O)C[C@@H]1C=CC[C@H](c2ccccc2)C1</smiles>

[6b]

inl

$210 \quad 200 \quad 190$

$180 \quad 170 \quad 160$

$160 \quad 150$

$50 \quad 140$

$40 \quad 130$

120

$90 \quad 80$

$70 \quad 60$




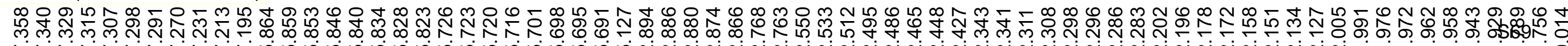

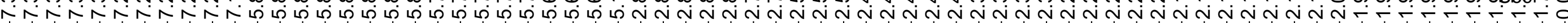

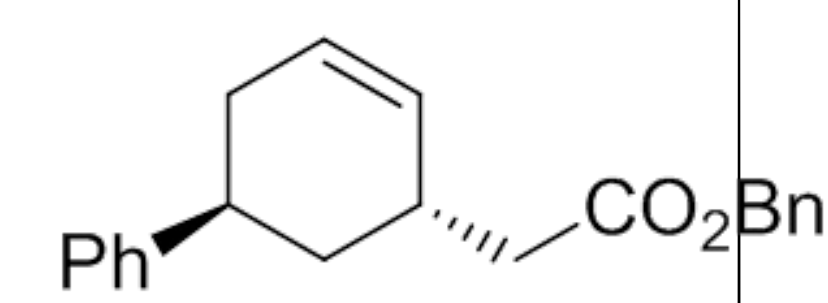

$[6 c]$

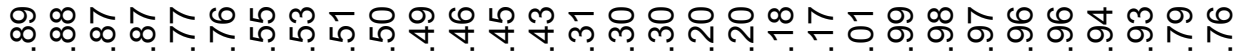

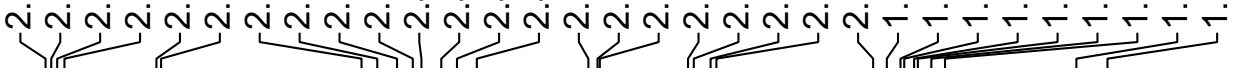

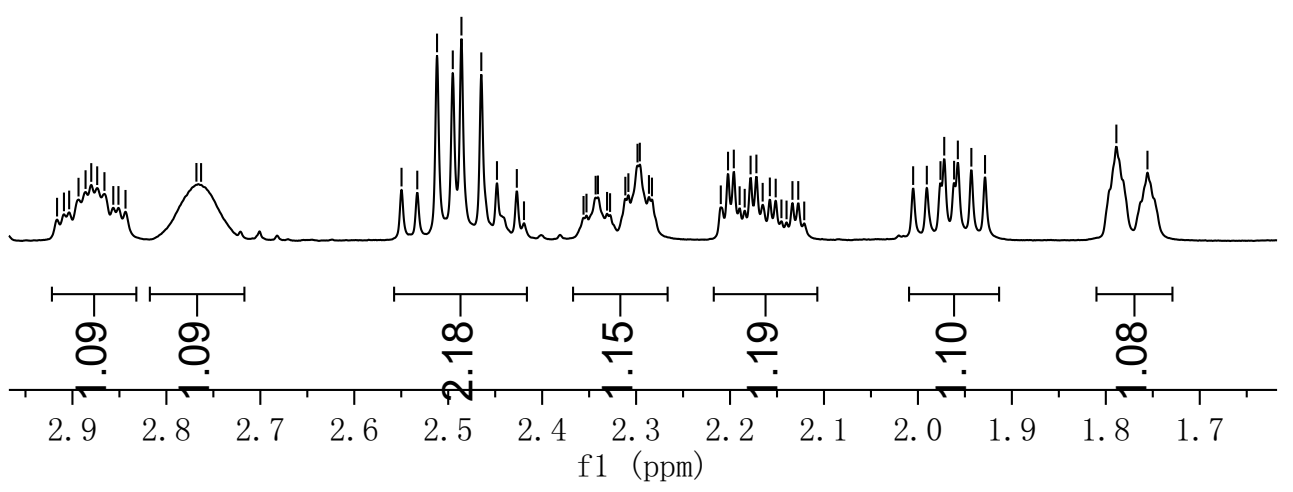

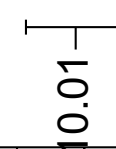

†ा

요

श्रास Tाभ Tा

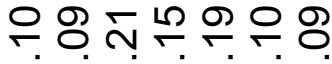

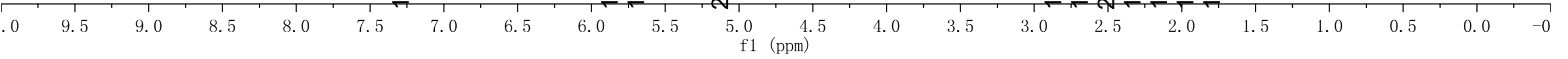


[6c]<smiles>O=C(C[C@@H]1C=CC[C@H](c2ccccc2)C1)OCc1ccccc1</smiles>

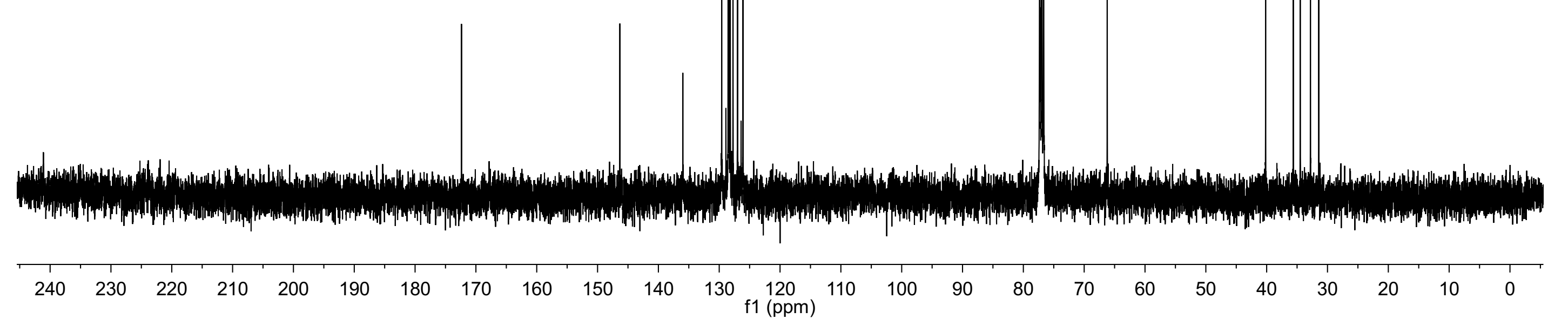




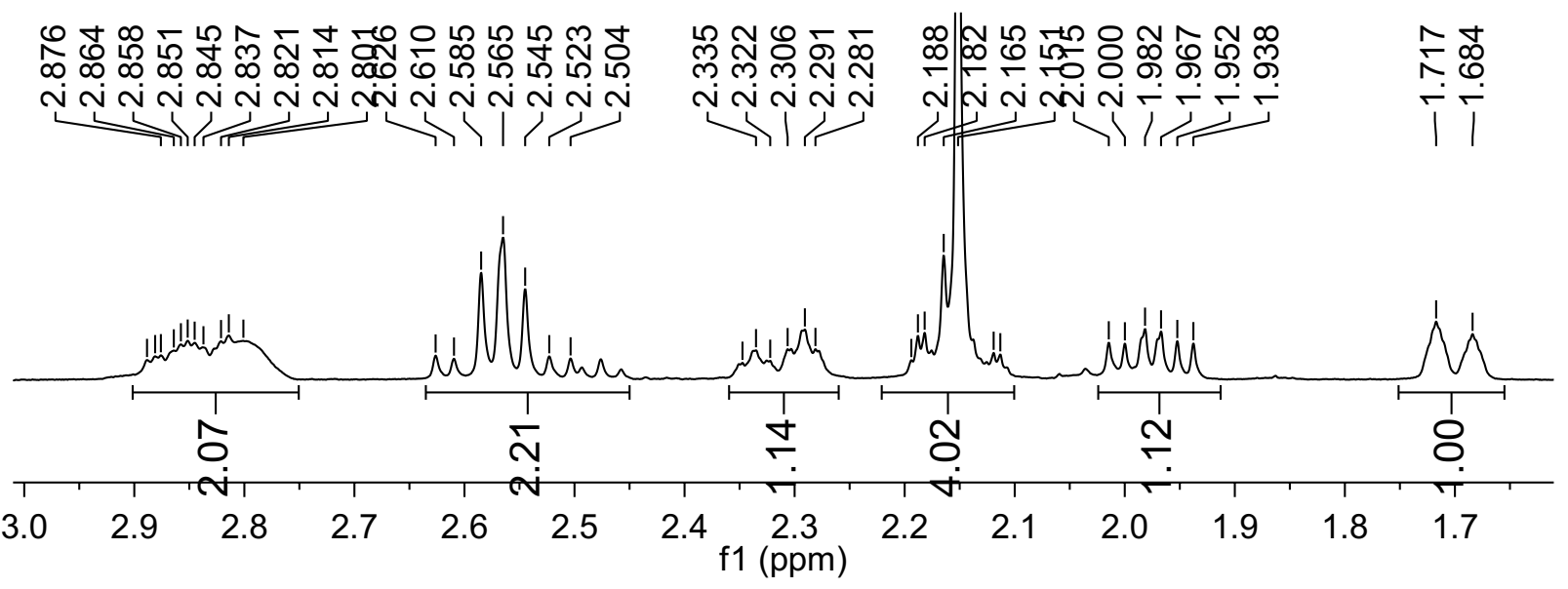

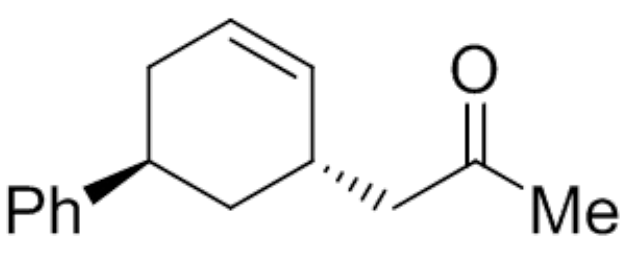

[6d]

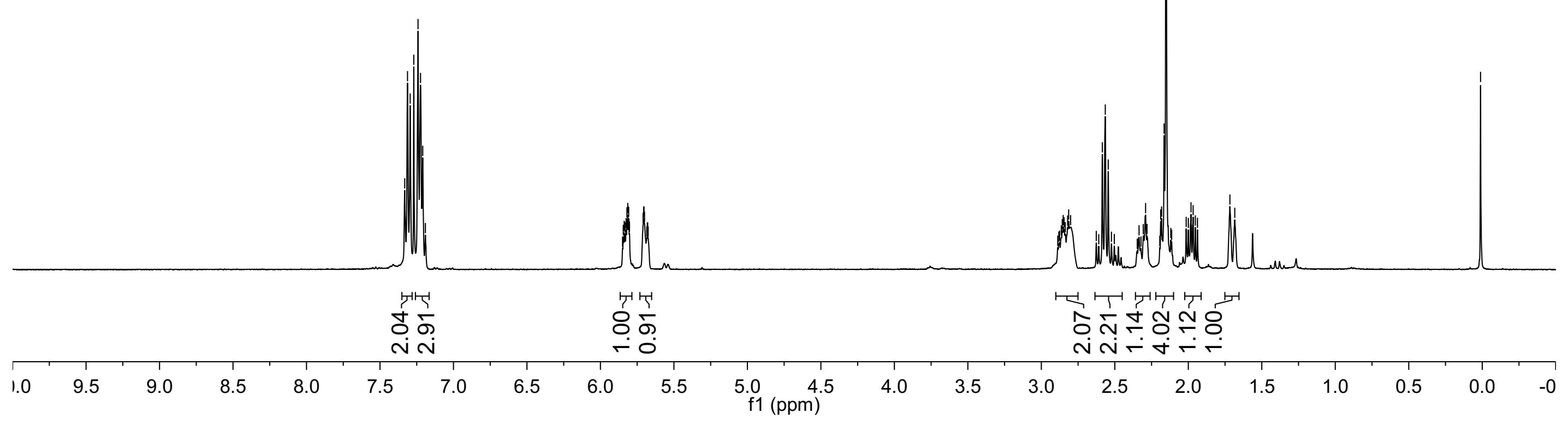




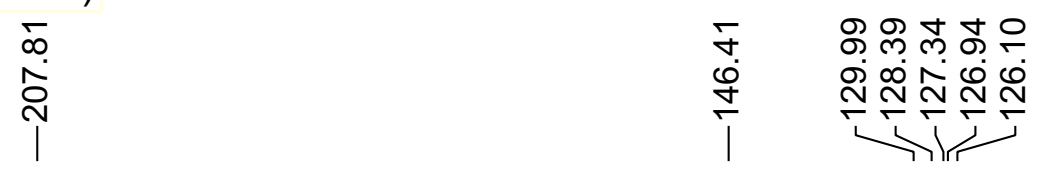

$$
\begin{aligned}
& \text { ల) } \\
& \text { 守 }
\end{aligned}
$$<smiles>CC(=O)C[C@@H]1C=CC[C@H](c2ccccc2)C1</smiles>

[6d]

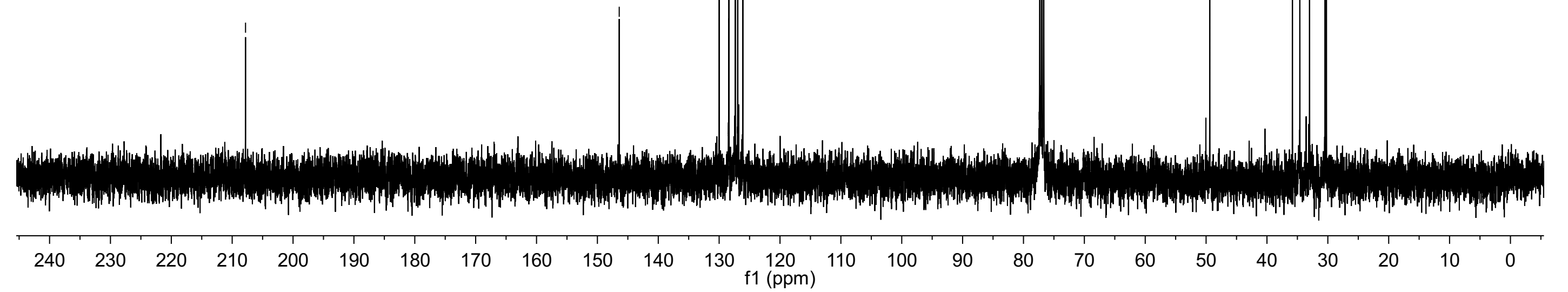




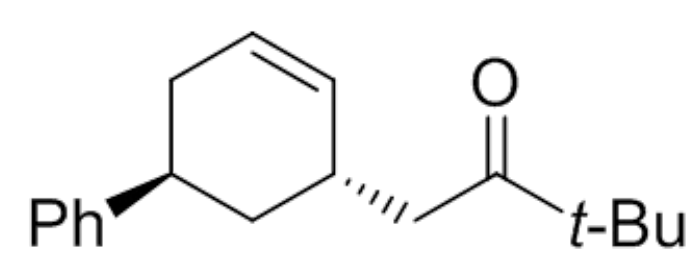

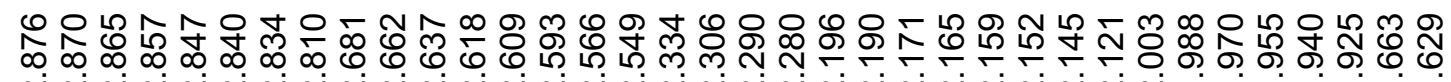

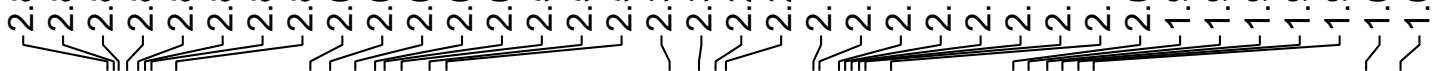

[6e]

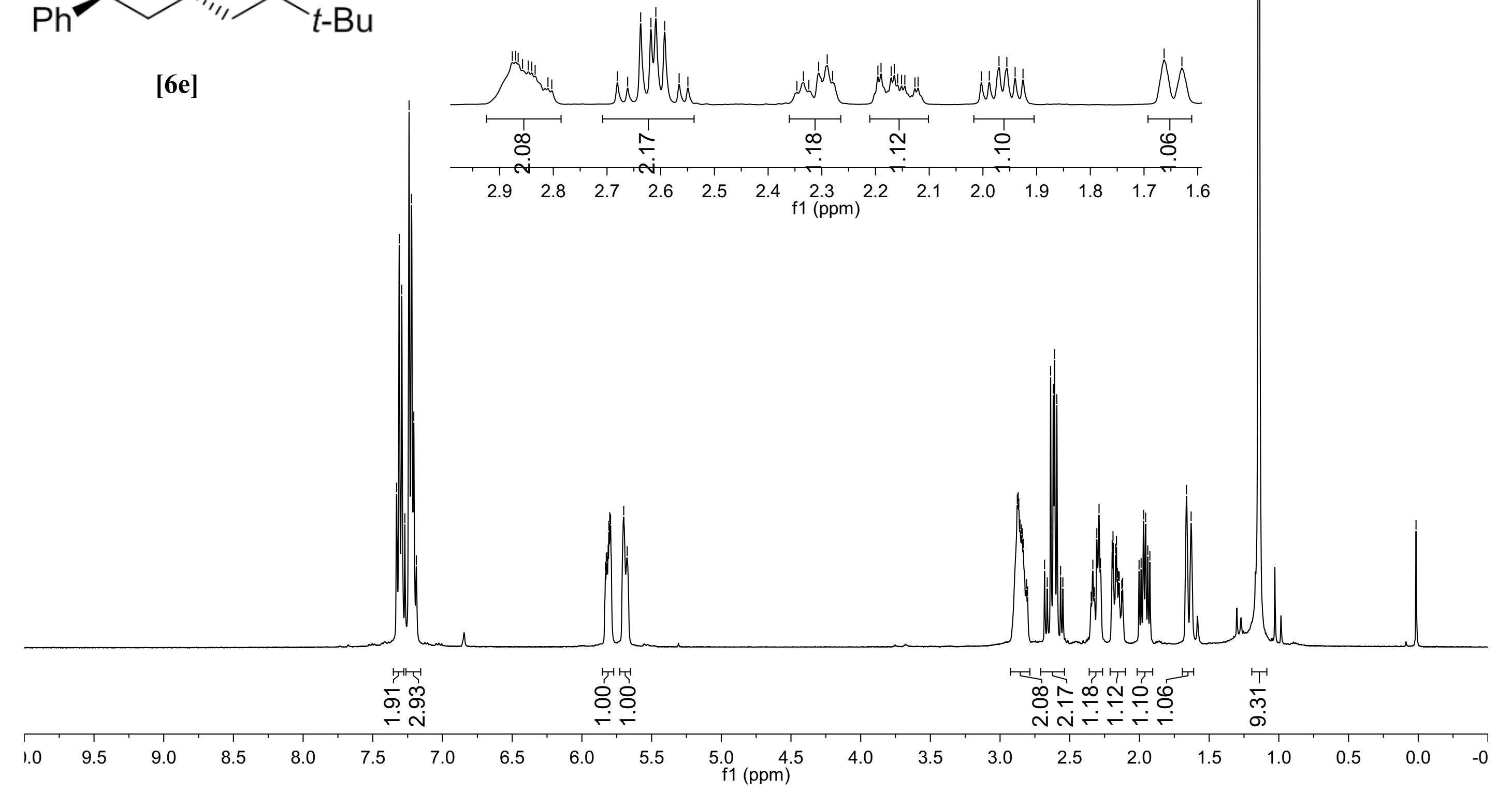


<smiles>O=C(CCCCC[Se]C(=O)[C@H]1C=CC[C@@H](P)C1)c1ccccc1</smiles>

[6e]

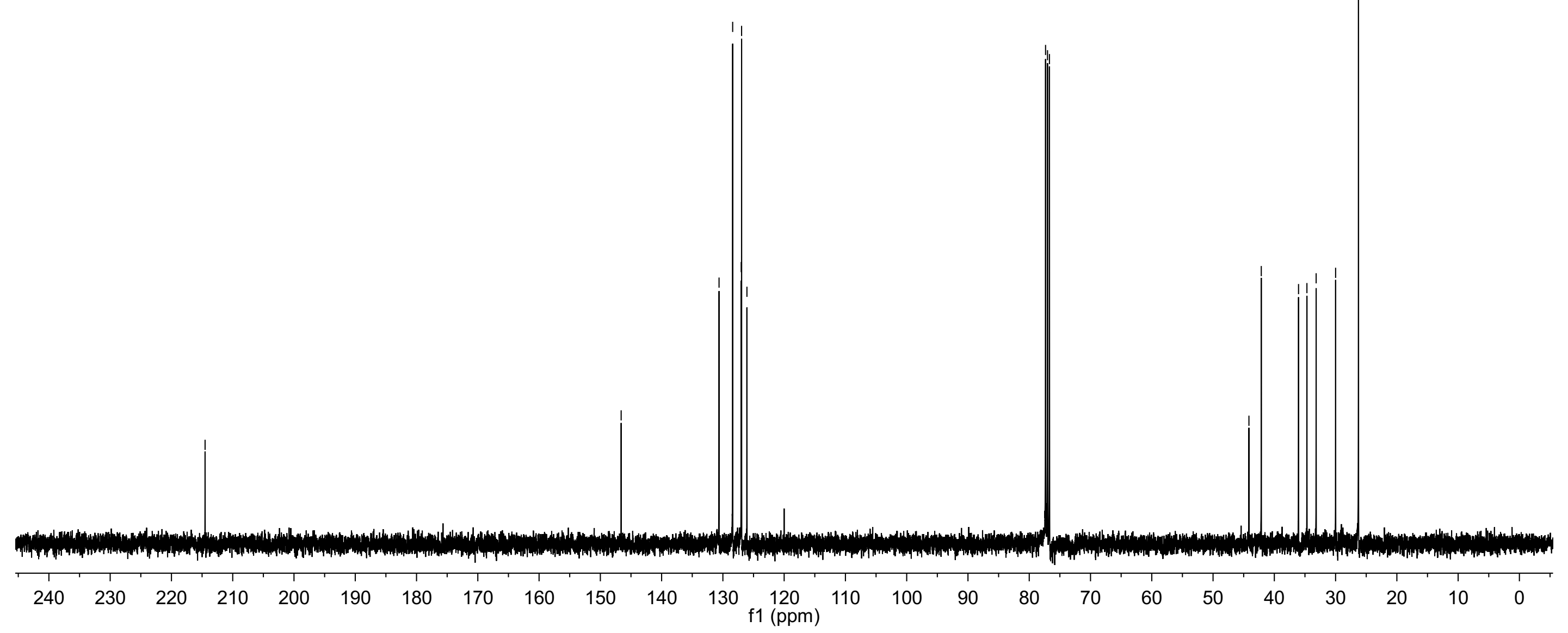


<smiles>O=C(C[C@@H]1C=CC[C@H](P)C1)c1ccccc1</smiles>

[6f]

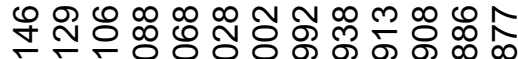
mं்

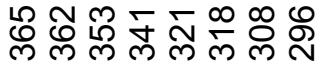

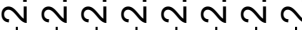

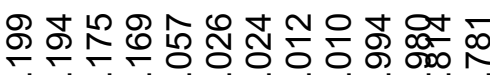
NNNNNNNNN-TH

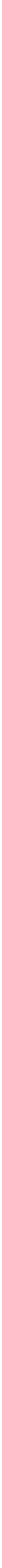


<smiles>O=C(P)C[C@@H]1C=CC[C@@H](P)C1</smiles>

[6f]
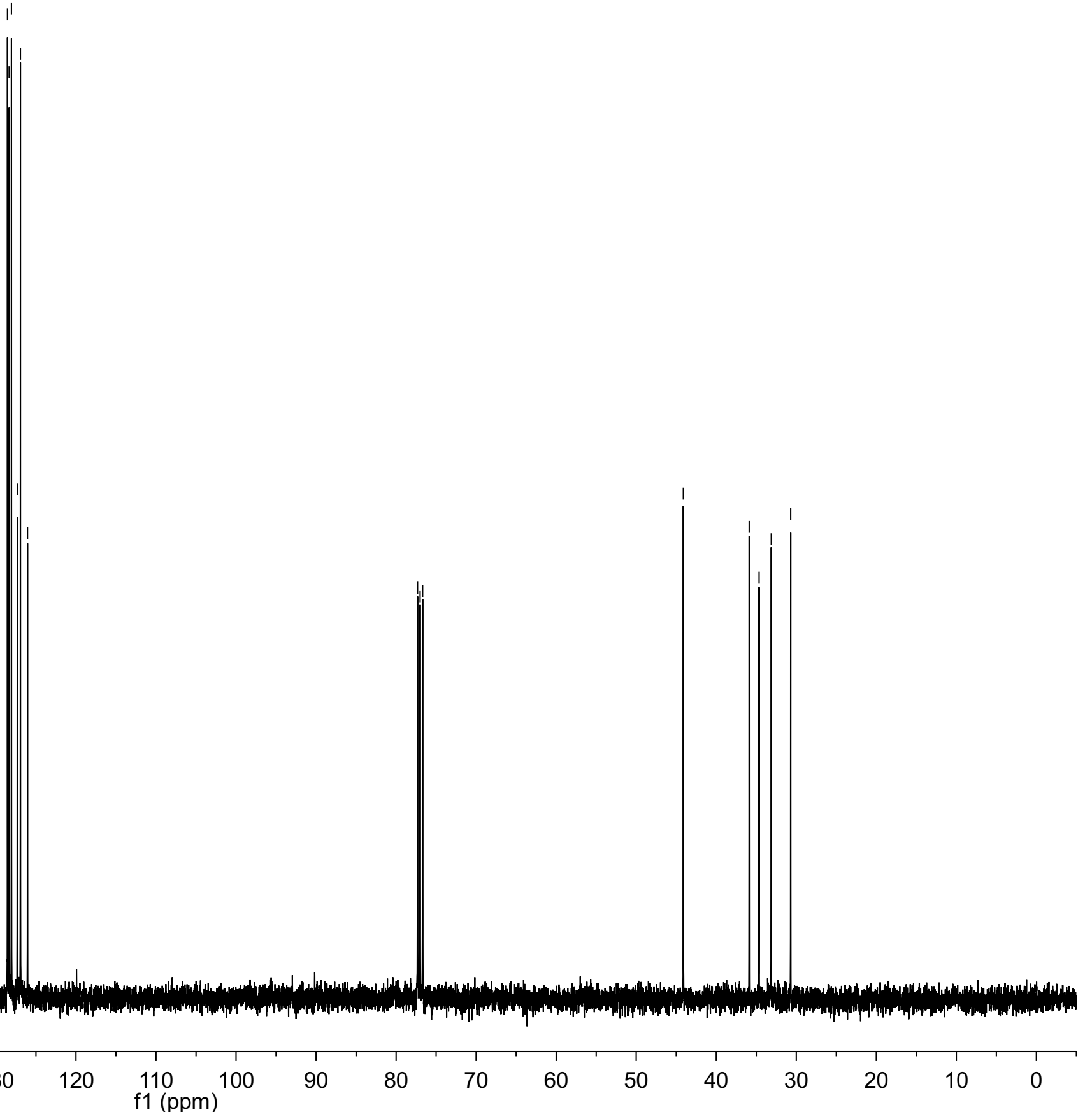


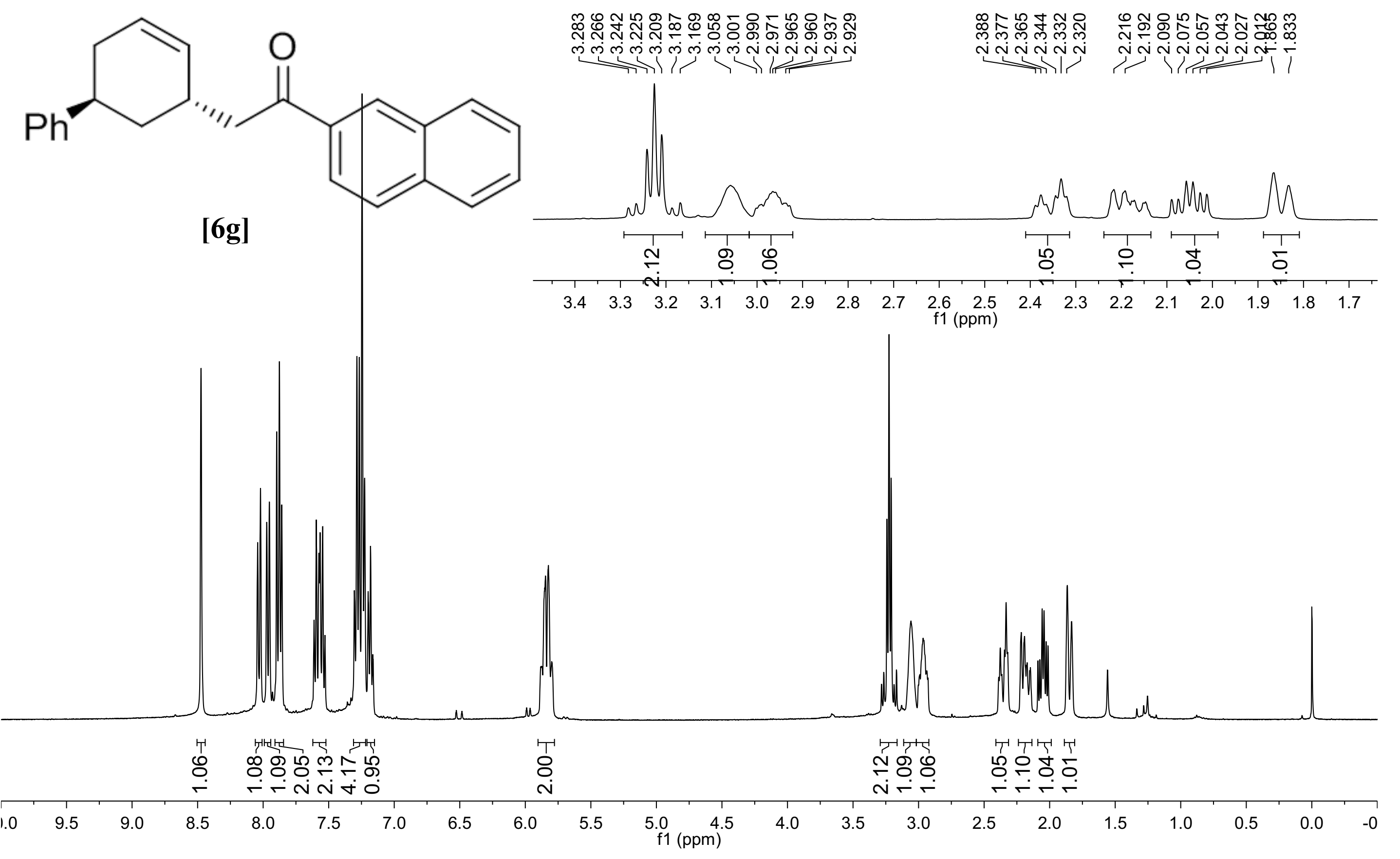



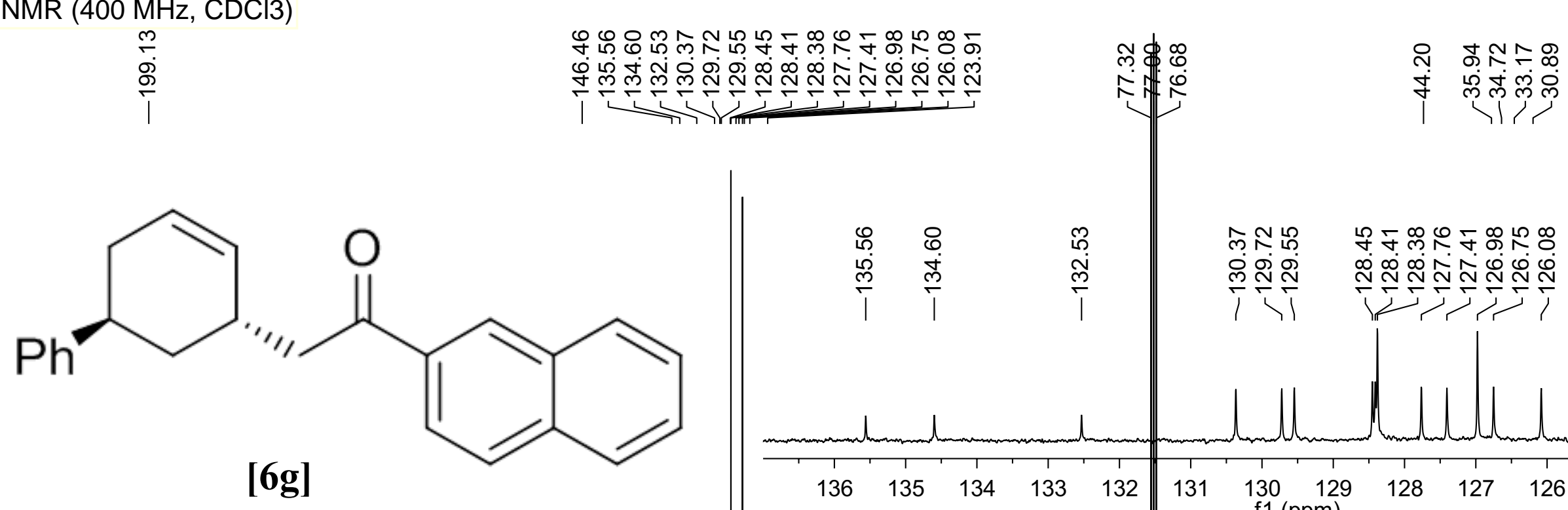

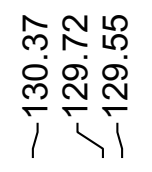

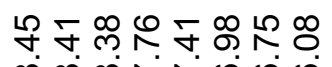

ลั

许

ธ్
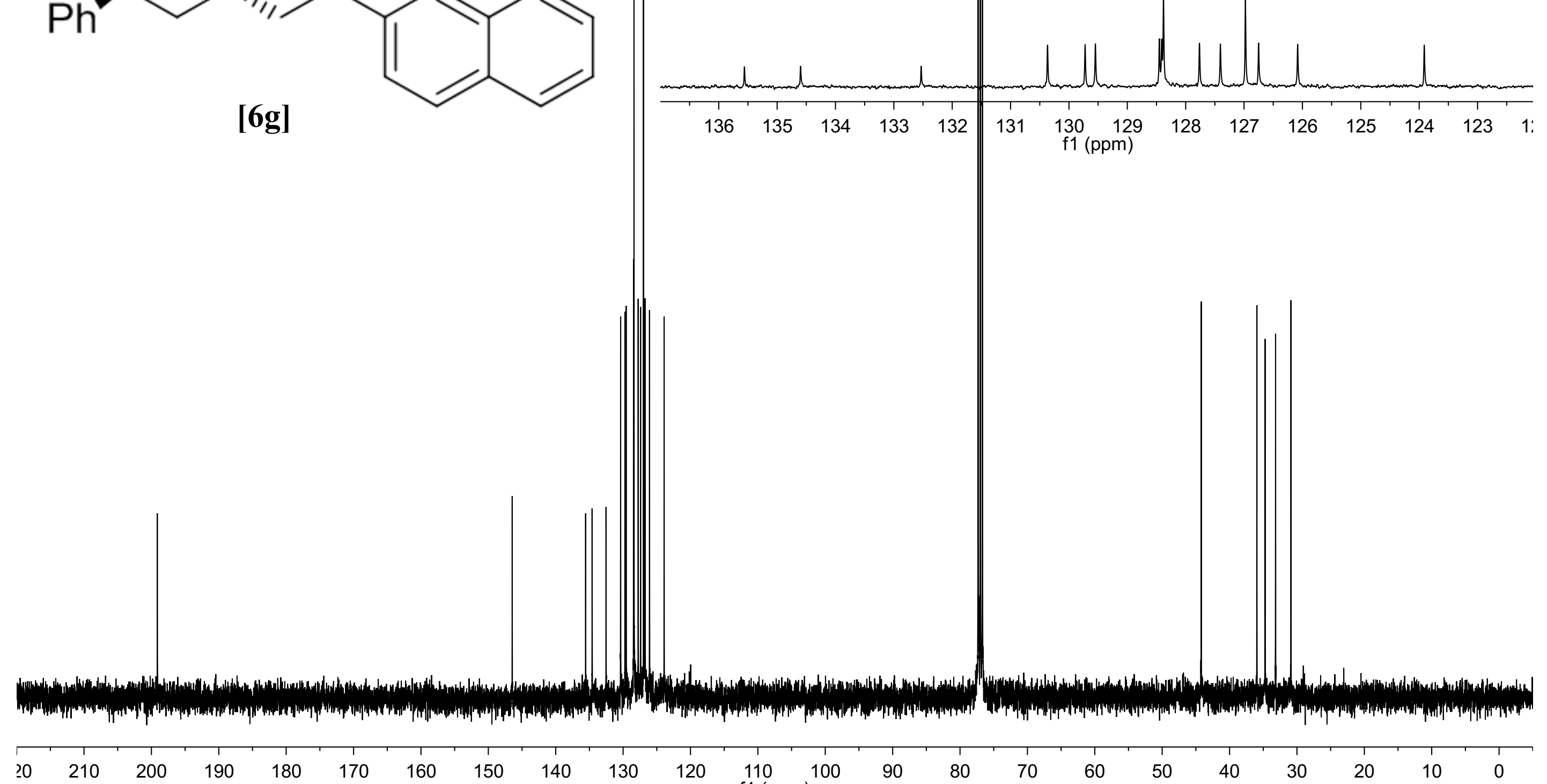


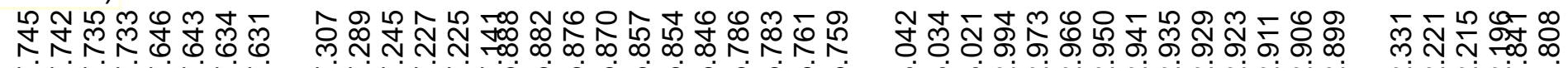

NNNNNNN

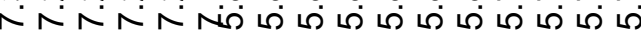

๓่

舟

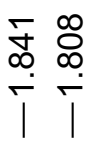

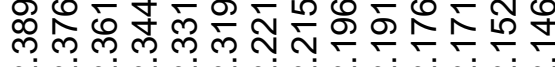

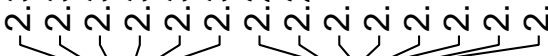
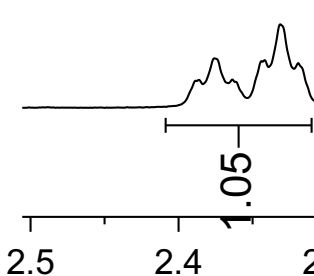

$4 \quad 2.3$

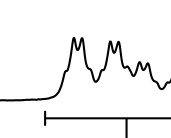

$M n$
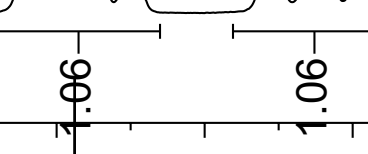

\&

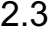

f.1 1 (ppm)

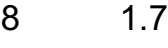

1.7
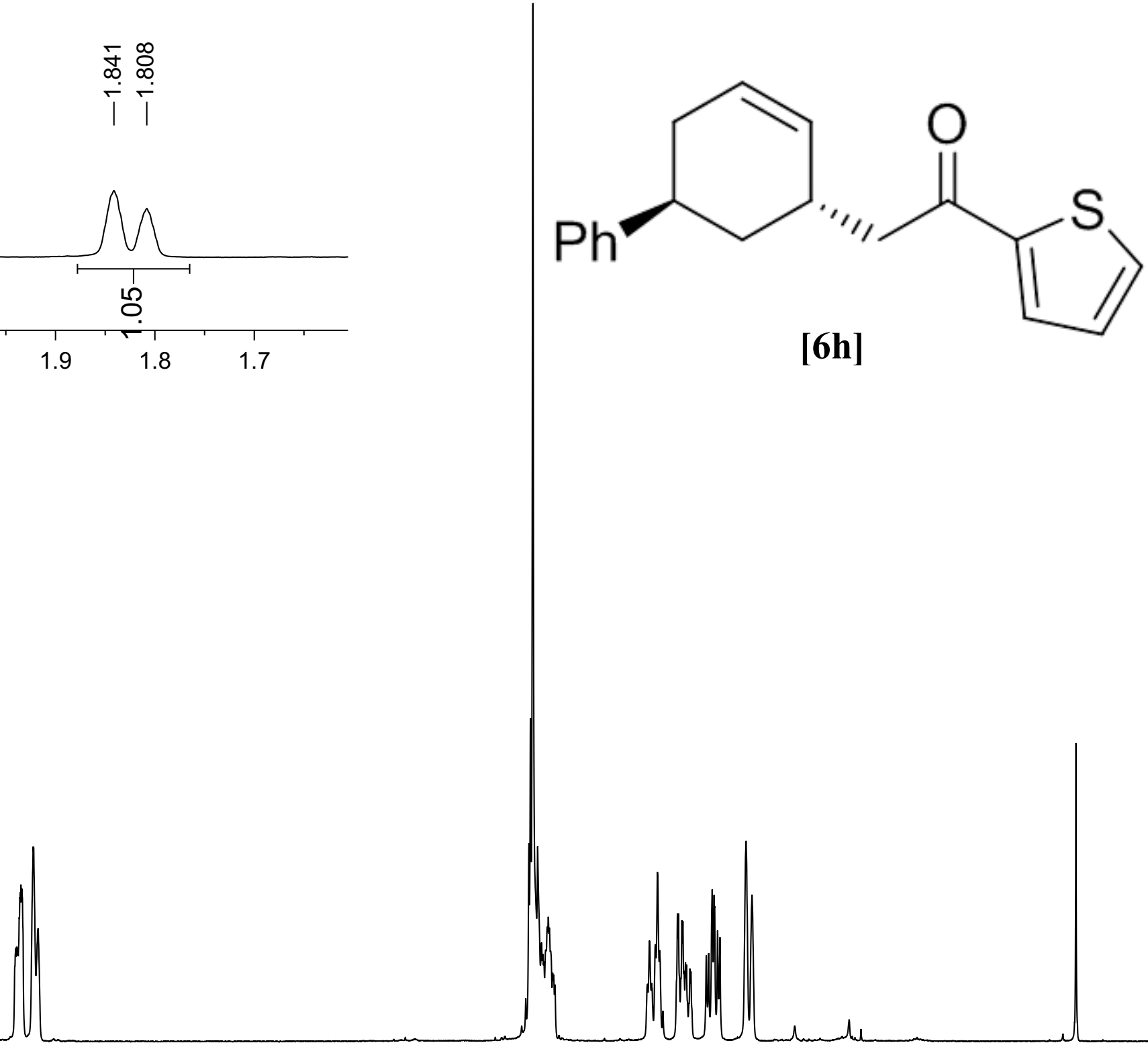

$[6 h]$

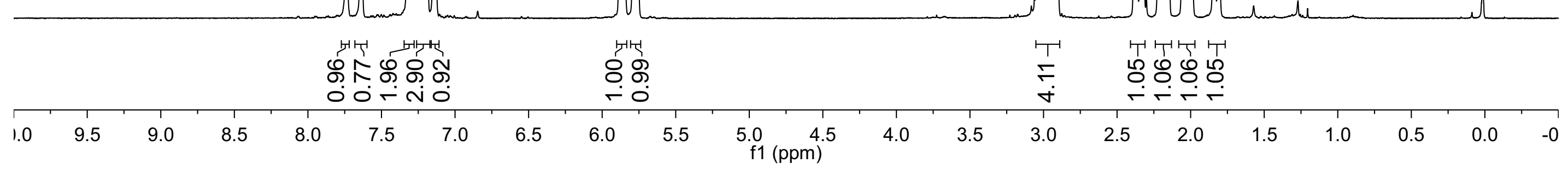




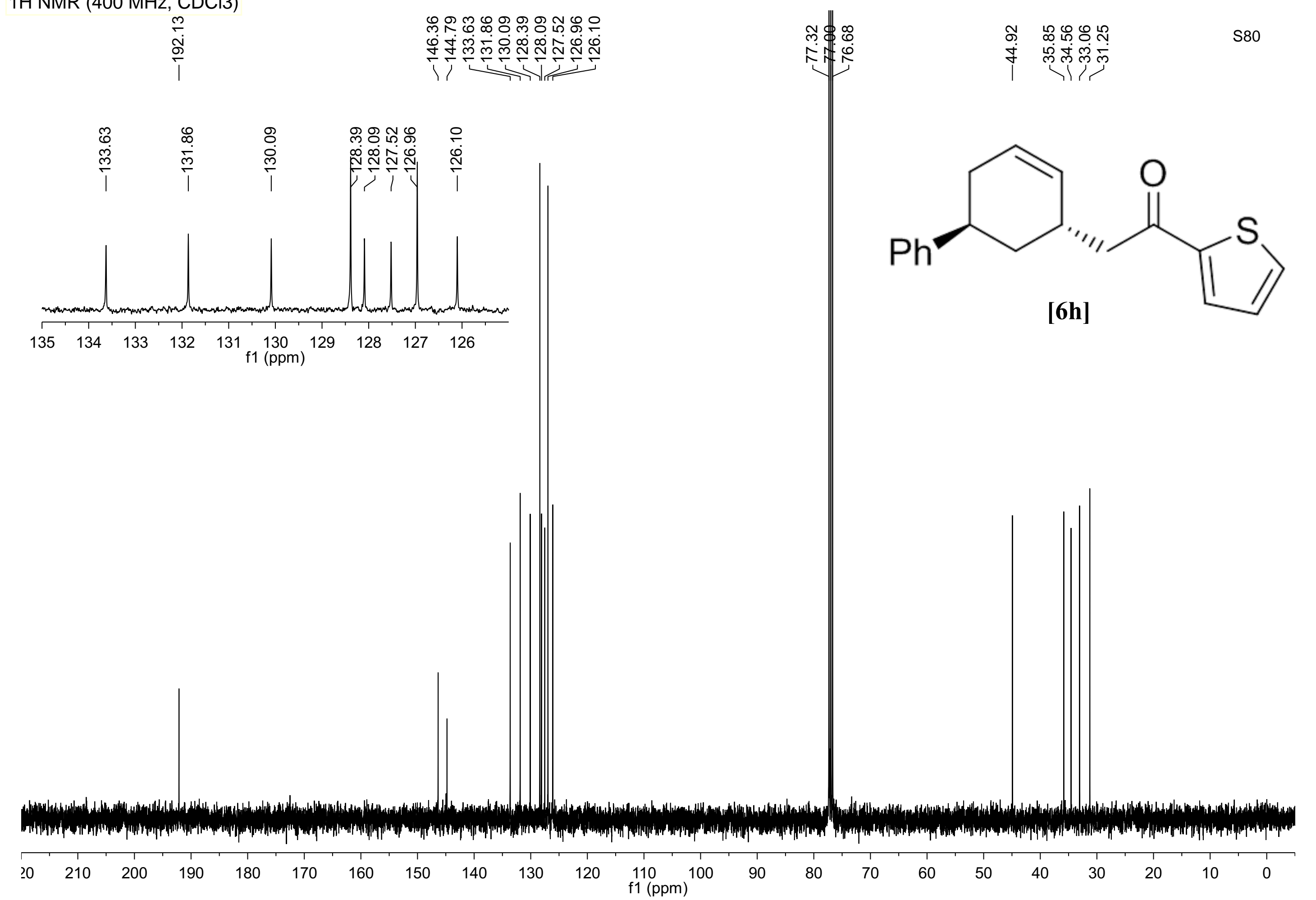

( -

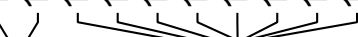

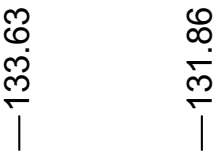

वे

융 ิำ

ํํㄴ 원

$\stackrel{\text { I }}{\text { I }}$
ᄂ மำ

न लिल्लm 


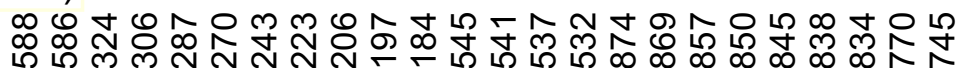

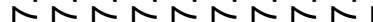

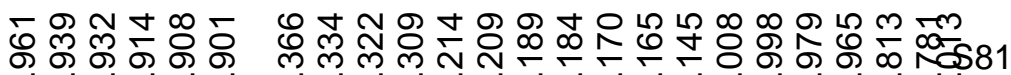

ก่

"ه

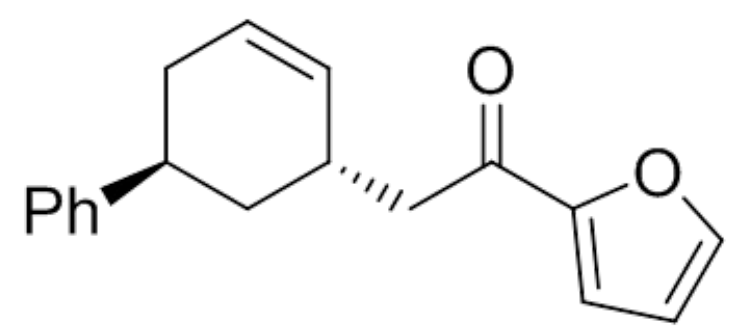

[6i]
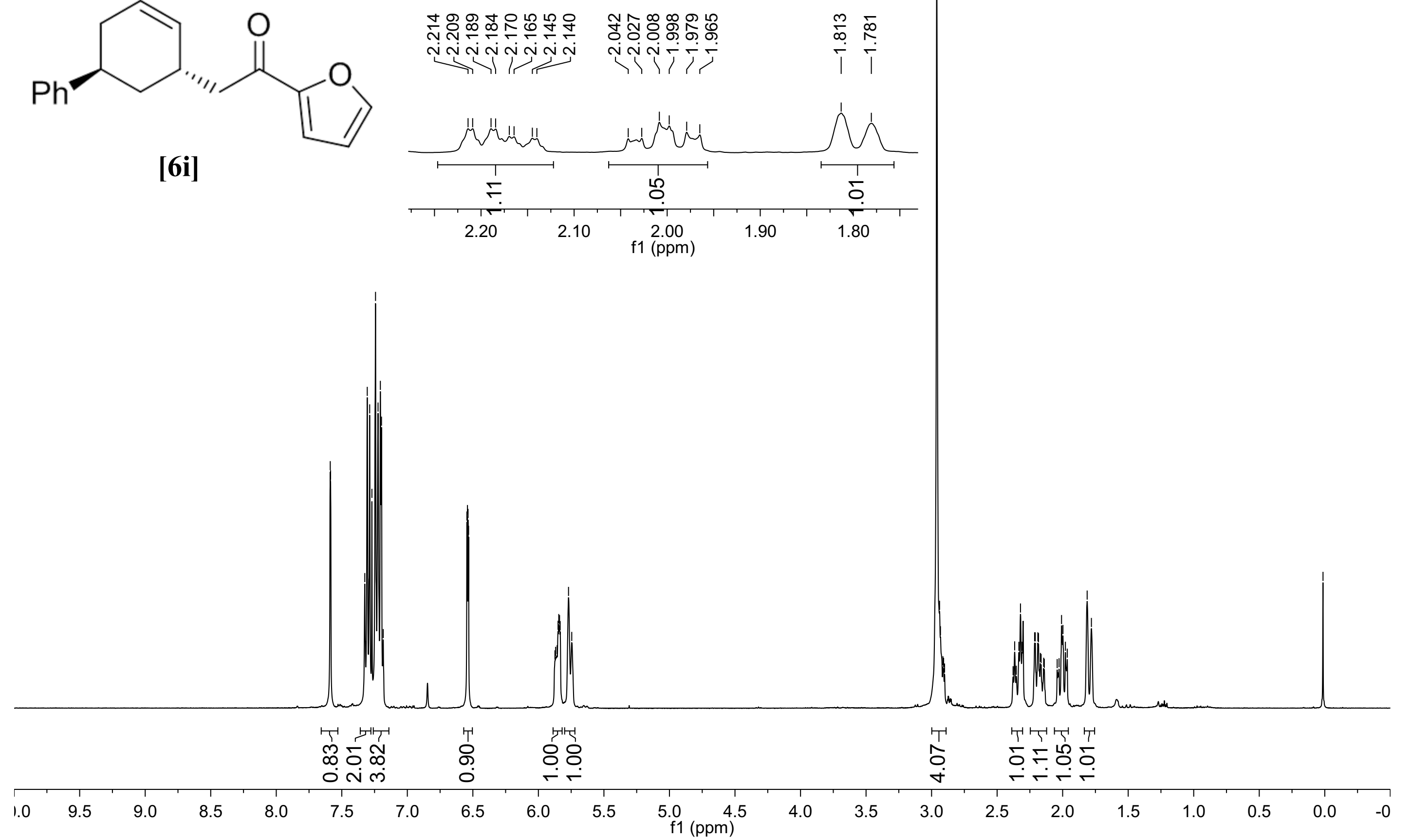
<smiles>O=C(C[C@@H]1C=CC[C@H](c2ccccc2)C1)c1ccco1</smiles>

[6i]

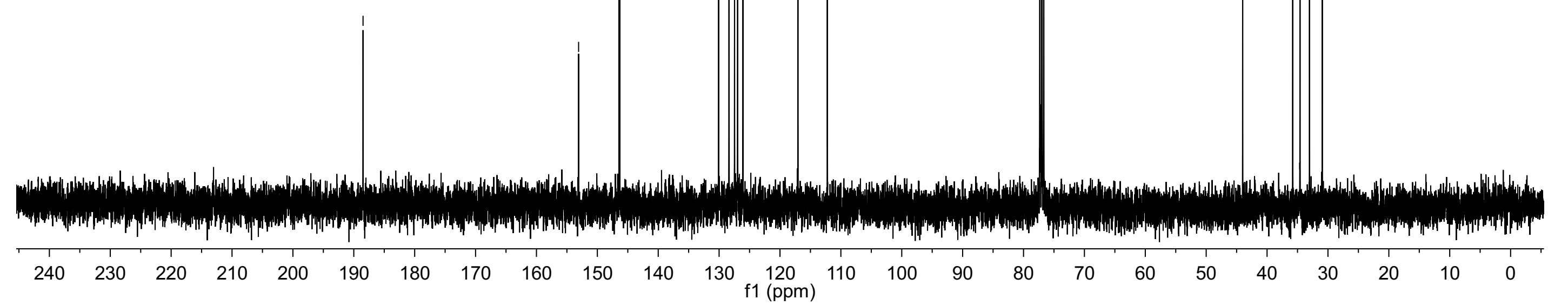




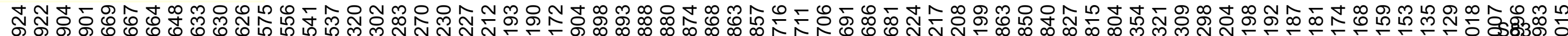

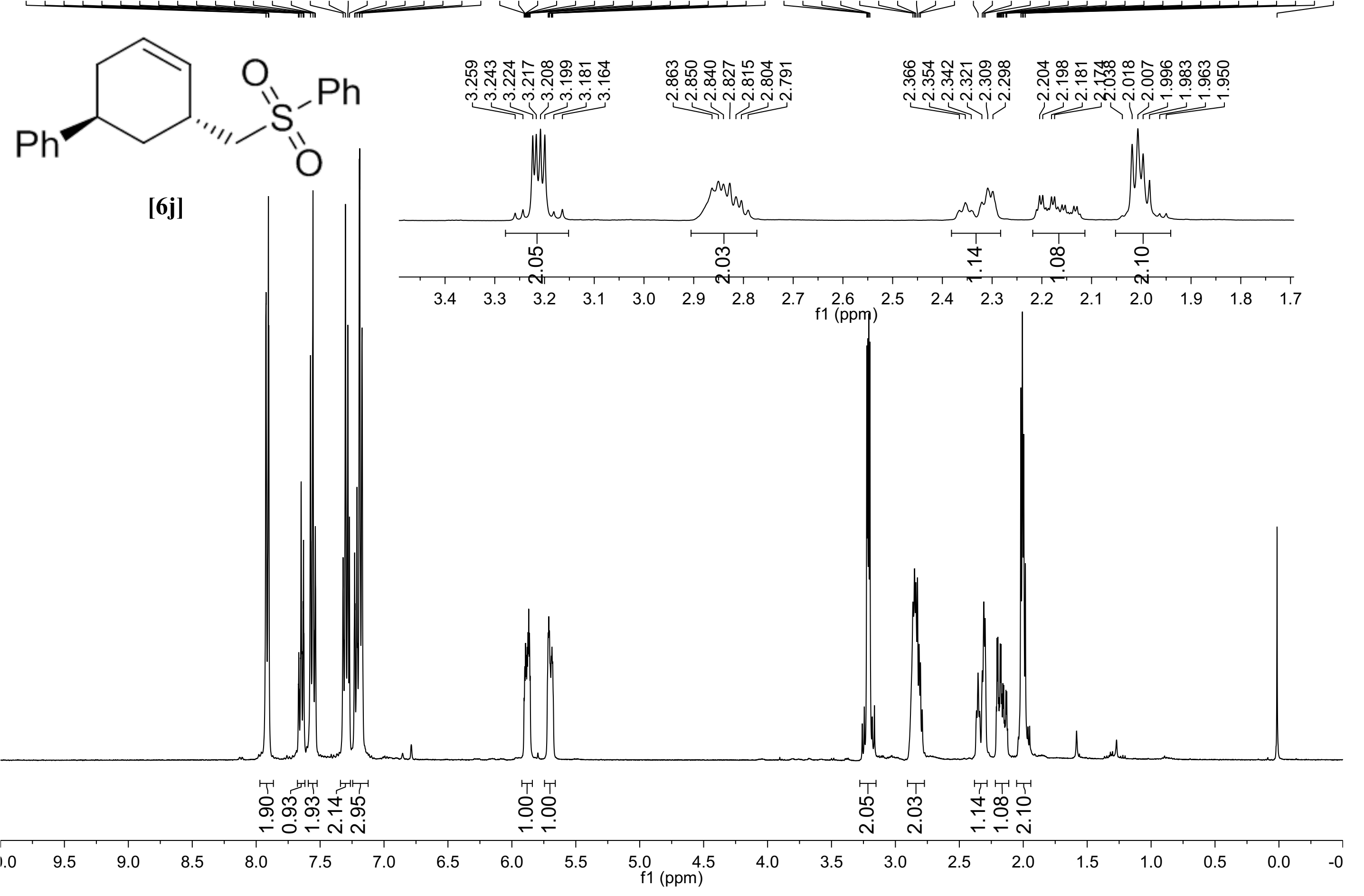




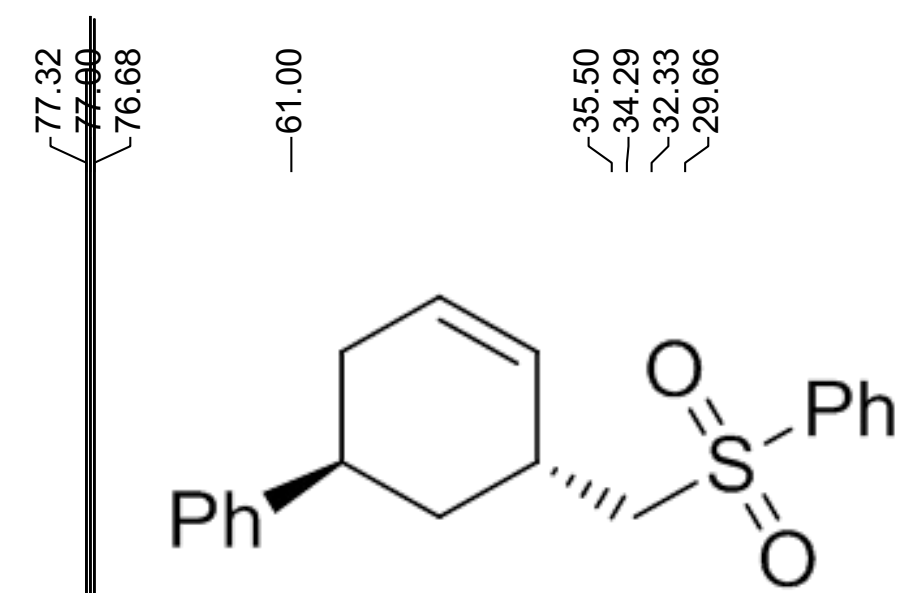

[6j]

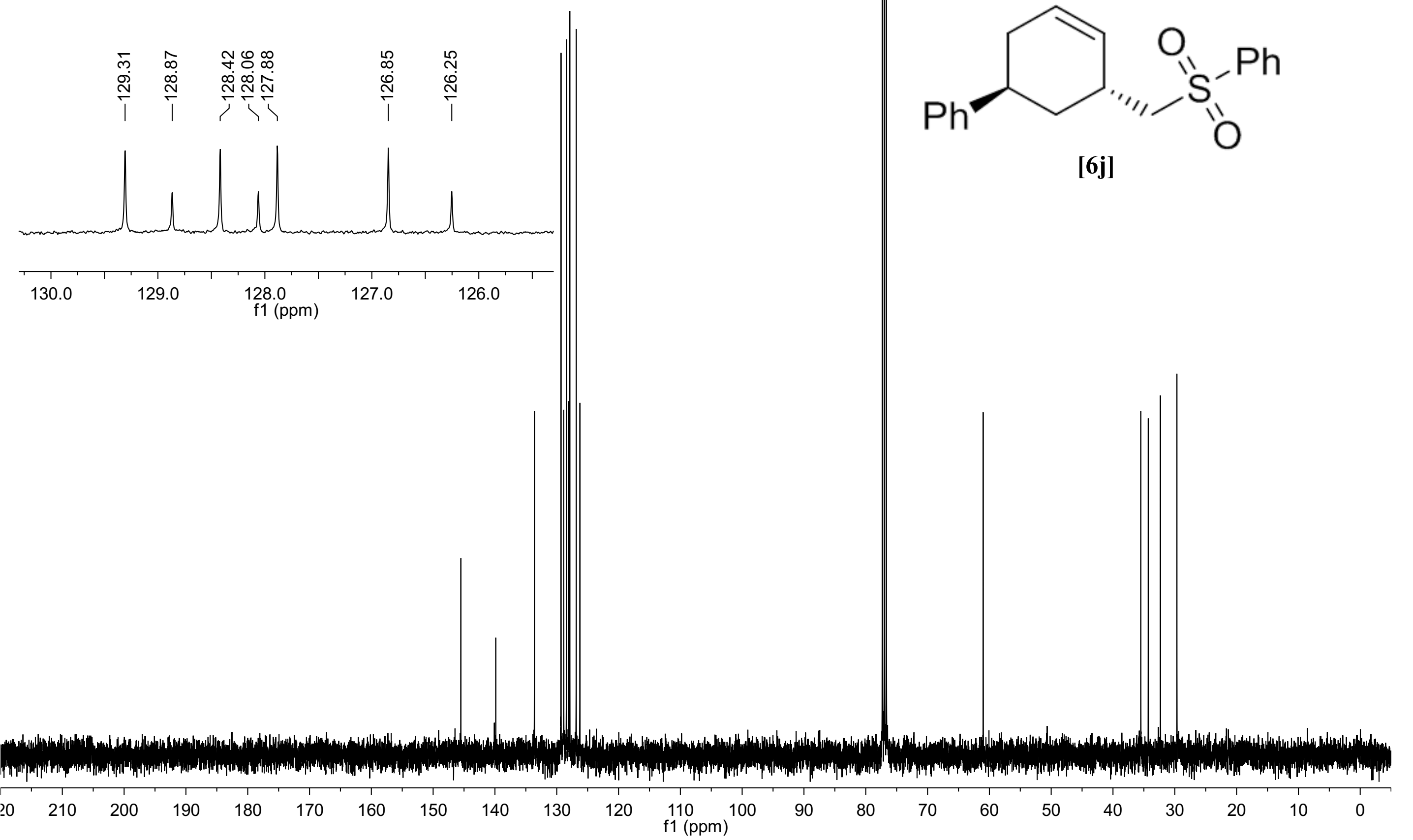




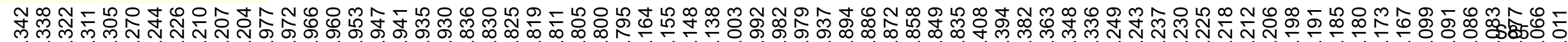

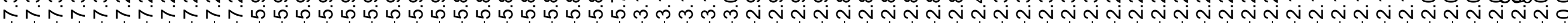

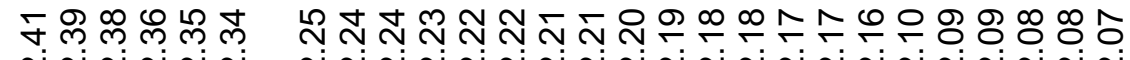
กij

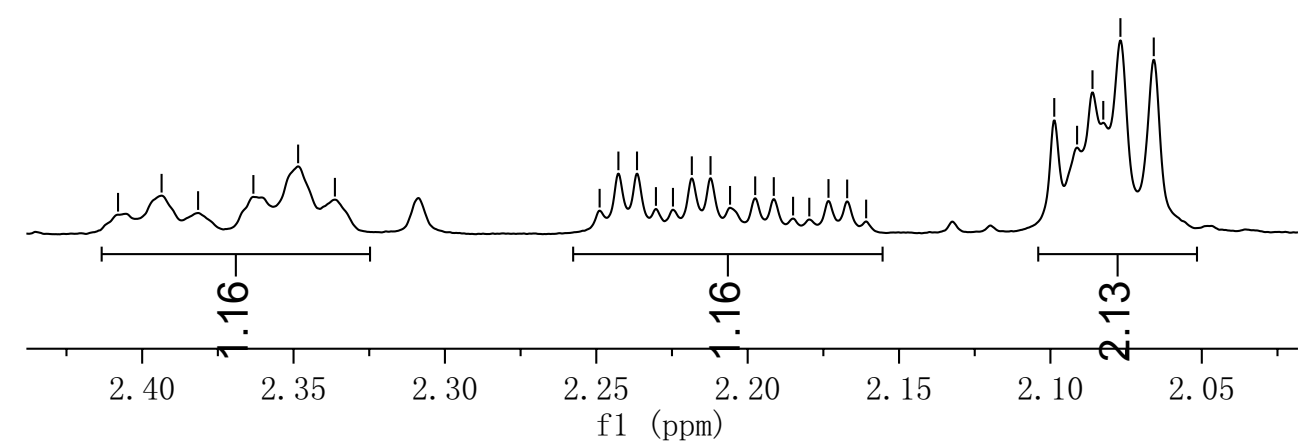

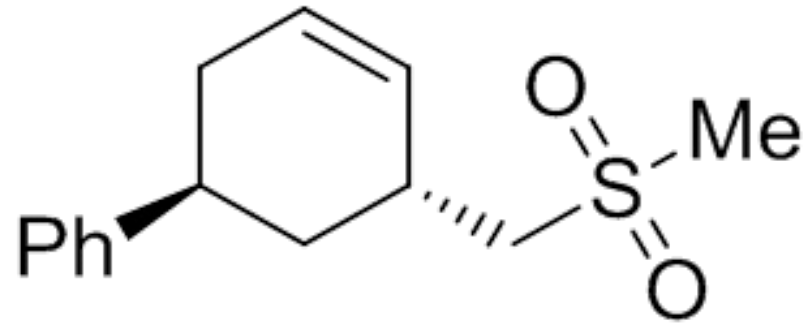

$[6 k]$

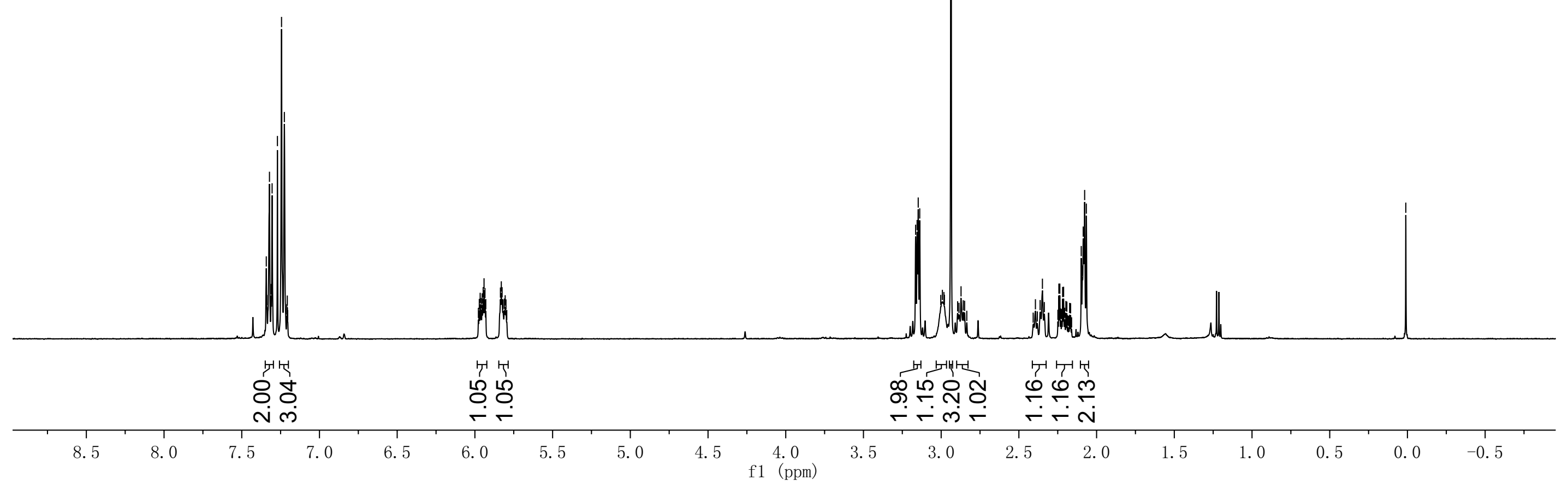


<smiles>CS(=O)(=O)C[C@@H]1C=CC[C@H](P)C1</smiles>

[6k]

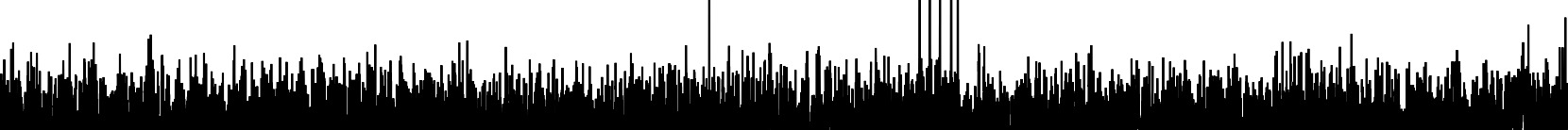
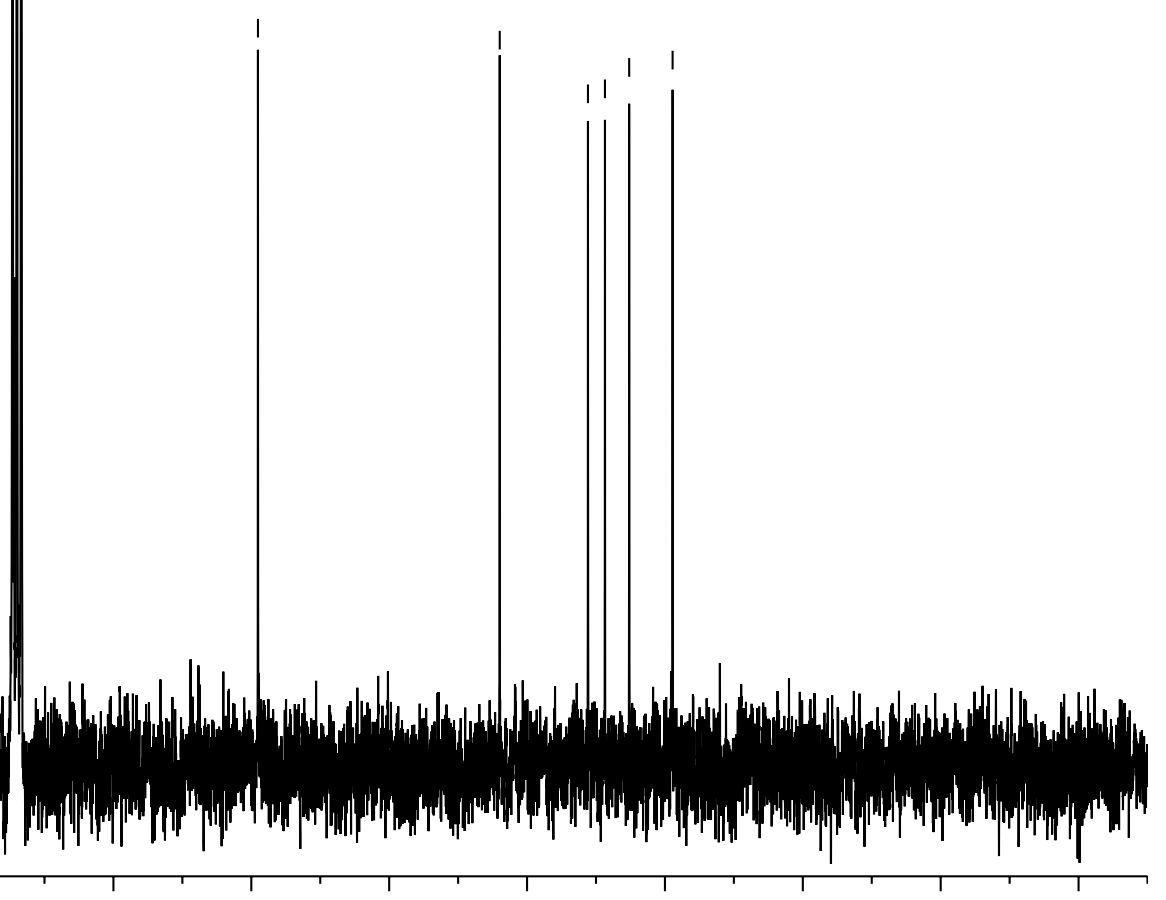

190180

$\begin{array}{rrr}1 & 1 & 1 \\ 170 & 160 & 150\end{array}$

$140 \quad 130$

120

110

f1 (ppm) 


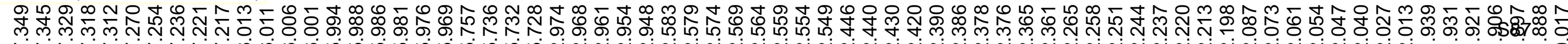

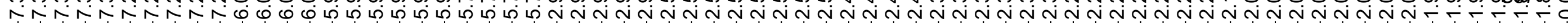

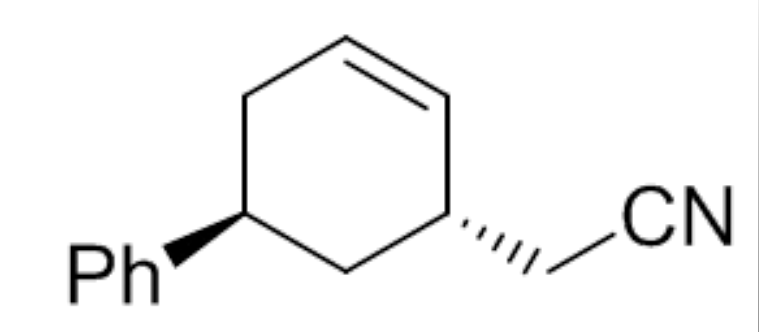

[61]

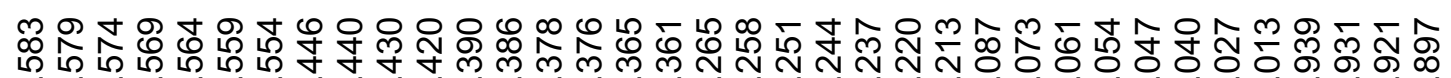

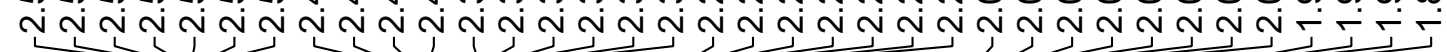

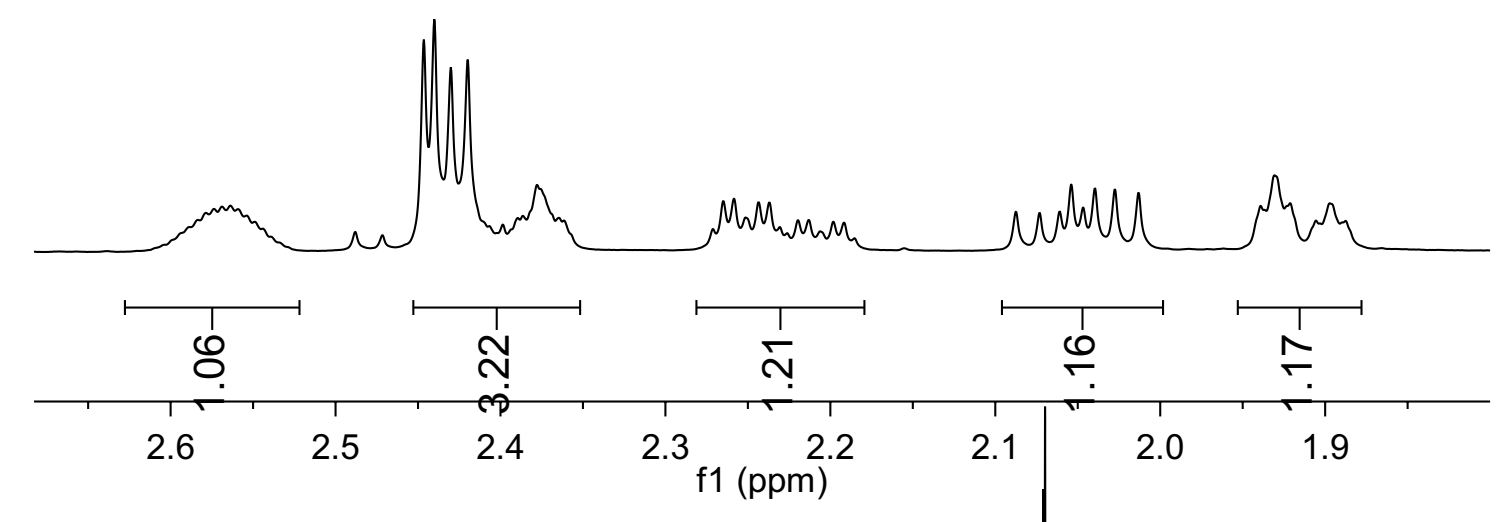

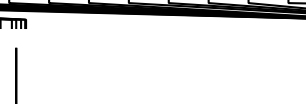




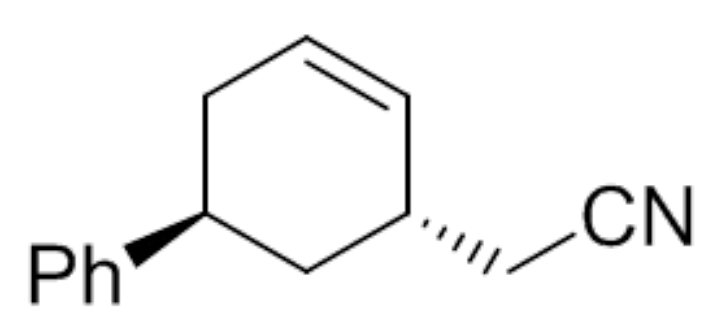

[61]

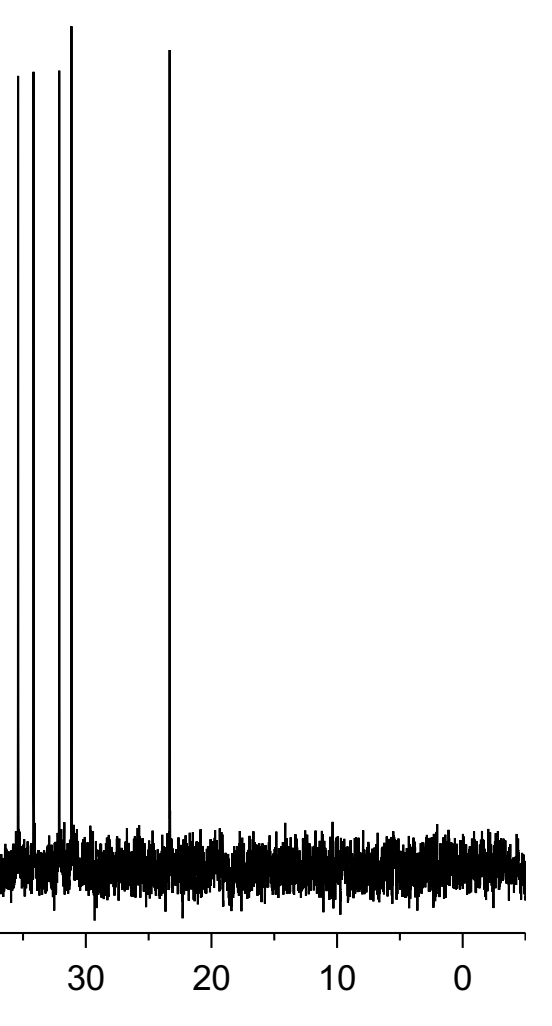




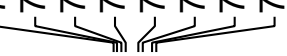

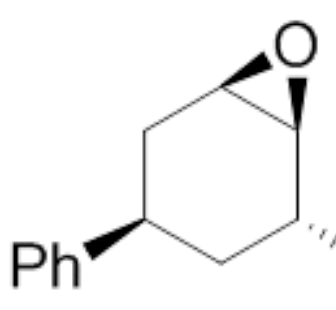

${ }^{\prime \prime} \mathrm{CH}\left(\mathrm{CO}_{2} \mathrm{Me}\right)_{2}$

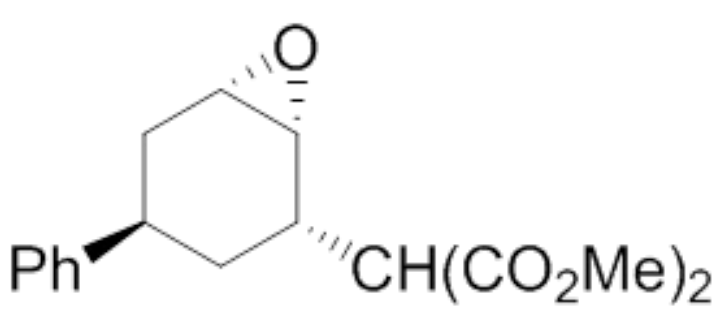

\section{[7a,7a']}

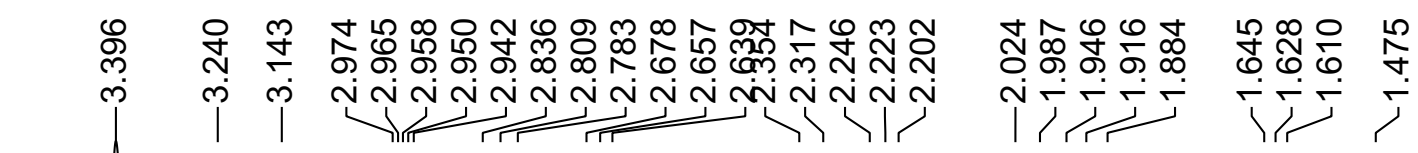

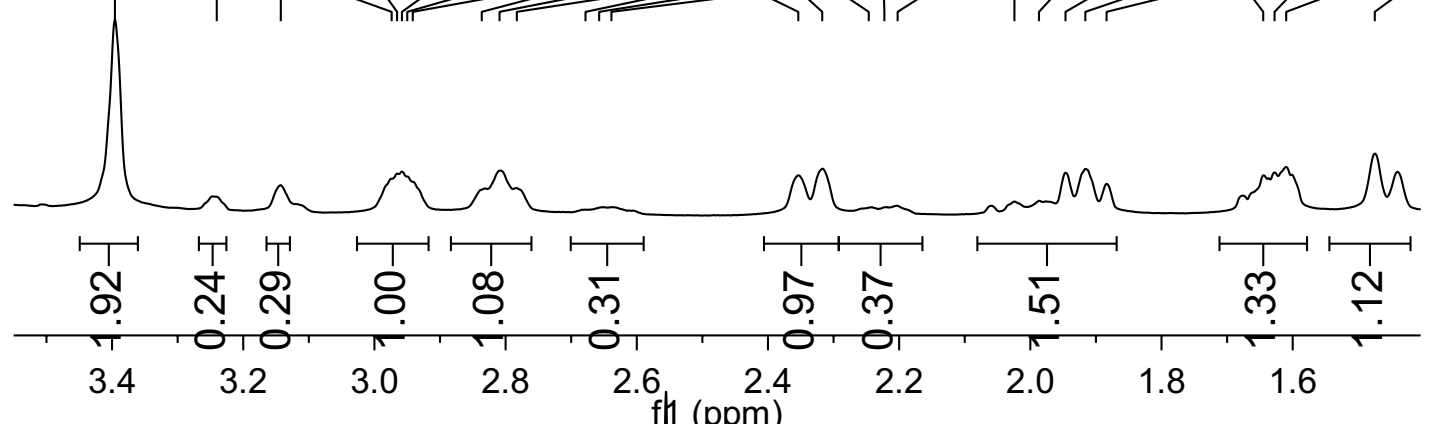

$3.4 \quad 3.2$

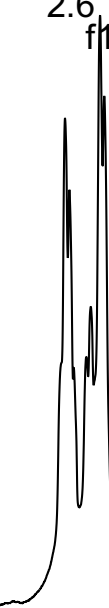

חर

$1 /$

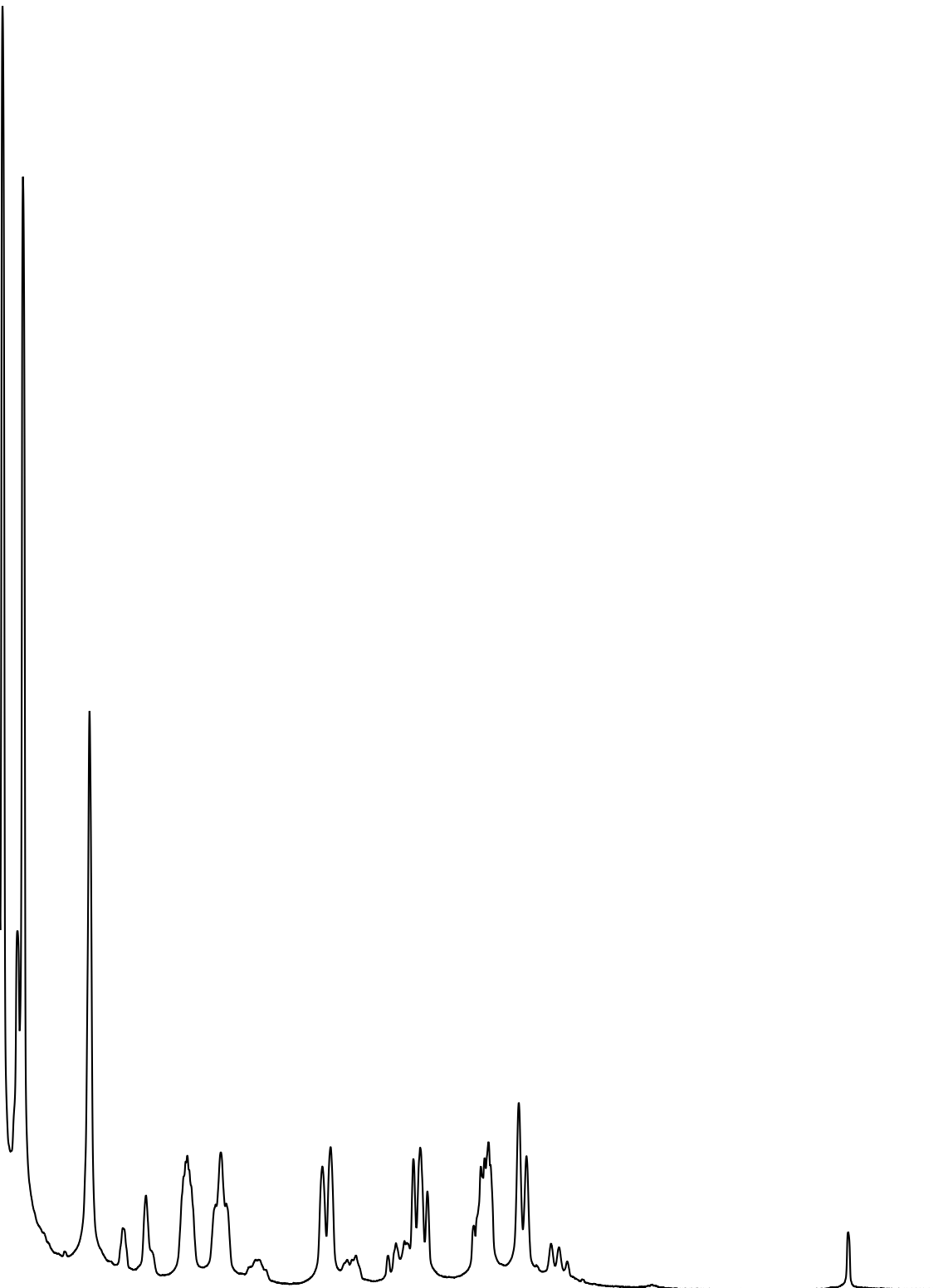

\section{in}

$\sim$

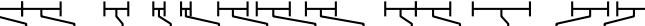

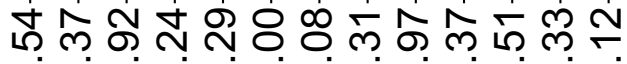

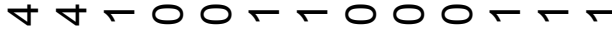

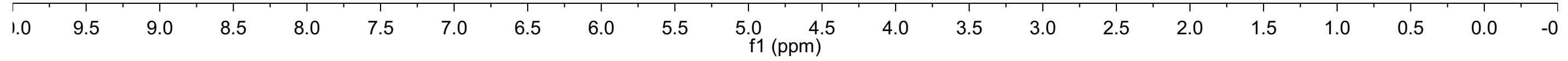




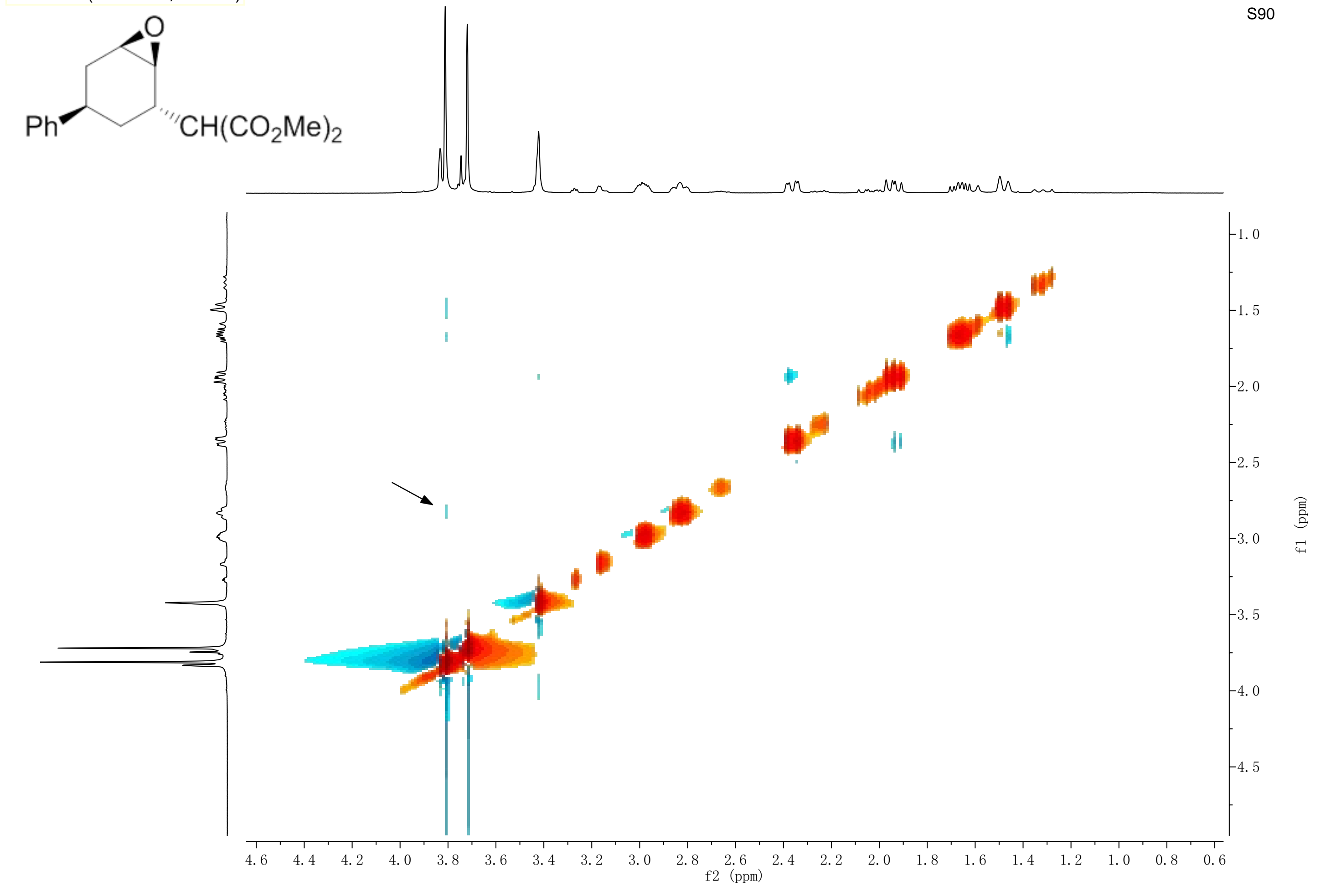




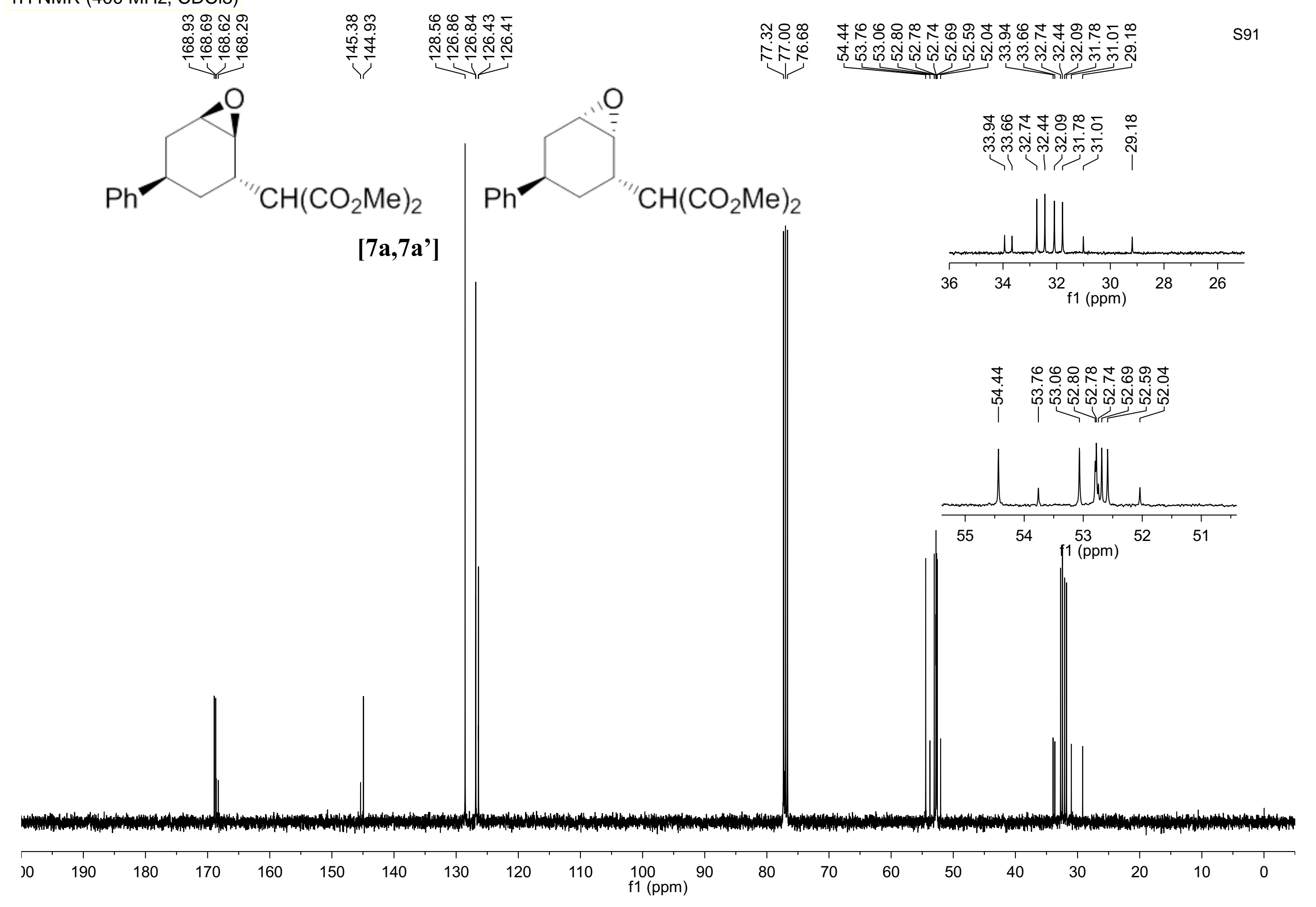




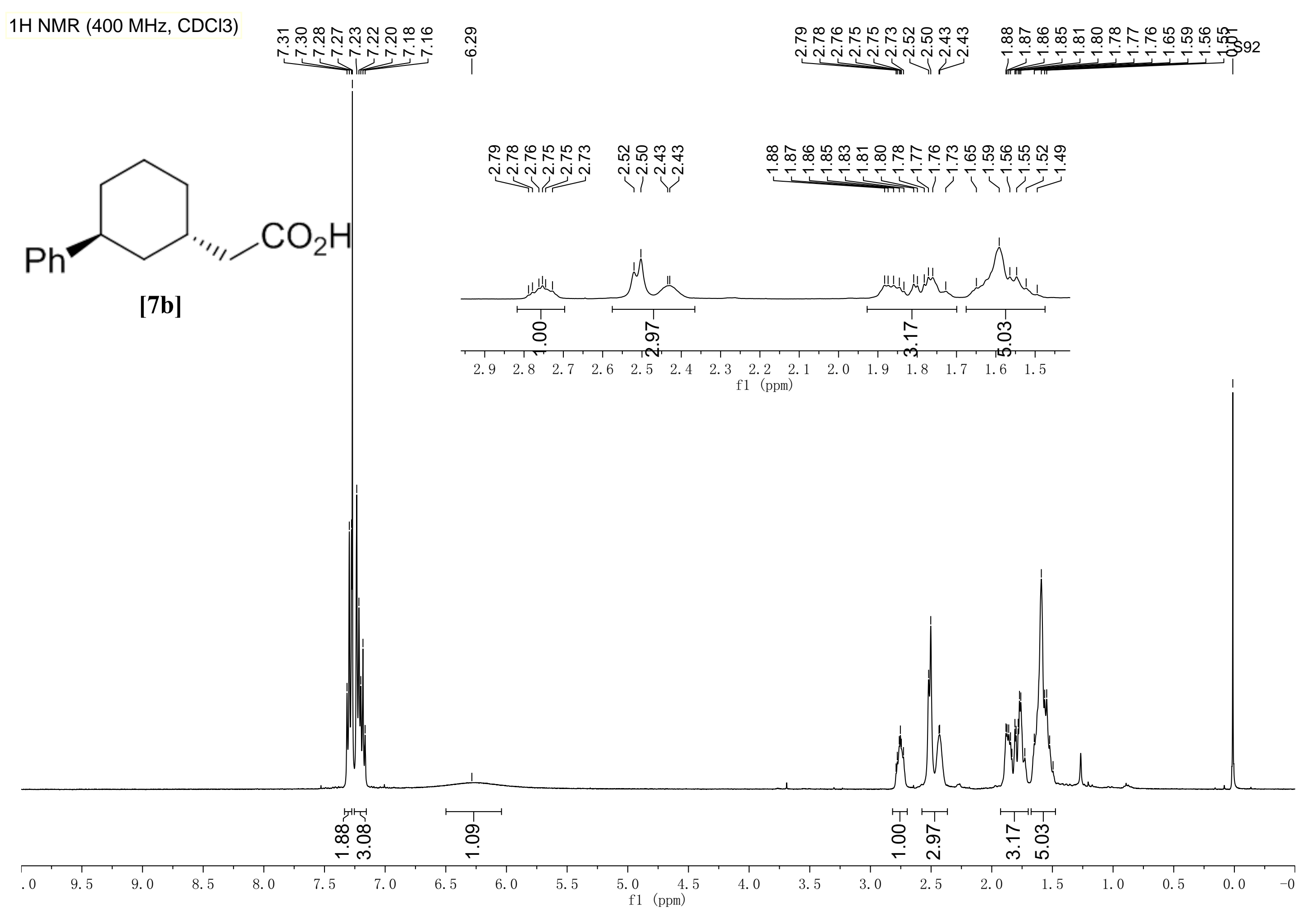




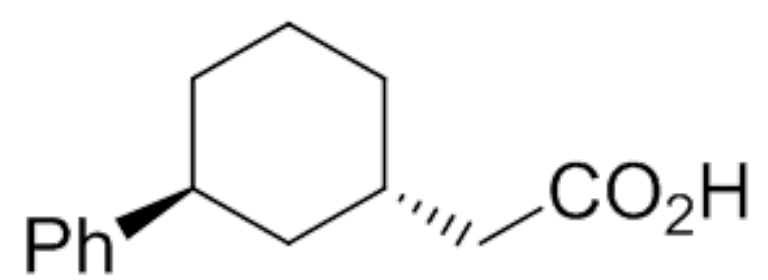

[7b]

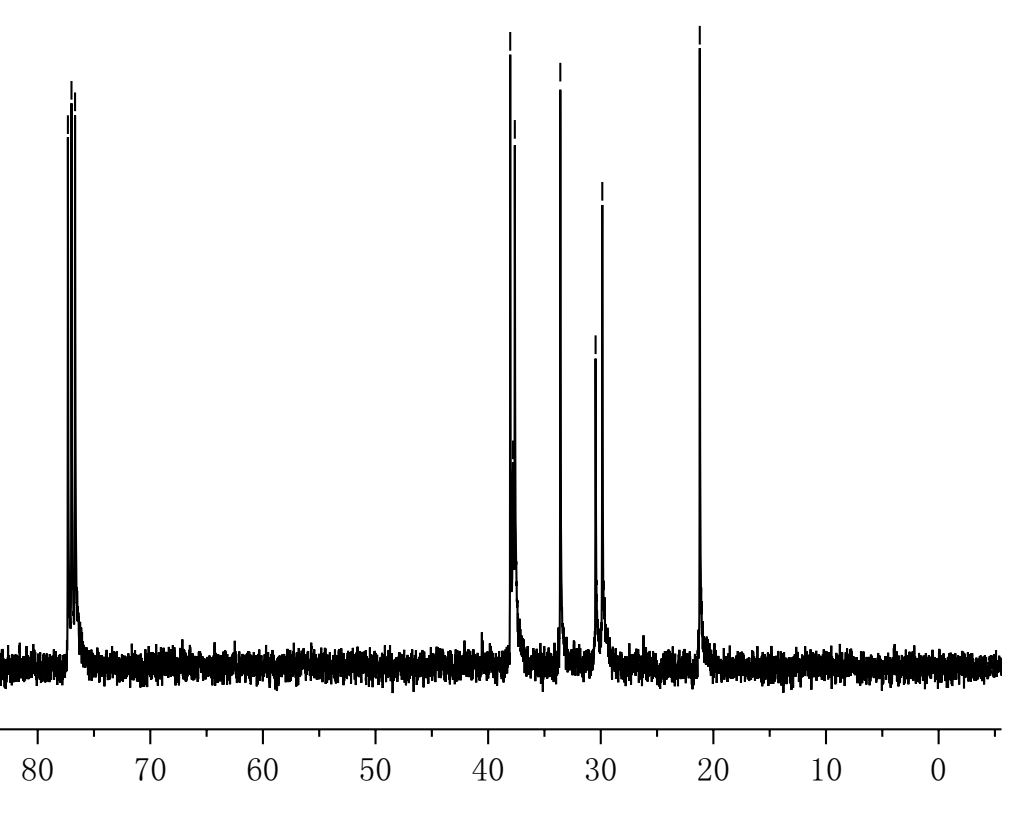




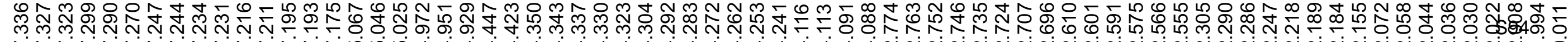

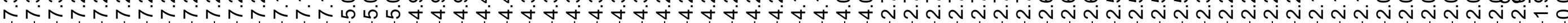
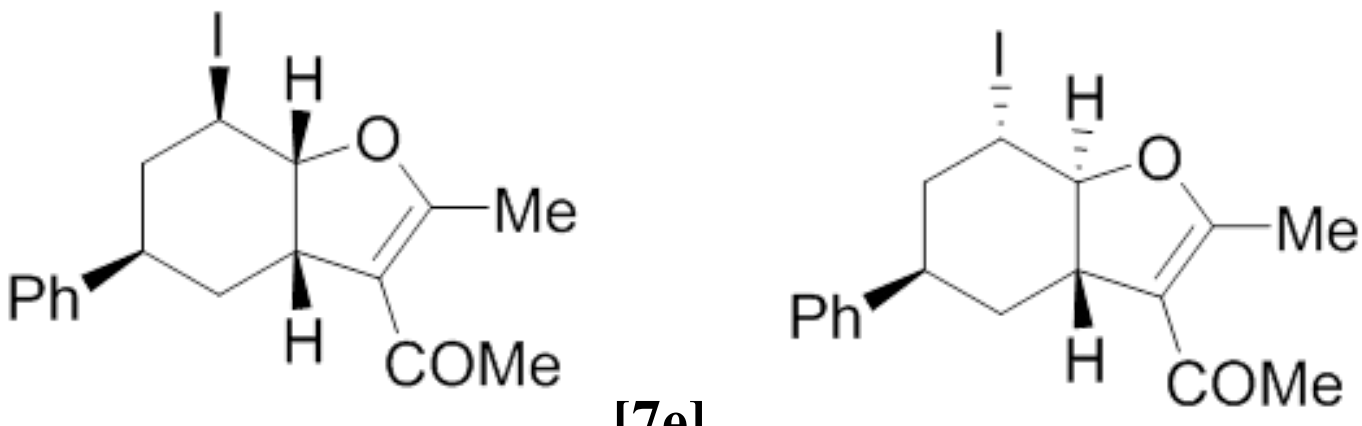

$[7 \mathrm{e}]$

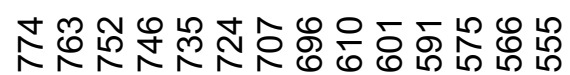
ก i

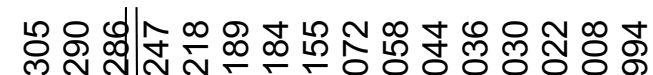

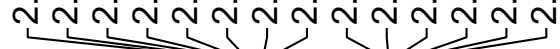

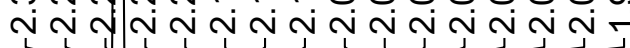
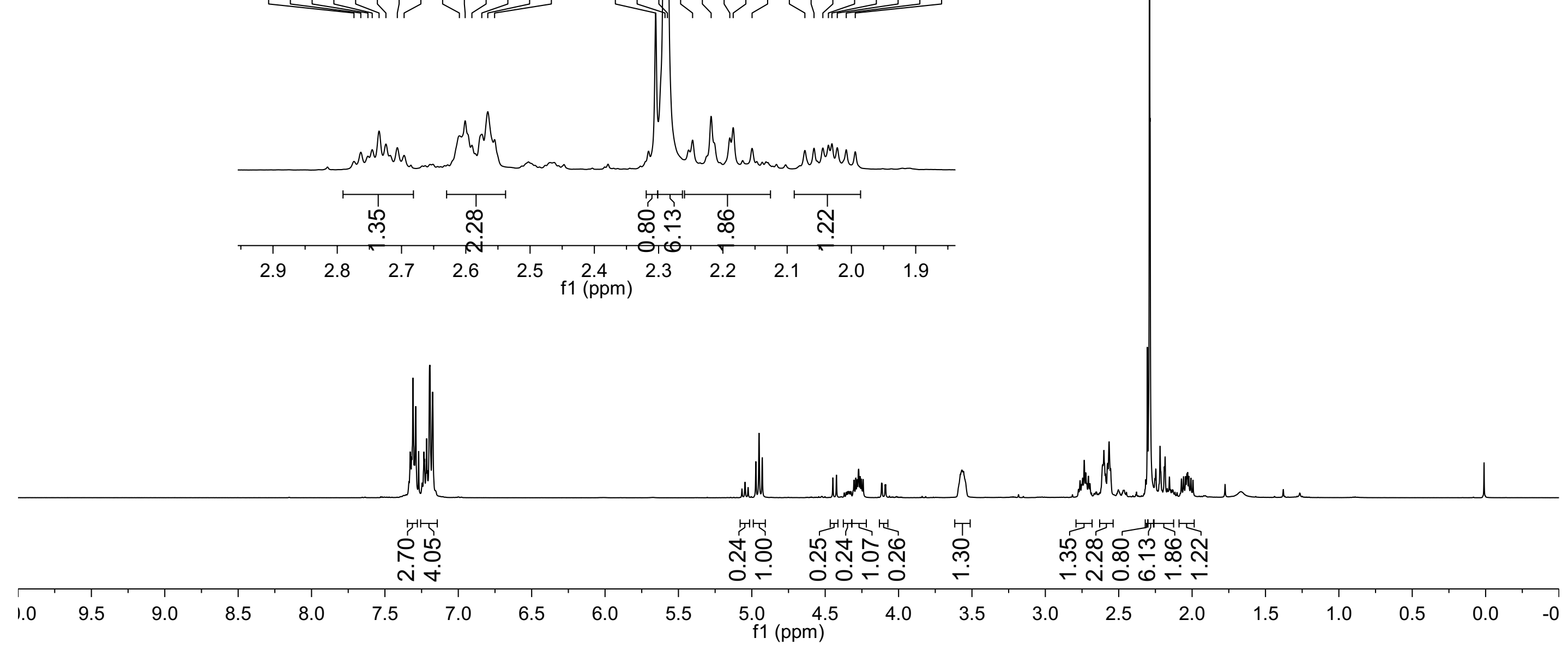

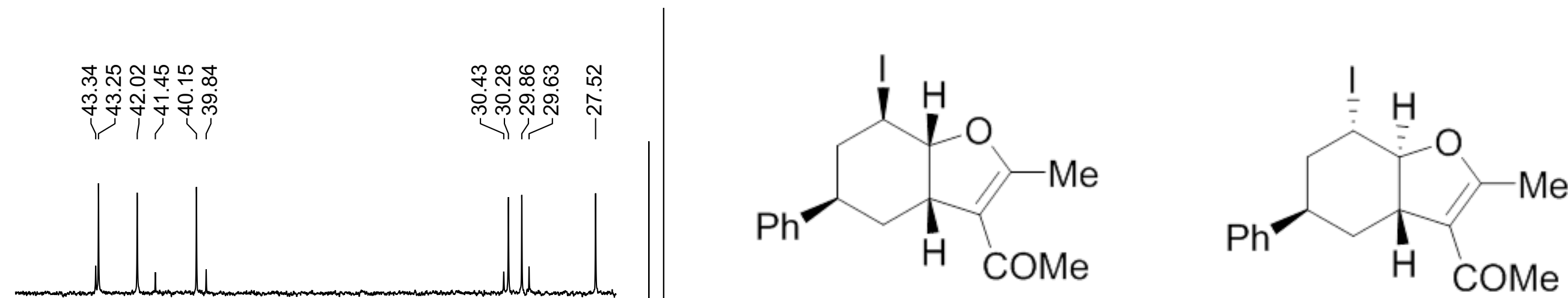

[7e]

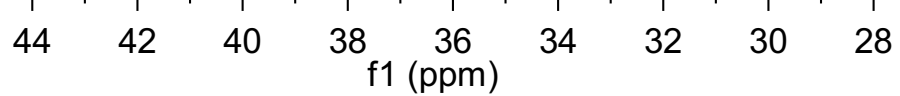




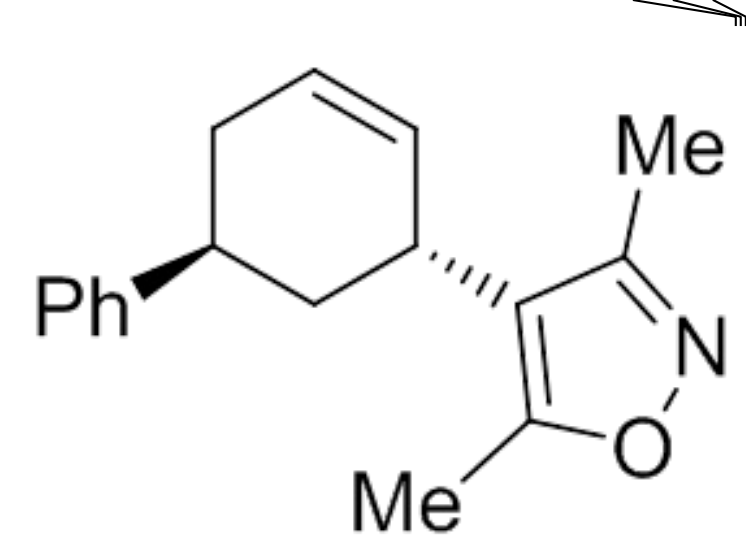

[7g]
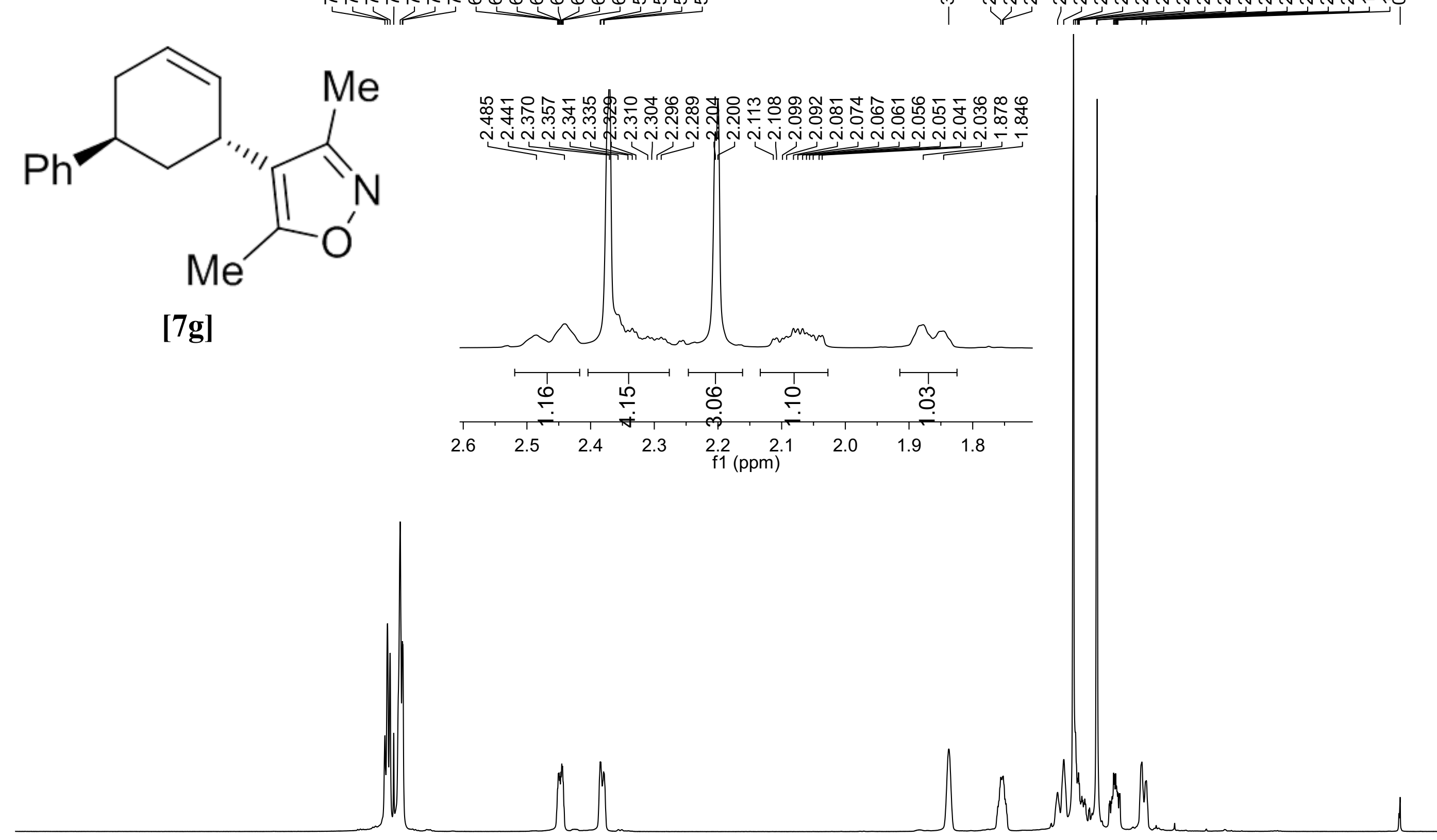

\begin{tabular}{|c|c|c|c|c|c|c|c|c|c|c|c|c|c|c|c|c|c|c|c|c|}
\hline & & & & & $\begin{array}{l}y^{\prime} \\
\stackrel{8}{ } \\
\dot{1}\end{array}$ & & & & & & & & 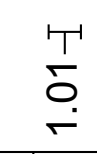 & 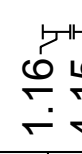 & : & & & & & \\
\hline 1.0 & 9.5 & 9.0 & 8.5 & 8.0 & 7.5 & 7.0 & 6.5 & 6.0 & 5.5 & $\begin{array}{c}5.0 \\
\text { f1 (ppm) }\end{array}$ & 4.0 & 3.5 & 3.0 & 2.5 & 2.0 & 1.5 & 1.0 & 0.5 & 0.0 & -0 \\
\hline
\end{tabular}


<smiles>Cc1noc(C)c1[C@H]1C=CC[C@H](c2ccccc2)C1</smiles>

[7g]
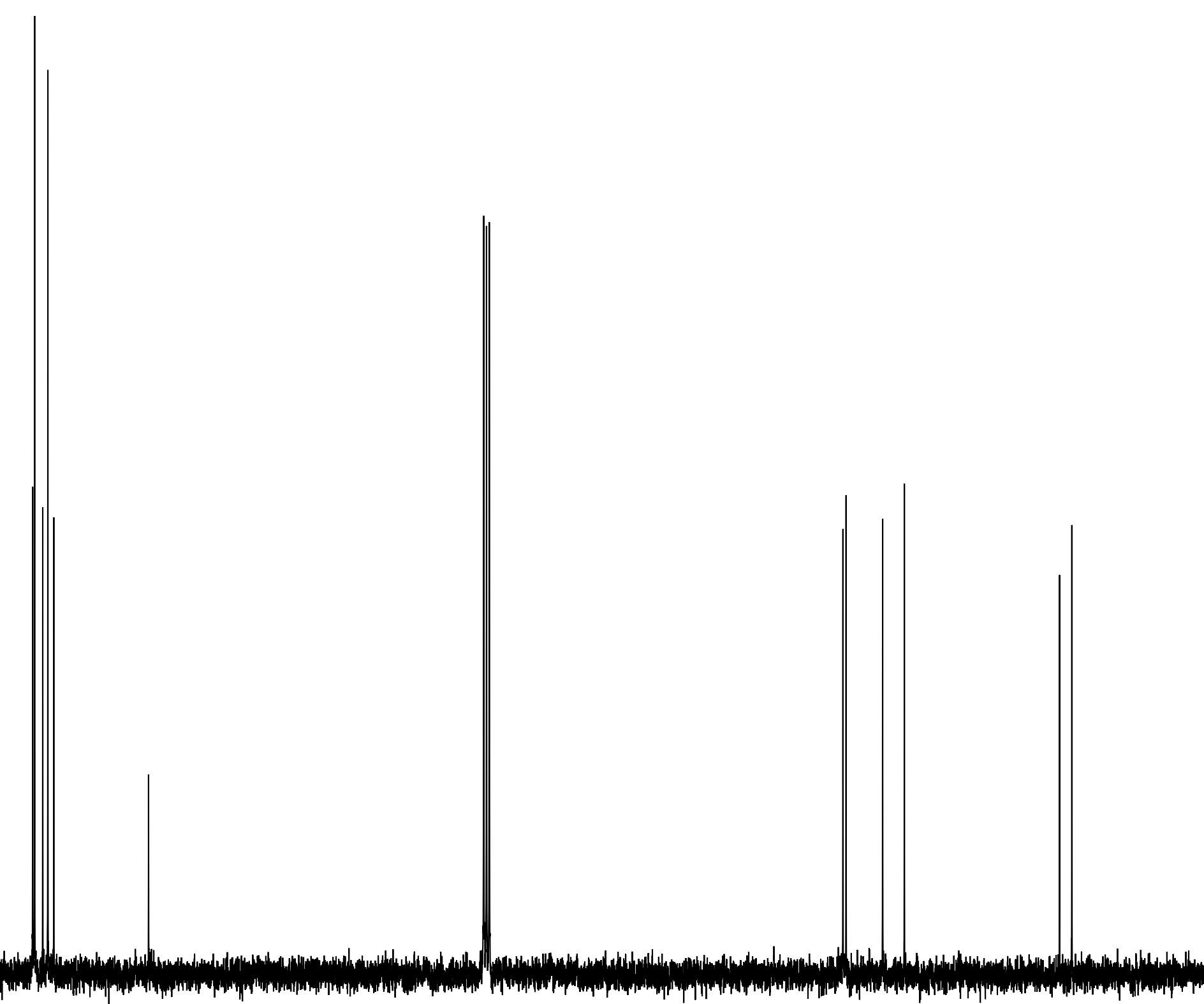
Nㅗㅇ

i

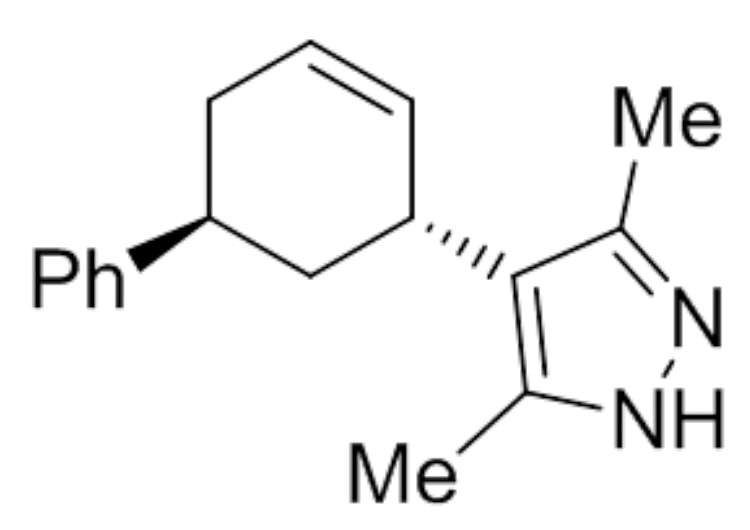

[7f]
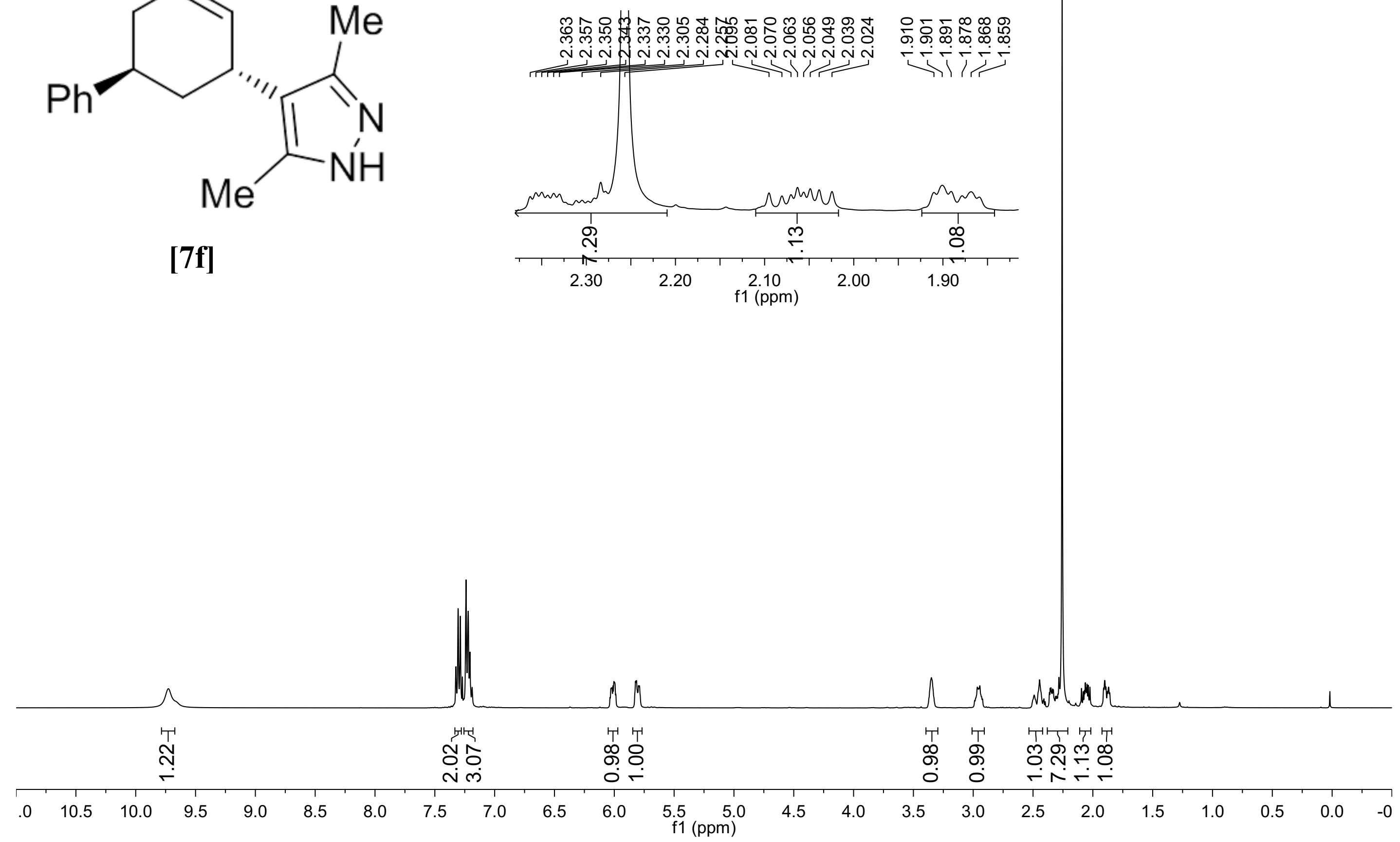


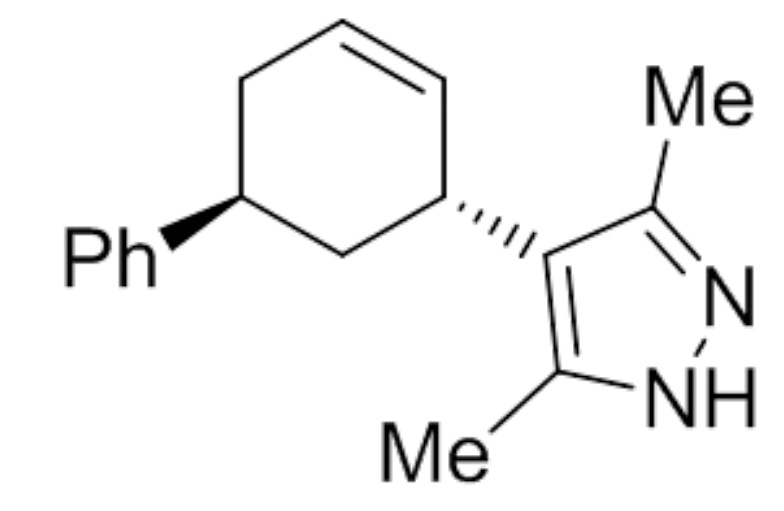

[7f]

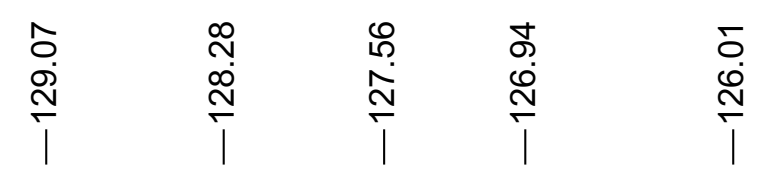

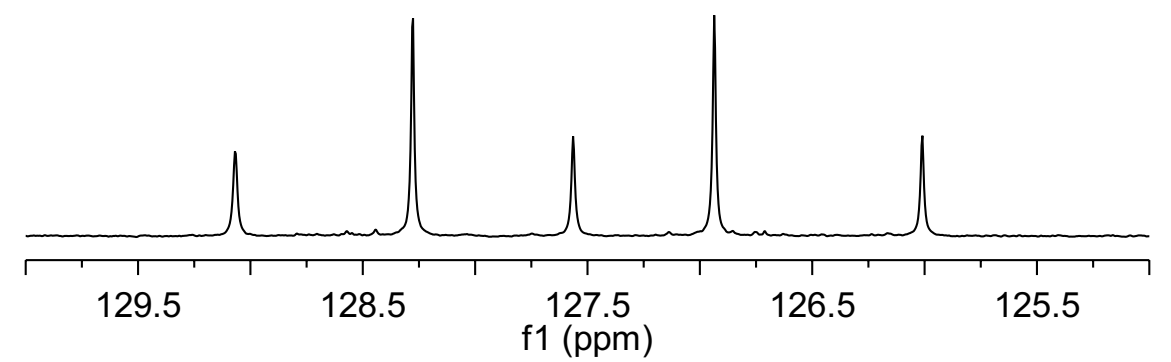

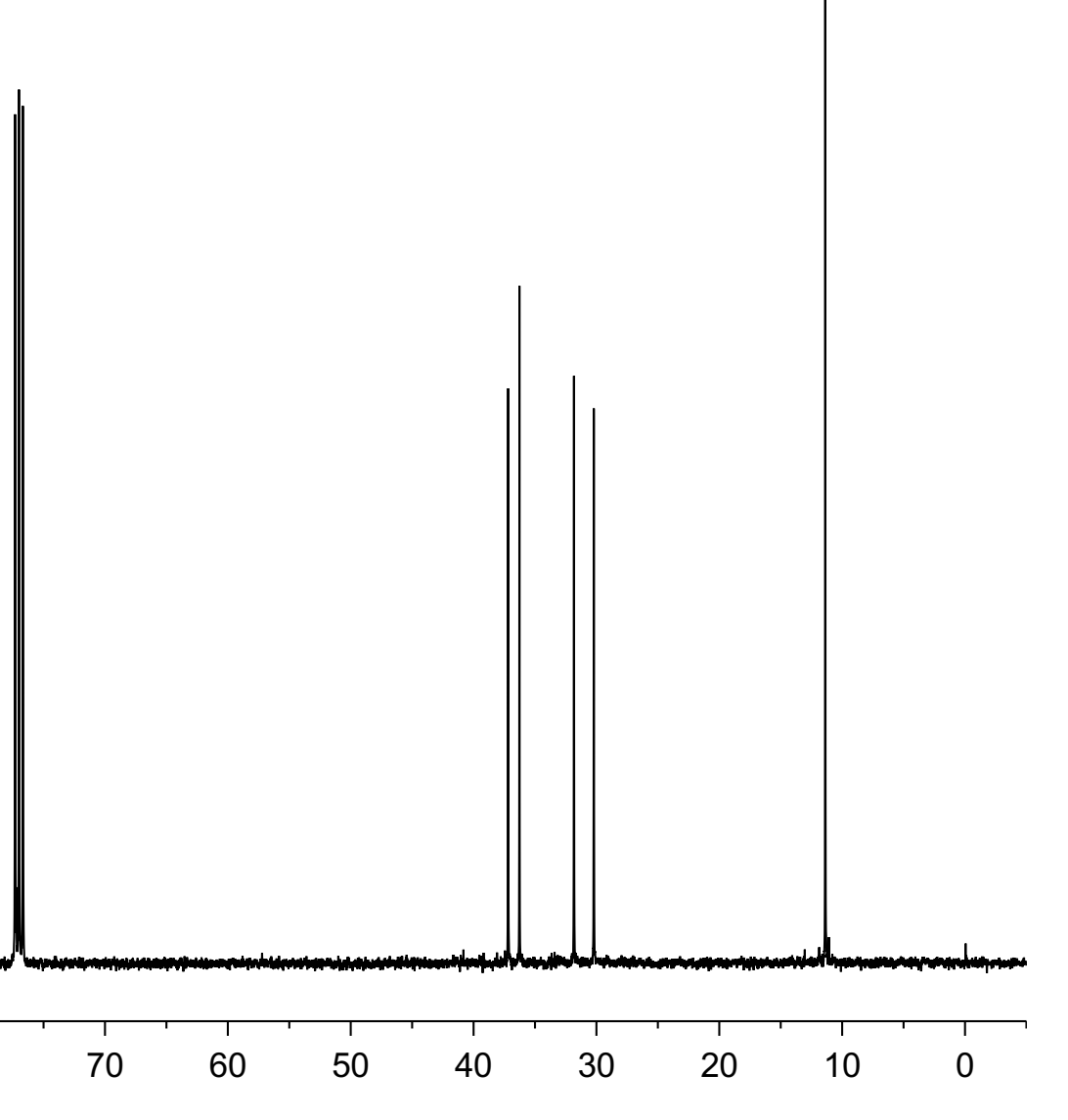




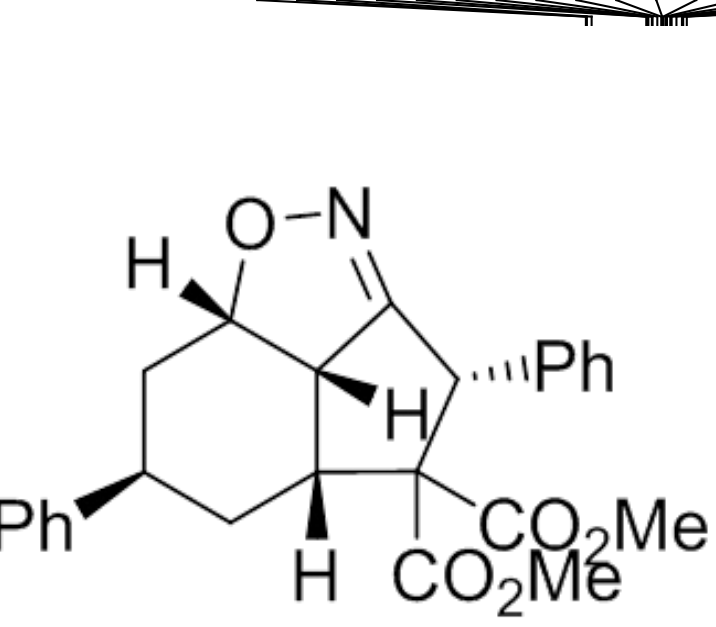

[7d]

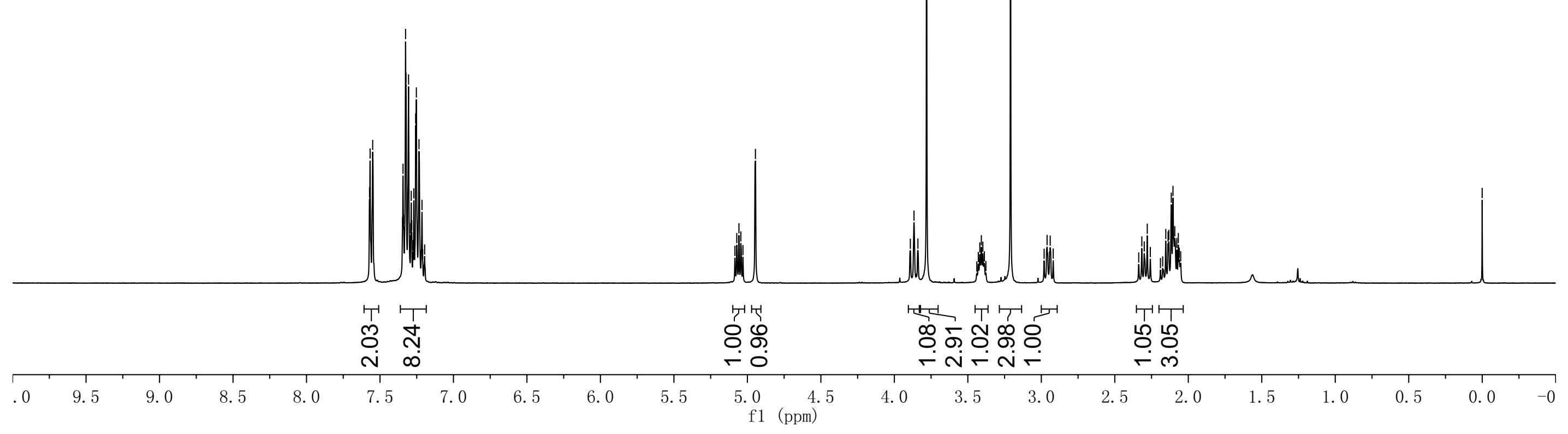



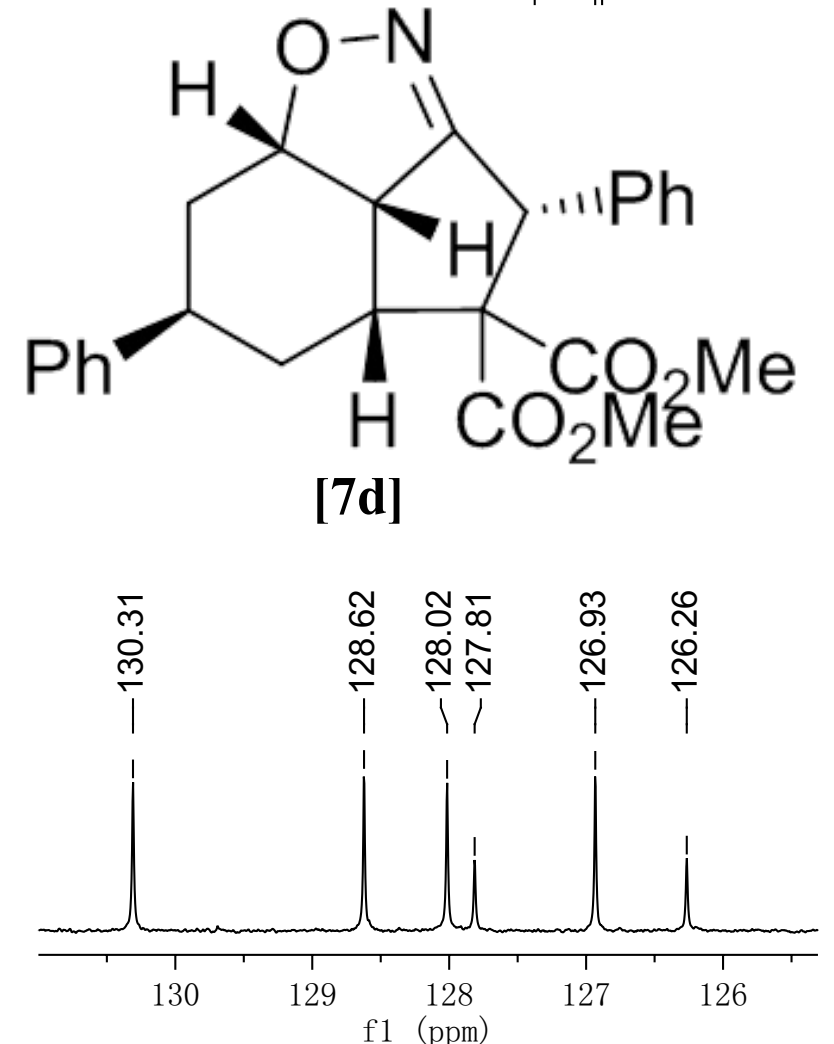

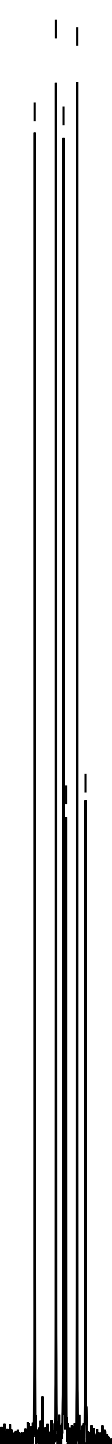

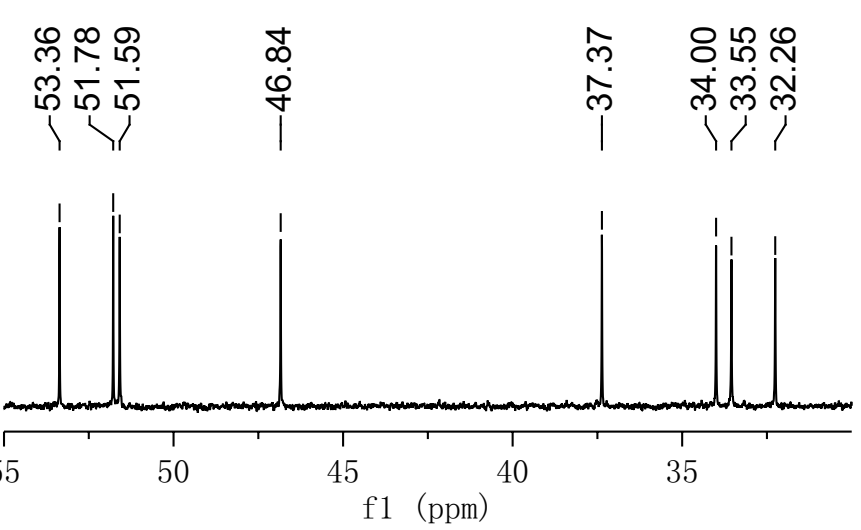



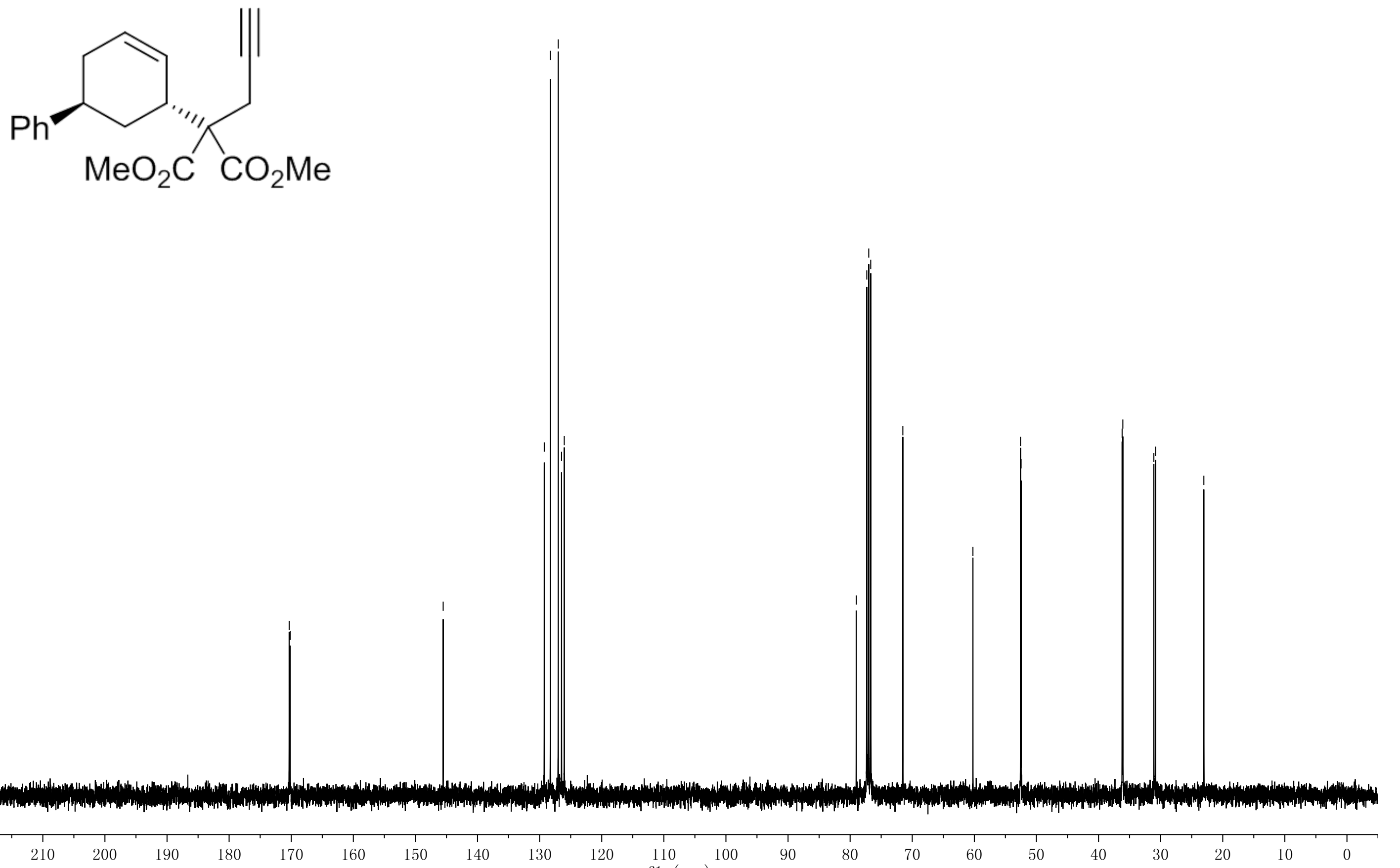


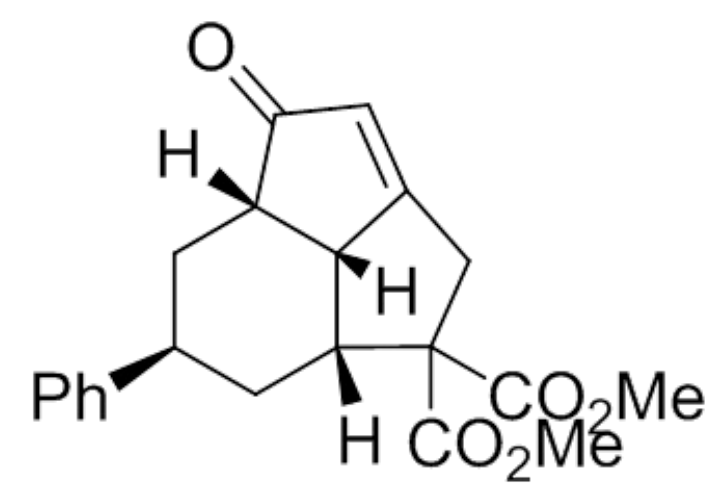

[7c]

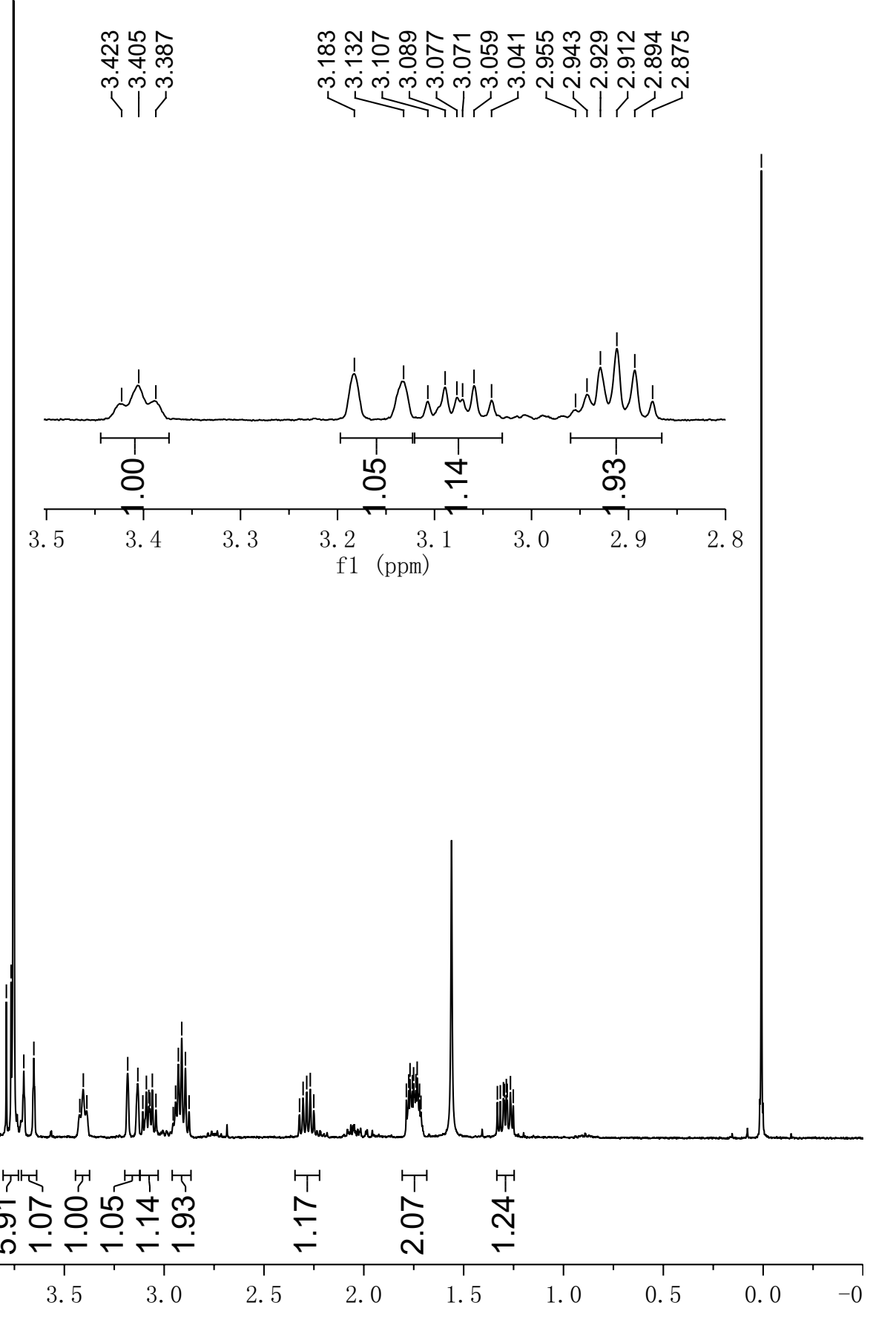




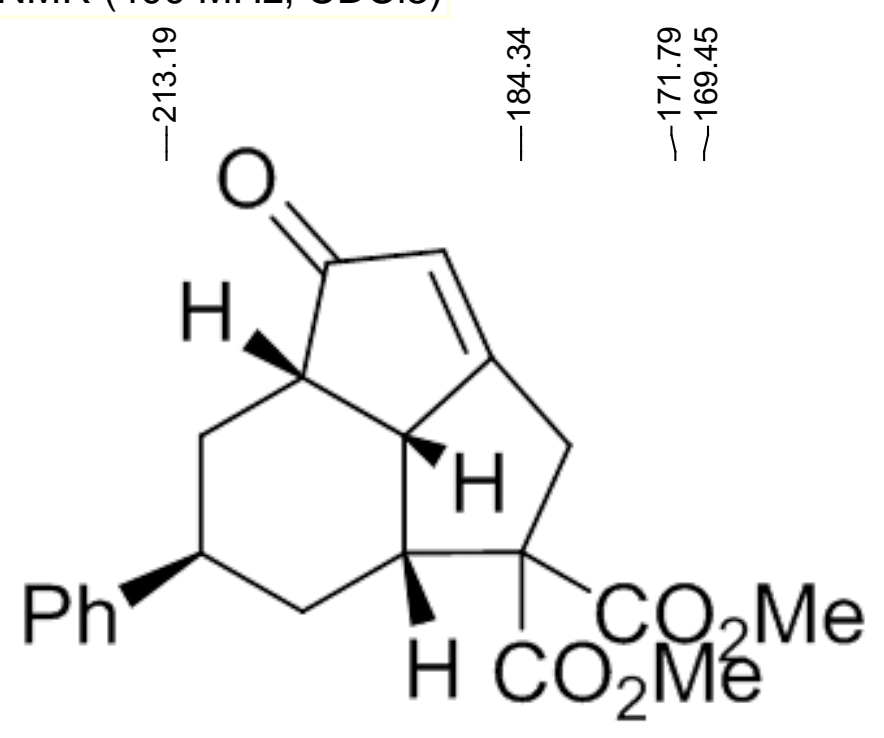

[7c]

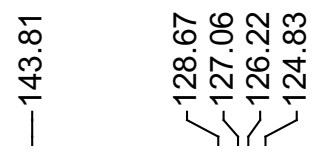

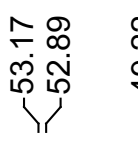

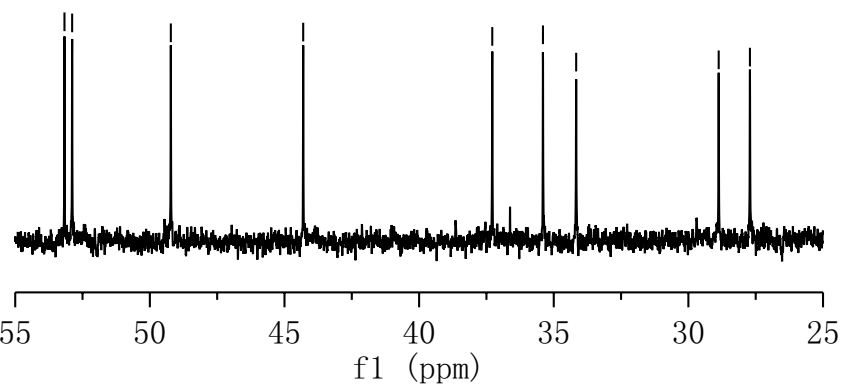

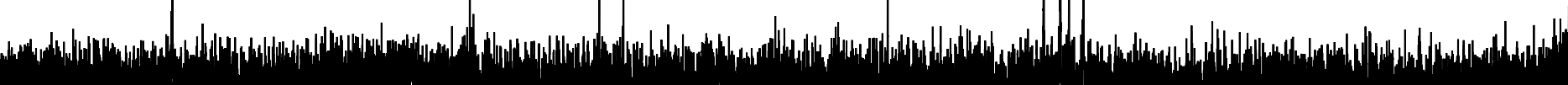
H. W

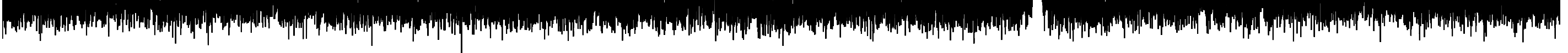

